ORNL/M-6641

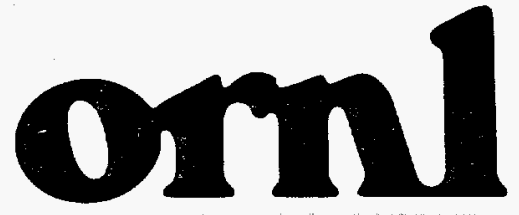

OAK RIDGE NATIONAL LABORATORY

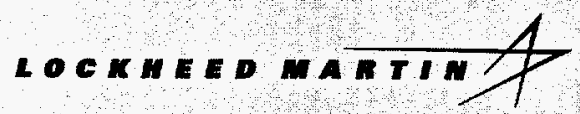

C/ORNL 92-0117

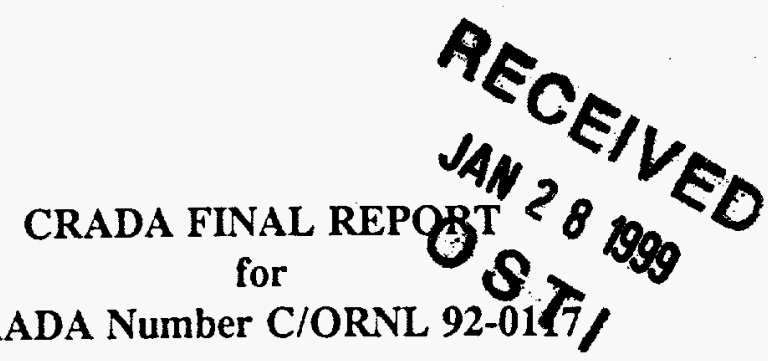

\section{DEVELOPMENT OF A COMPREHENSIVE WELD PROCESS MODEL}

\author{
B. Radhakrishnan \\ T. Zacharia \\ Oak Ridge National Laboratory \\ A. Paul \\ Concurrent Technologies Corporation
}

Approved for

Public release;

Unlimited distribution
MANAGED AND OPERATED BY

LOCKHEED MARTN ENERGY RESEARCH CORPORATION FOA THE UNTED STATES

DEPARTUENT OF ENERCY 
This report has been reproduced directly from the best available copy.

Available to DOE and DOE contractors from the Office of Scientific and Technical Information, P. O. Box 62. Oak Ridge, TN 37831: prices available from (423) 576-8401, FTS 626-8401.

Available to the public from the National Technical Information Service, U.S. Department of Commerce, 5285 Port Royal Road, Springfield. VA 22161.

This report was prepared as an account of work sponsored by an agency of the United States Government. Neither the United States Government nor any agency thereof, nor any of their employees, makes any warranty, express or implied, or assumes any legal liability or responsibility for the accuracy, completeness. or usefulness of any information, apparatus, product, or process disclosed, or represents that its use would not infringe privately owned rights. Reference herein to any specific commercial product, process, or service by trade name. trademark, manufacturer, or otherwise, does not necessarily constitute or imply its endorsement, recommendation, or favoring by the United States Government or any agency thereof. The views and opinions of authors expressed herein do not necessarily state or reflect those of the United States Government of any agency thereof. 


\section{DISCLAIMER}

Portions of this document may be illegible in electronic image products. Images are produced from the best available original document. 
CRADA FINAL REPORT

for

CRADA Number C/ORNL 92-0117

\title{
DEVELOPMENT OF A COMPREHENSIVE WELD PROCESS MODEL
}

\author{
B. Radhakrishnan \\ T. Zacharia \\ Oak Ridge National Laboratory \\ A. Paul \\ Concurrent Technologies Corporation
}

Date Published: May 1997

Prepared by the

OAK RIDGE NATIONAL LABORATORY

Oak Ridge, Tennessee 37831-6140

managed by

LOCKHEED MARTIN ENERGY RESEARCH CORPORATION

for the

U.S. DEPARTMENT OF ENERGY

under contract DE-AC05-96OR22464 



\section{TABLE OF CONTENTS}

LIST OF FIGURES $\ldots \ldots \ldots \ldots \ldots \ldots \ldots \ldots \ldots \ldots \ldots \ldots \ldots \ldots \ldots \ldots \ldots \ldots$

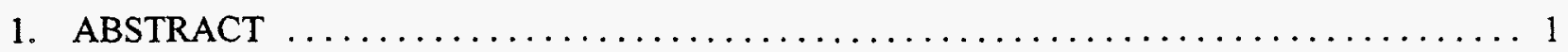

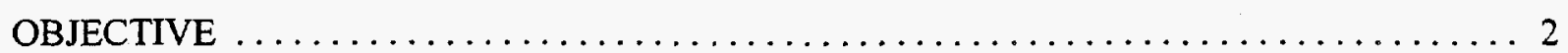

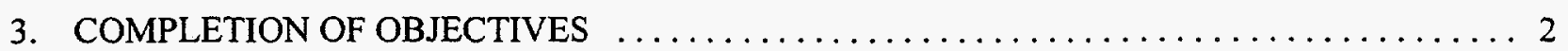

4. BENEFIT TO SPONSORING DOE PROGRAM $\ldots \ldots \ldots \ldots \ldots \ldots \ldots \ldots \ldots \ldots \ldots \ldots$

5. INVENTIONS, COMMERCIALIZATION POTENTIAL AND PLANS FOR FUTURE COLLABORATION $\ldots \ldots \ldots \ldots \ldots \ldots \ldots \ldots \ldots \ldots \ldots$

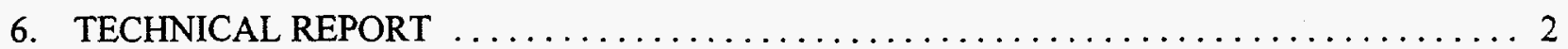

6.1. PARALLELIZATION OF THE WELDING SIMULATION CODE $\ldots \ldots \ldots \ldots \ldots \ldots 2$

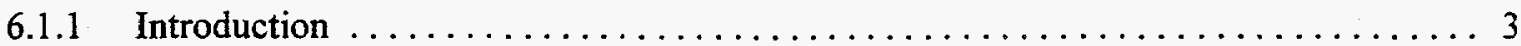

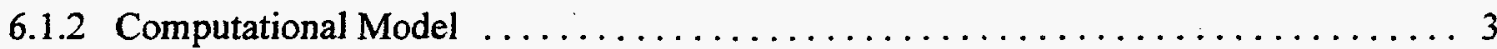

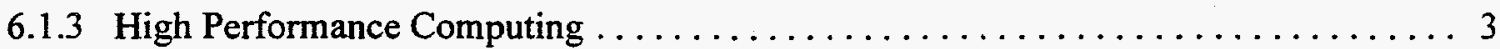

6.1.4 Parallel Implementation . . . . . . . . . . . . . . . . 4

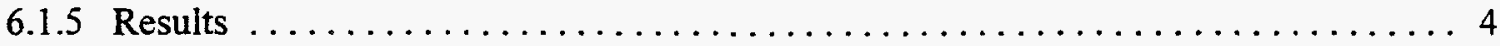

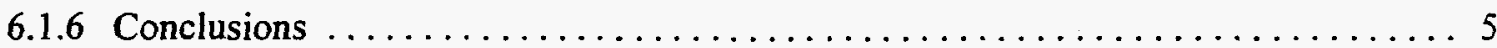

6.2 MONTE CARLO SIMULATION OF HEAT AFFECTED ZONE (HAZ)

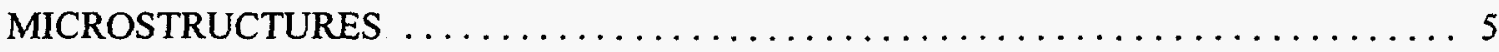

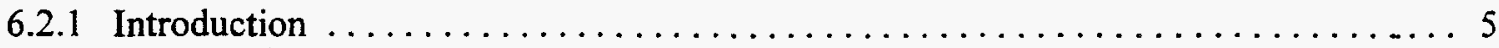

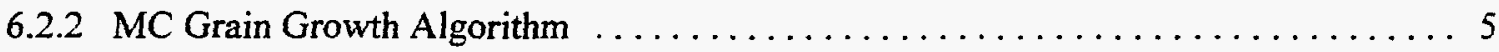

6.2.3 Survey Isothermal Grain Growth Simulations $\ldots \ldots \ldots \ldots \ldots \ldots \ldots \ldots \ldots$

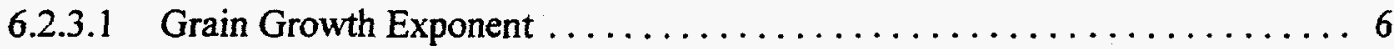

6.2.3.2 Grain Size Distribution $\ldots \ldots \ldots \ldots \ldots \ldots \ldots \ldots \ldots \ldots \ldots \ldots \ldots \ldots \ldots \ldots \ldots \ldots \ldots \ldots$

6.2.3.3 Anisotropic Grain Boundary Energy ................ 6

6.2.4 Limitations of the Existing Grain Growth Algorithm $\ldots \ldots \ldots \ldots \ldots \ldots \ldots$

6.2.4.1 Low Grain Growth Exponent . . . . . . . . . . . . . . . 7

6.2.4.2 Grain Coalescence $\ldots \ldots \ldots \ldots \ldots \ldots \ldots \ldots \ldots \ldots \ldots \ldots \ldots$

6.2 .4 .3 Grain Nucleation $\ldots \ldots \ldots \ldots \ldots \ldots \ldots \ldots \ldots \ldots \ldots \ldots \ldots$

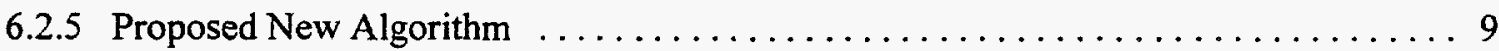

6.2.5.1 Comparison of Results Obtained Using the Old and the New Algorithms $\ldots \ldots \ldots \ldots \ldots \ldots \ldots \ldots$ 
6.2.6 One-to-one Correlation between $\mathrm{MC}$ and Real Parameters $\ldots \ldots \ldots \ldots \ldots \ldots \ldots$

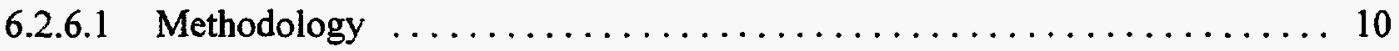

6.2.6.2 Application of the Methodology to Cr-Mo-V Steel . . . . . . . . . . 11

Isothermal Simulations $\ldots \ldots \ldots \ldots \ldots \ldots \ldots \ldots \ldots \ldots \ldots \ldots \ldots \ldots$

Simulation of Weld $\mathrm{HAZ} \ldots \ldots \ldots \ldots \ldots \ldots \ldots \ldots \ldots \ldots \ldots \ldots \ldots$

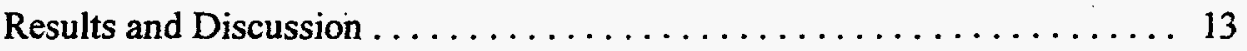

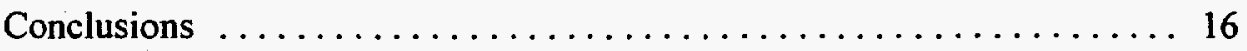

6.3 PARALLELIZATION OF MONTE CARLO GRAIN GROWTH CODE $\ldots \ldots \ldots \ldots \ldots 16$

6.4 SIMULATION OF WELD FUSION ZONE MICROSTRUCTURE USING CELLULAR

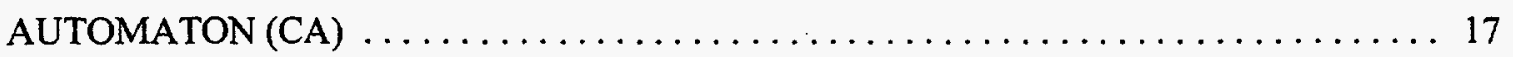

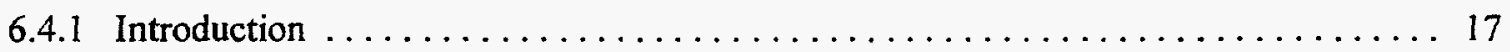

6.4.1.1 CAs as Efficient Modelers ......................... 17

6.4 .2 Initial Simulation of Grain Microstructure $\ldots \ldots \ldots \ldots \ldots \ldots \ldots \ldots \ldots \ldots$

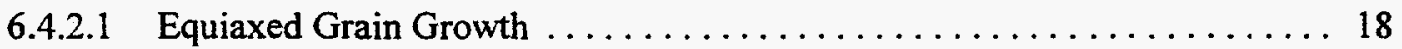

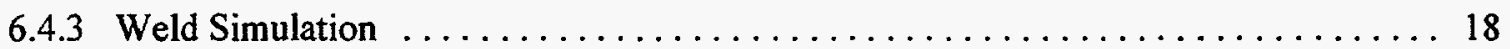

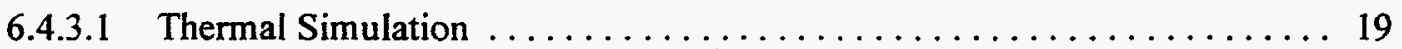

6.4.3.2 Local Growth Directions and Angles .................... 19

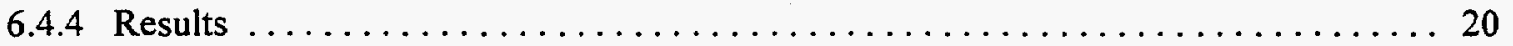

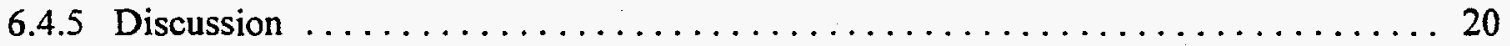

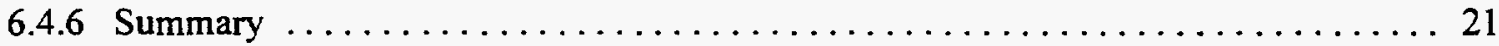

6.5 TRANSFORMATION PLASTICITY MODEL $\ldots \ldots \ldots \ldots \ldots \ldots \ldots \ldots \ldots \ldots \ldots \ldots$

6.6 INTEGRATION OF THE WELD SIMULATION SOFTWARE WITH

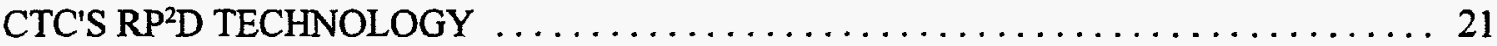

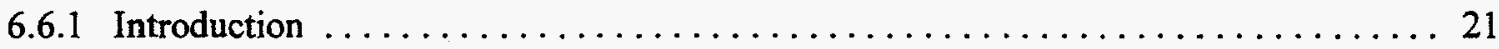

6.6.2 Rational Product and Process Design $\ldots \ldots \ldots \ldots \ldots \ldots \ldots \ldots \ldots \ldots \ldots \ldots \ldots \ldots \ldots \ldots \ldots$

6.6.3 Rational Product and Process Design for Welding Processes . . . . . . . . . . 22

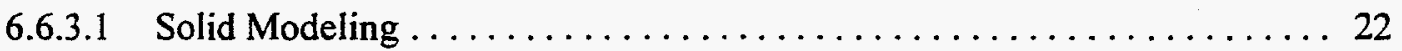

6.6.3.2 Welding Setup and Welding Simulation $\ldots \ldots \ldots \ldots \ldots \ldots \ldots \ldots \ldots$

6.6.3.3 Welding Simulation Analysis $\ldots \ldots \ldots \ldots \ldots \ldots \ldots \ldots \ldots \ldots \ldots \ldots$

6.6.3.4 Welding Engineering Knowledge $\ldots \ldots \ldots \ldots \ldots \ldots \ldots \ldots \ldots \ldots \ldots$

6.6.4 User Interface for the Welding Simulation $\ldots \ldots \ldots \ldots \ldots \ldots \ldots \ldots \ldots \ldots$

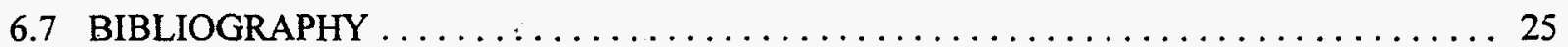




\section{LIST OF FIGURES}

1. Domain decomposition and communication $\ldots \ldots \ldots \ldots \ldots \ldots \ldots \ldots$

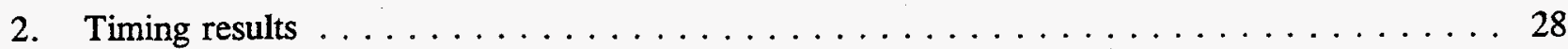

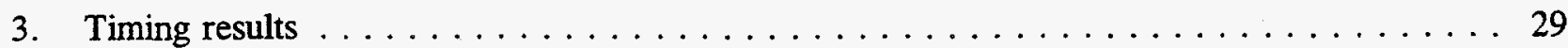

4. Grain growth in the presence of decreasing grain mobility $\ldots \ldots \ldots \ldots \ldots$

5. Potential for grain nucleation during grain growth in the presence of anisotropy in grain boundary energy, using the algorithm $\ldots \ldots \ldots \ldots \ldots \ldots \ldots \ldots$

6. Variation of $R_{\max } / R_{a v}$ ratio with grain size in 2-D simulations with the old algorithm . . . . 32

7. Variation of $R_{\max } / R_{a v}$ ratio with grain size in 2-D simulations with the modified old

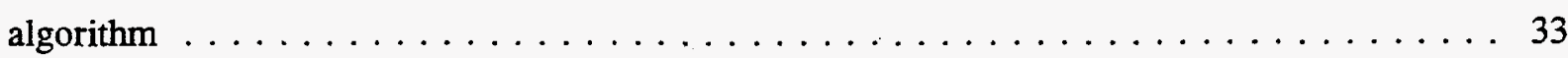

8. Variation of $R_{\max } / R_{\mathrm{av}}$ ratio with grain size in 2-D simulations with the new algorithm . . . . 34

9. Variation of $R_{\max } / R_{a v}$ ratio with grain size in 3-D simulations with the old algorithm . . . . . 35

10. Grain size distribution in 2-D obtained with the algorithm at a mean grain size $-10 \ldots 36$

11. Grain size distribution in 3-D obtained with the new algorithm . . . . . . . . . 37

12. Fits of log-normal and Louat function to the grain size distribution obtained in 2-D using the new algorithm, with an anisotropy parameter of $0.6 \pi \ldots \ldots \ldots 38$

13. Simulated isothermal grain growth data using an anisotropy parameter of $0.45 \pi \ldots \ldots 39$

14. Plot of the derivative of the best-fit function shown in Fig. 13 as a function of $D_{M C S} \ldots \ldots$. . . 40

15. Derivative of the best-fit function to the isothermal grain growth data of Alberry et al for the $0.5 \mathrm{Cr}-\mathrm{Mo}-\mathrm{V}$ steel, $\mathrm{dD}_{\mathrm{r}} / \mathrm{dt}$, as a function of the grain size, $\mathrm{D}_{\mathrm{r}} \ldots \ldots \ldots \ldots$

16. $\mathrm{K}_{2}$ as a function of temperature using the methodology described in the text $\ldots \ldots \ldots 2$

17. Isothermal grain growth data of Alberry et al on which the simulated grain growth data are superimposed $\ldots \ldots \ldots \ldots \ldots \ldots \ldots \ldots \ldots \ldots \ldots \ldots \ldots \ldots$

18. Thermal cycles in the heat affected zone using Rosenthal equation and the material and process parameters shown in Table $2 \ldots \ldots \ldots \ldots \ldots \ldots \ldots$

19. Cumulative Monte Carlo step for the thermal cycles shown in Fig. 6 as a function of distance from the fusion line $\ldots \ldots \ldots \ldots \ldots \ldots \ldots \ldots \ldots$

20. Kinetics of grain growth in the weld heat affected zone (HAZ) of $0.5 \mathrm{Cr}-\mathrm{Mo}-\mathrm{V}$ steel at a distance of $120 \mu \mathrm{m}$ from the fusion line, and bulk heating using the corresponding thermal cycle .

21. Cumulative Monte Carlo step for the thermal cycles shown in Fig. 18 for various assumed liquation temperatures .

22. Simulated heat affected zone (HAZ) grain structures obtained for various assumed liquation temperatures and for bulk heating 
23. Ultimate grain size at a distance of $120 \mu \mathrm{m}$ from the fusion line, for the HAZ

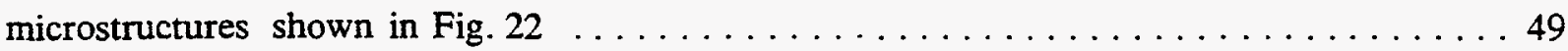

24. Grain growth kinetics at the heat affected zone location $120 \mu \mathrm{m}$ from the fusion line ... 50

25. Sequence of operations involved in parallel computing of grain growth $\ldots \ldots \ldots . \ldots 51$

26. Results of two-dimensional parallel simulation $\ldots \ldots \ldots \ldots \ldots \ldots \ldots \ldots \ldots \ldots \ldots \ldots$

27. Results of three-dimensional parallel simulation $\ldots \ldots \ldots \ldots \ldots \ldots \ldots \ldots \ldots \ldots \ldots \ldots$

28. Speedup of computations in two-dimensional and three-dimensional grain growth

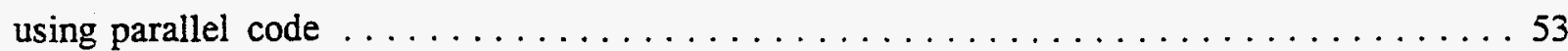

29. Velocity distribution around a cubic grain as a function of the angle between the crystallographic axis and an arbitrary point $\ldots \ldots \ldots \ldots \ldots \ldots \ldots \ldots \ldots \ldots$

30. Growth of a single grain with [100] axis at an angle of $15^{\circ}$ with respect to the

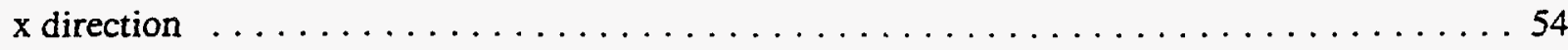

31. Contour plot of isotherms 33 s after starting the arc off the plate to the left $\ldots \ldots \ldots 4$

32. Anisotherm at the solidus interface showing the direction of the temperature gradient at every tenth cell along the width ordinate $\ldots \ldots \ldots \ldots \ldots \ldots \ldots \ldots \ldots \ldots \ldots \ldots \ldots \ldots$

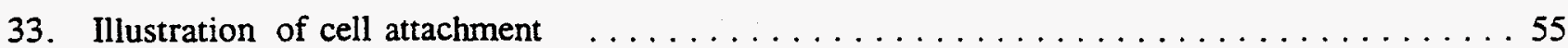

34. Partially solidified plate showing grain growth following the arc $\ldots \ldots \ldots \ldots \ldots$

35a. Contours of temperature, residual stress, percentage austenite, proeutectoid ferrite, pearlite and bainite after 1400 seconds of natural cooling

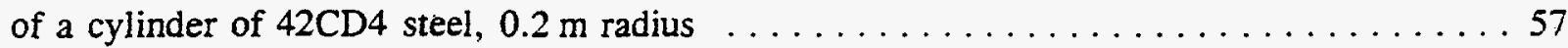

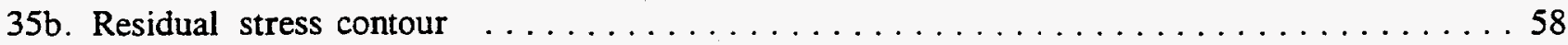

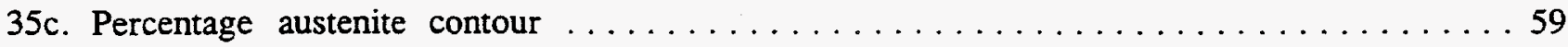

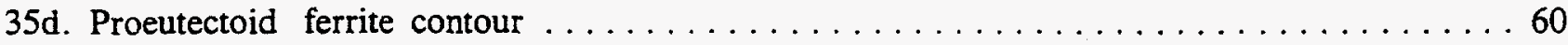

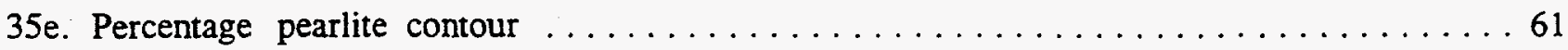

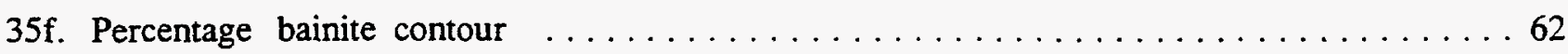

36. Application of the Rational Product and Process Design Methodology

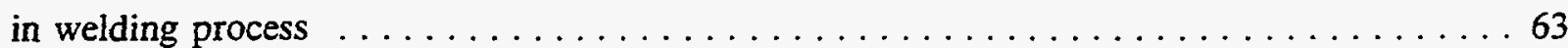

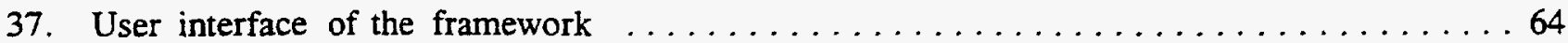

38. Internal temperature profile and final microstructure in the weld fusion zone $\ldots \ldots \ldots 5$ 


\section{ABSTRACT}

This cooperative research and development agreement (CRADA) between Concurrent Technologies Corporation (CTC) and Lockheed Martin Energy Systems (LMES) combines CTC's expertise in the welding area and that of LMES to develop computer models and simulation software for welding processes. This development is of significant impact to the industry, including materials producers and fabricators. The main thrust of the research effort was to develop a comprehensive welding simulation methodology. A substantial amount of work has been done by several researchers to numerically model several welding processes. The primary drawback of most of the existing models is the lack of sound linkages between the mechanistic aspects (e.g., heat transfer, fluid flow, and residual stress) and the metallurgical aspects (e.g., microstructure development and control). A comprehensive numerical model which can be used to elucidate the effect of welding parameters/conditions on the temperature distribution, weld pool shape and size, solidification behavior, and microstructure development, as well as stresses and distortion, does not exist. It was therefore imperative to develop a comprehensive model which would predict all of the above phenomena during welding. The CRADA built upon an already existing threedimensional (3-D) welding simulation model which was developed by LMES which is capable of predicting weld pool shape and the temperature history in 3-d single-pass welds. However, the model does not account for multipass welds, microstructural evolution, distortion and residual stresses. Additionally, the model requires large resources of computing time, which limits its use for practical applications. To overcome this, CTC and LMES have developed through this CRADA the comprehensive welding simulation model described above.

The following technical tasks have been accomplished as part of the CRADA.

1. The LMES welding code has been ported to the Intel Paragon parallel computer at ORNL. The timing results illustrate the potential of the modified computer model for the analysis of large-scale welding simulations.

2. The kinetics of grain structure evolution in the weld heat affected zone (HAZ) has been simulated with reasonable accuracy by coupling an improved $\mathrm{MC}$ grain growth algorithm with a methodology for converting the MC parameters of grain size and time to real parameters. The simulations effectively captured the thermal pinning phenomenon that has been reported in the weld HAZ.

3. A cellular automaton (CA) code has been developed to simulate the solidification microstructure in the weld fusion zone. The simulations effectivly captured the epitaxial growth of the HAZ grains, the grain selection mechanism, and the formation of typical grain structures observed in the weld fusion zone.

4. The point heat source used in the LMES welding code has ben replaced with a distributed heat source to better capture the thermal characteristics and energy distributions in a commercial welding heat source.

5. Coupled thermal-mechanical and metallurgical models have been developed to accurately predict the weld residual stresses, and

6. Attempts have been made to integrate the newly developed computational capabilities into a comprehensive weld design tool. 


\section{OBJECTIVE}

The objective of this cooperative research and development agreement (CRADA) is to develop a comprehensive design tool for welding, by combining the existing capabilities at Lockheed Martin Energy Systems (LMES) for predicting the weld pool shape, heat and fluid flow with newly developed models for predicting the weld and heat affected zone microstructures, and the residual stress distribution, and incorporate these models into a design methodology developed by Concurrent Technologies Corporation (CTC) through a graphical user interface.

\section{COMPLETION OF OBJECTIVES}

All the major objectives of this CRADA were completed, except for the integration of the computer models into the design tool through the graphical user interface. The development of the design tool and the graphical user interface described in the report is preliminary, and it was being further modified by CTC at that time. The final version of the user interface was to have been made available to LMES for incorporation of the various simulation models developed by LMES. However, LMES has not received the final version of the graphical interface to date. Consequently, the application of the design tool to a benchmark problem and the validation of the tool could not be accomplished.

\section{BENEFIT TO SPONSORING DOE PROGRAM}

The computer models developed as part of this CRADA are extremely valuable to the Office of Defense Programs. Since the models are fairly generic, they are applicable to a wide variety of materials, and they can be readily used in the design and manufacture of weapons components.

\section{INVENTIONS, COMMERCIALIZATION POTENTIAL AND PLANS FOR FUTURE COLLABORATION}

Thus far, no inventions have been reported. However, the computer codes developed as part of this CRADA may have potential commercial applications in materials processing, especially in the fabrication of metallic structures through fusion welding techniques.

\section{TECHNICAL REPORT}

This report describes in detail the research carried out in connection with each of the major tasks of the CRADA.

\subsection{PARALLELIZATION OF THE WELDING SIMULATION CODE}

The computer program for 3-D transient analyses of welding processes has been modified for use on massively parallel computers. The model is based on a discrete element method that takes into account geometric variations of an object, heat transfer, fluid flow, deformable free surface, solid/liquid interface, buoyancy, electromagnetic and surface forces acting on a weld. The computational performance of the modified code with respect to the number of available processors and problem complexity was assessed to illustrate its potential for detailed, fast, and accurate welding simulations. The computational requirements for real time welding simulations are also investigated. 


\subsubsection{Introduction}

For computational modeling of material processes to be successful it must be based on proper identification of all relevant physical phenomena and their accurate mathematical description. The variety of competing physical mechanisms in welding results in complex mathematical models that render previously developed respective computational models unfeasible for moderate and large discretization grids. Transient effects add further complexity to simulations, effectively restricting computational analyses utilizing standard single-processor computer architectures to only two-dimensional (2-D) discretizations. This project has developed materials based modeling and implemented the model utilizing the computational power of emerging massively parallel computers offering potential for performing realistic multidimensional transient welding simulations in a relatively short amount of time.

\subsubsection{Computational Model}

The computational model for welding simulations used in this study incorporates the influence of transient effects, heat transfer from arc to weld surface, coupled conduction and convection heat transfer, and fluid flow in the weld pool. The model is also capable of handling realistic geometries and uses temperature-dependent material properties. Details of the computational model employed can be found elsewhere ${ }^{1.2}$. The constitutive models used to describe each phenomena can be rather complex. For example, the fluid flow model considers buoyancy, electromagnetic, surface tension, and surface curvature forces as driving mechanisms for fluid flow. The computational model solves the full differential equations governing fluid dynamics phenomena on a logically rectangular three-dimensional grid. The equations are solved by a discrete-element method in which the solution domain is subdivided into grid cells bounded by continuous lines or surfaces aligned in the coordinate directions. From this discretization for each of the dependent variables, a discrete equation is constructed for each grid point utilizing a 7-point stencil for the discretization of the dependent variables. As a result, the overall simulation model becomes computationally unfeasible, even for moderate-size discretizations, on high-end workstations. Moreover, because of the explicit scheme used for time integration, stability criteria mandate that the time step be proportional to the minimum discrete element size. This fact, in conjunction with the number of discretization points, results in the quadratic increase of required processing time with respect to refinement of the grid. Computer memory may also become the limiting factor (approximately 40 variables are used per discrete element) since the time penalty associated with disk operations prohibits its usage for memory reference. On the up side, the computational model is inherently parallel: similar operations (i.e., stencil) take place throughout the computational domain and as such are amenable to parallelization.

\subsubsection{High Performance Computing}

Parallel supercomputers ${ }^{3}$ can be broadly classified by their memory organization as: shared- memory and distributed-memory multiprocessors based Shared-memory multiprocessors allow all processors equal access to memory that has been declared global, usually through a common communication channel. This means that all of the processors can access any portion of the computer's memory. As the number of processors sharing the memory and the communication channel increases, the potential for contention between the processors for control of the memory increases. Distributed-memory multiprocessors are characterized by a network of communication channels, each of which connects a processor to another processor and memory units. Typically, each processor has a local memory of limited size. When a processor needs data stored in memory other than its own, the computer program must explicitly request the transmission of those data. The processors send and receive messages containing the results of calculations in a processor. Extra programming effort is required for coordinating data movement. Because communication channels are not shared in distributed-memory architectures, they are more efficient than bus architectures in the use of processors and memory. Lack of equal access to memory by all the processors makes the use of distributed-memory computers more difficult and more limited. 


\subsubsection{Parallel Implementation}

Discrete element code for the analysis of heat and fluid flow in the weld pool has been ported to the Oak Ridge National Laboratory (ORNL) massively parallel computers: iPSC/860, Intel Paragon, and Kendall Square Research, utilizing the Message Passing Interface (MPI). ${ }^{4}$ The domain decomposition technique has been employed as a principal method for exploiting concurrent processing. The program uses onedimensional domain decomposition in the $\mathrm{x}$ direction, decomposing the computational domain into blocks of approximately equal size. Each block is assigned to a processor that has its identification number (id) equal to the block ordinal number with respect to the block position along $\mathrm{x}$ axis, the first block having the ordinal number 0 . Data for stencil evaluation for control volumes in the interior of a block are needed by only one processor, while data for control volumes on the boundary are required by more than one processor. The efficiency of this computation is influenced by two factors: the computer's "load balance" and communications costs. If work is distributed unevenly, then most of the processors may be idle during much of the computation time -- a waste of computer cycles. However, even if work is well distributed, processors will be idle while they are waiting to receive the data from other processors needed to perform the next task. The communication that a processor needs to perform is between the processors that are assigned to the adjacent blocks and the communication with all the processors in an active topology that is required for global operations. Such a computational domain assignment and communication pattern makes a line processor topology suitable for efficient parallel processing. The computation and communication domains for the line topology of processors are illustrated in Fig 1 .

The characteristic of the domain decomposition approach is that, for a given problem size, there is a limit of the number of processors that can be effectively utilized. ${ }^{5}$ After the computational effort, which is proportional to sub-domain size, becomes comparable to communication the program execution time cannot be further reduced by increasing the number of processors. Therefore, the communication phase of a program must be efficiently designed in order to maximally utilize the computational power by avoiding non-local reference of data.

\subsubsection{Results}

In order to illustrate the benefits of high-performance computing to welding simulations it would be useful to consider a welding simulation that is so computationally intensive that it would take approximately a month to execute using a single-processor workstation. A stationary gas tungsten arc (GTA) spot welding with a Gaussian heat source on top of an axisymmetric domain was considered. The analysis used a 250 $x 1 \times 120$ grid in the $x, y$, and $z$ directions, respectively. The average central processing unit (CPU) time per time increment for the analysis on the Intel Paragon, using different numbers of processors, is given in Fig. 2. The processor utilization can be more accurately assessed by examining the scaling diagram, as shown in Fig. 3. In this diagram, the time required by a single processor $\left(T_{2}\right)$ to perform an iteration is divided by the time used by a set of processors for the same task $\left(T_{n}\right)$ and displayed against the number of processors (nodes, $n$ ). Perfect scaling is indicated by the linear progression, i.e., the time required for computation would be inversely proportional to the number of processors used. It can be seen that processor utilization drops after 32 processors. Communication time becomes large, relative to computation time, due to the small number of elements assigned to each processor. As the problem discretization is further refined, the number of processors that can be effectively utilized will increase. The computational load becomes dominant over the communication phase. 


\subsubsection{Conclusions}

Massively parallel computers are currently being used to simulate coupled heat and fluid flow during welding. Problems that required several weeks on a workstation were solved in a few hours on the massively parallel machine. The timing results illustrate the potential of the modified computer model for the analysis of large-scale welding simulations. Further work in the development of the welding simulation program for massively parallel computers will involve domain decomposition in two and three directions. Such a program will be able to utilize the computational power of distributed-memory supercomputers more efficiently by reducing the communication, thus allowing for fine grids and better assessment of the discretization and model complexity influence on the accuracy of welding simulations.

\subsection{MONTE CARLO SIMULATION OF HAZ MICROSTRUCTURES}

\subsubsection{Introduction}

The MC technique has been widely used to simulate the evolution of grain structures during recrystallization and curvature-driven grain growth processes. However, the existing $\mathrm{MC}$ codes have certain limitations which include the prediction of a significantly lower grain growth exponent than the theoretical limit for curvature-driven grain growth, the occurrence of grain coalescence, and the potential for grain nucleation when the anisotropy in grain boundary energy is taken into account. Also, in the existing codes, there is no one-to-one correlation between the simulation parameters and real parameters. This is because the two important quantities, grain size and time, have been represented in the simulations as dimensionless quantities. Hence, the codes cannot be used to quantitatively predict the evolution of microstructures in real materials and in real time. This report describes the development of a modified MC code for curvature-driven grain growth which eliminates the above topological drawbacks. It also describes a simple methodology for obtaining a one-to-one correlation between $\mathrm{MC}$ and real measures of grain size and time, so that the code can be readily applied to solve real world problems. Finally, it describes the application of the modified code and the methodology developed for obtaining a one-to-one correlation between $\mathrm{MC}$ and real parameters in order to simulate the $\mathrm{HAZ}$ grain structure of a real material during welding.

\subsubsection{Grain Growth Algorithm}

The algorithm used for simulating curvature-driven grain growth ${ }^{6-20}$ is as follows. A simulation domain of a suitable size $200 \times 200$ is chosen. Each point in the domain is assigned a random number, $S_{i}$, between 1 and $\mathrm{N}_{0}$, where $\mathrm{N}_{\mathrm{Q}}$ is the total number of grain orientations. A grain is defined by a collection of points which have the same orientation number. Typically $N_{Q}$ is greater than 36 (above which the grain growth exponent becomes independent of $\mathrm{N}_{\mathrm{Q}}{ }^{6-8}$ ). Each point is then accessed randomly, and the energy change associated with switching the orientation to another random value between 1 and $N_{Q}$ is calculated. The energy change is calculated by measuring the local energy of a cluster of lattice points before and after the switching process. The energy of the cluster of lattice points is defined as

$$
E=-J \sum\left(\delta_{s, \delta_{j}}-1\right)
$$

where $\mathrm{J}$ is a constant which is proportional to the grain boundary energy, $\delta_{\mathrm{ij}}$ is the Kronecker $\delta$ function, $S_{i}$ is the orientation of the lattice point whose orientation change is being attempted, and $S_{j}$ is the orientation of a nearest neighbor. The summation is taken over all the nearest neighbors. The probability 
of switching is based on the magnitude of the net energy change, $\delta \mathrm{E}$, as a result of the switching process. The probability of switching is defined as follows:

$$
p=\left[\begin{array}{ll}
1 & \delta E \leq 0 \\
0 & \delta E>0
\end{array}\right.
$$

The simulation time is defined by a quantity known as the Monte Carlo Step (MCS), which is related to the number of reorientation attempts. MCS is equal to 1 , when the number of attempts equals the number of points in the domain. It is related to the real time through a temperature-dependent jump frequency. Grain size, in the simulations, is calculated either from the mean of the number of lattice points within a grain, which is proportional to the grain area in 2-D simulations, and the grain volume in 3-D simulations, or from linear intercept measurements carried out on grain structures obtained in 2-D simulations, and on cross sections of grain structures obtained in 3-D simulations. Grain growth kinetics are followed by plotting the grain size as a function of MCS. The grain growth exponent, $n$, is calculated from the long-time slope of the log-log plot of the grain size versus MCS.

\subsubsection{Survey Isothermal Grain Growth Simulations}

\subsubsection{Grain Growth Exponent}

In the simulations which first appeared in the literature, ${ }^{6-16}$ the grain growth exponent was found to be significantly lower than that obtained for the Ising model. The simulations predicted an exponent of 0.41 \pm 0.03 for grain growth in metallic and ceramic systems. However, in the case of the Ising model, where only two degenerate states exist, the exponent was approximately equal to 0.5 , the theoretical limit for curvature-driven growth. The above difference was believed to be a consequence of the presence of vertices in a topologically connected grain structure and the absorption of curvature at these vertices. ${ }^{6-8}$ More recent simulations $s^{17-19}$ carried out on larger domains and extended to very large growth periods showed that the growth exponent, at least in 2-D, did approach the theoretical limit of 0.5 . The domain sizes used in 3-D simulations so far have not been large enough to achieve a limiting growth exponent of 0.5 , although recent simulations ${ }^{18}$ did indicate the existence of such an asymptotic limit.

\subsubsection{Grain Size Distribution}

The best fit to a grain size distribution curve when the grain sizes were obtained from grain volume data utilizing 3-D simulations has been reported to follow the log-normal function. ${ }^{18}$ However, when the linear intercept or grain area measures were used to calculate the grain sizes, the best fit was obtained using a function proposed by Louat. ${ }^{21}$ Grain-size distributions obtained from earlier 2-D simulations ${ }^{7,9,13}$ also matched closely with the size distributions measured using 3-D cross-sectional data. ${ }^{18}$ The ratio of the maximum grain size to the average grain size in the distribution was in the 3.0-3.5 range.

\subsubsection{Anisotropic Grain Boundary Energy}

The simulation results described above were under the assumption that the grain boundary energy was isotropic. However, in real materials, the grain boundary energy is anisotropic since it depends upon the misorientation between two grains. The effect of grain misorientation on grain boundary energy in 2-D was related to an anisotropy parameter, ${ }^{11}$ which was proportional to the difference between two adjacent grain orientations. The analysis indicated that the presence of anisotropy in grain boundary energy lowered 
the grain growth exponent compared to the isotropic case and broadened the grain-size distribution curve. ${ }^{11}$ The analysis also indicated that the probability of occurrence of low-angle boundaries was greater than that of high-angle boundaries.

\subsubsection{Limitations of the Existing Grain Growth Algorithm}

This section describes the limitations in the $M C$ grain growth algorithm which currently exist in the literature. The limitations include (1) the prediction of a significantly lower grain growth exponent than the theoretical limit at reasonable grain sizes, (2) the occurrence of grain coalescence, and (3) the occurrence of grain nucleation during curvature-driven grain growth, in the presence of anisotropy in grain boundary energy.

\subsubsection{Low Grain Growth Exponent}

In the old algorithm, the theoretical limit to the grain growth exponent was reached only when the simulations were carried out to large grain sizes using domain sizes of the order of $1000 \times 1000^{17-19}$. In fact, earlier simulations which used a domain size of $200 \times 200$ predicted a growth exponent of only 0.41 \pm 0.03 , which led to the belief that the theoretical limit of 0.5 could not be obtained even in ultra-high-purity metals. However, it can be shown ${ }^{22}$ that the variation of the grain growth exponent with grain size in MC simulations is due to the fact that the average grain boundary mobility for the system decreases with increasing grain size. The grain boundary mobility, $k$, is defined as

$$
k=\frac{V}{F}
$$

where $\mathrm{V}$ is the migration velocity, and $\mathrm{F}$ is the driving force. In the case of normal grain growth, the driving force is the reduction in curvature. The mobility at any temperature is related to the frequency of jumps of those atoms situated adjacent to a grain boundary in the direction of the grain boundary. Since thermal vibrations occur randomly, only a fraction of the jumps will be directed towards the grain boundary. The probability of jump towards a grain boundary is higher for grain boundary atoms situated close to a triple junction than those situated far away from triple junctions. Since the ratio of triple point atoms to grain boundary atoms decreases with increasing grain size, there is a decrease in the average mobility with increasing grain size. In real microstructures where the grain size is of the order of microns and the distance between the atoms is of the order of angstroms, the fraction of atoms near the triple junctions to those near the boundaries is negligible, and hence mobility practically remains constant at these grain sizes. However, in MC simulations where the grain sizes are comparable to the distance between lattice sites, the above effect would be fairly slgnificant.

In $\mathrm{MC}$ simulations, each atomic jump is equivalent to the reorientation attempt at an $\mathrm{MC}$ lattice site described earlier. In the old algorithm, the reorientation attempt at any point covers all orientations, 1 through $\mathrm{N}_{\mathrm{Q}}$, in the simulation domain. The mobility is proportional to $\mathrm{N}_{\mathrm{L}} /\left(\mathrm{N}_{\mathrm{Q}}-1\right)$, where $\mathrm{N}_{\mathrm{L}}$ is the total number of nearest-neighbor orientations which are different from that of the central point, and $N_{Q}$ is the total number of initial orientations. In a triangular lattice with six nearest neighbors, $N_{L}$ varies from 6 to 1, depending upon the grain size and the position of the central point. At the beginning of grain growth, when the orientations of the points are randomly distributed and each point effectively represents a grain, $N_{L}$ is equal to 6 . However, after sufficient grain growth has taken place, $N_{L}$ reduces to either 1 or 2 , depending on whether the point is close to a grain boundary or a triple point. As further grain growth

occurs, the fraction of triple points to grain boundary points decreases, and $N_{L}$ slowly tends towards a 
constant value of 1 . Hence, using the old algorithm, the theoretical limit for the grain growth exponent can be reached only when the average mobility is reduced to about $16 \%$ of its initial value.

Figure $4 a$ shows a set of grain growth curves for mobilities ranging from $k_{1}$ to $k_{6}$, where $k_{1}$ is the highest and $k_{6}$ is the lowest. The solid curve shows the effective grain growth kinetics that will be observed when the grain growth starts with the mobility $k_{1}$, continues in the presence of decreasing mobility, and ends when the mobility is $k_{6}$. The effective grain growth curve was computed using an initial $k_{1}$ value of 2.0 and letting it asymptotically change to the final $k_{6}$ value of 1 after an MCS of 1000 . Such a variation is fairly typical in the simulations. Figure $4 b$, shows the log-log plot of grain size versus MCS for the effective grain growth kinetics curve shown in Fig. $4 a$. Note that the effective grain growth exponent remains lower than the theoretical value as long as the mobility is decreasing. Once the lowest mobility is reached, the exponent becomes equal to the theoretical limit, and grain growth continues along the curve for which the mobility is $k_{6}$. The above description applies to the MC simulation of grain growth where the grain size is comparable to the site size and consequently, the mobility decreases with increasing grain size.

\subsubsection{Grain Coalescence}

According to the old algorithm, the total number of grain orientations, $\mathrm{N}_{Q}$, need only be greater than a finite positive value (typically 36), in order to prevent the coalescence of grains, which does not occur during normal grain growth. The probability of coalescence is estimated to be $1-(1-1 / Q) Z,{ }^{8}$ where $Z$ is the number of second-nearest-neighbor grains, and $Q$ is the total number of orientations. In 2-D, since, on an average, a grain has six sides, there will be 12 second-nearest- neighbor grains. For an $N_{Q}$ value of 64 , for example, the probability of grain coalescence is about 0.17 , which is not negligible. In 3-D, where an average grain has 14 sides, the number of second-nearest-neighbor grains on an average is 28 , resulting in a probability of coalescence of 0.36 , which is quite significant. A careful examination of the simulation results documented in the literature showed that some grain coalescence did indeed occur in the grain growth simulations.

\subsubsection{Grain Nucleation}

One of the potential sources of error in the old algorithm is grain nucleation, which can occur especially when the anisotropy in grain boundary energy is considered. The variation of grain boundary energy with misorientation involves the introduction of an energy function ${ }^{11}$ defined as

$$
E_{i}=\sum V\left(S_{i}, S_{j}\right)
$$

where the summation is taken over the nearest neighbors, $\mathrm{S}_{\mathrm{j}}$ is one of the nearest-neighbor orientations, and $\mathrm{V}$ is a local anisotropy potential. The local anisotropy potential is related to the misorientation between two adjacent grains which is given by ${ }^{11}$

$$
\theta_{i j}=2 \pi \frac{\left(S_{i}-S_{j}\right)}{Q}
$$

The local anisotropy potential is given by

$$
V(\theta)=\begin{array}{cc}
J \frac{\theta^{\prime}}{\theta^{*}}\left[1-\log \left(\frac{\theta^{\prime}}{\theta^{*}}\right)\right] & \theta^{\prime}<\theta^{*} \\
J & \theta^{\prime} \geq \theta^{*}
\end{array}
$$


where $\theta^{*}$ is the anisotropy parameter, $\theta^{\prime}=|\theta|$ for $0 \leq|\theta| \leq \pi$ and, $\theta^{\prime}=2 \pi-|\theta|$ for $\pi \leq|\theta| \leq 2 \pi$. $\theta^{*}$ is also the misorientation angle above which the grain boundaries are considered high angle. Now, let us apply the above equations to calculate the local energy changes in the presence of anisotropy in grain boundary energy, using the old algorithm. Figures $5 a$ and $5 b$ show the orientations of a cluster of points before and after the orientation of the central point is changed from 1 to 11 . Using an anisotropy parameter of $0.3 \pi$ and a $Q$ value of 64 , the initial energy of the cluster is $4 \mathrm{~J}$. After the orientation of the central point is changed to 11 , the energy of the cluster is $3.75 \mathrm{~J}$. Since the orientation change results in a net decrease of energy, the re-orientation attempt would be successful. However, it results in grain nucleation, which does not occur during normal grain growth.

\subsubsection{Proposed New Algorithm (22)}

In the old algorithm, the reorientation attempt at any site included all possible orientations in the system. However, since in a real material the atomic vibrations are directed only toward one of the nearest neighbors, the reorientation attempt should only involve the orientations of the nearest neighbors. Hence, in the new algorithm, the reorientation attempt at every $\mathrm{MC}$ site is directed toward a nearest neighbor, which is randomly selected by employing a random number generator between 1 and $N_{N}$, where $N_{N}$ is the total number of nearest neighbors for a given lattice. With such a modification, the average grain boundary mobility is still a decreasing function of grain size. However, the asymptotic limit to the grain growth exponent can be reached much faster than in the old algorithm, since the difference between the mobilities at the triple point and the grain boundaries is less than in the old algorithm. In the old algorithm, the mobility at triple points is twice the mobility at the grain boundaries, while in the new algorithm it is roughly equal to 1.5 times the mobility at the grain boundaries.

In the old algorithm, the total number of initial orientations in the system had to be limited to a finite number. This was because the mobility was inversely proportional to the total number of orientations, and, hence, increasing the number of orientations to a large value resulted in an extremely low boundary mobility and, consequently, to very low growth rates. On the other hand, in the new algorithm, the boundary mobility is not a function of the total number of grain boundary orientations. Hence, the total number of initial orientations can be as high as the total number of points within the domain, so that no grain coalescence can occur at any stage of grain growth.

The proposed modification should also eliminate the problem of grain nucleation when the anisotropy in grain boundary energy is taken into consideration. Since only the nearest neighbor orientations are considered during a reorientation attempt, the occurrence of grain nucleation using the old algorithm, demonstrated in Fig. 5, will be totally eliminated using the new algorithm.

\subsubsection{Comparison of Results Obtained Using the Old and the New Algorithms}

The above modifications were implemented in 2-D and 3-D simulations of grain growth in single-phase materials. A triangular lattice ${ }^{3-10}$ of $200 \times 200$ points was used for 2-D simulations, and a cubic lattice of $50 \times 50 \times 50$ points, was used for the 3-D simulations. The simulations were carried out using both the old and the new algorithms. The results obtained can be summarized as follows:

1. The new algorithm gave a significantly higher grain growth exponent, closer to the theoretical limit of 0.5 , than the old algorithm at all grain sizes. The results for 2-D and 3-D simulations are shown in Table 1. 
2. Grain coalescence was completely eliminated using the new algorithm. Figures 6 through 9 show the variation of the ratio $R_{\max } / R$, where $R_{\max }$ is the maximum grain size, and $R$ is the average grain size in typical microstructures obtained for (a) 2-D simulations using the old (fig. 6), modified old (fig. 7) and new (fig. 8) algorithms, and (b) 3-D simulations using the old algorithm. Sudden fluctuations and large values of the ratio in the 4 to 6 range obtained using the old algorithm are caused by the coalescence of grains having the same orientation number. The variation of the ratio with grain size is much smoother for the new algorithm, and its maximum value is always in the 2 to 2.5 range, which indicates absence of grain coalescence.

3. Excellent fits to both the 2-D (fig. 10) and 3-D fig. 11) grain-size distributions were obtained using the log-normal function for the new algorithm. The use of two different functions, the Louat function for 2-D distributions, and the log-normal function for 3-D distributions, as in the case of the old algorithm, was not necessary. In figures 10 and 11 , the frequency refers to the number of grains within a given size class.

4. The closeness of fit to the log-normal function was significantly improved by considering grain boundary anisotropy, as shown in Fig. 12.

\subsubsection{One-to-one Correlation between MC and Real Parameters ${ }^{23}$}

As described earlier, the $\mathrm{MC}$ parameters of grain size and time are dimensionless. Grain size in the simulations is described in terms of the number of MC sites within a grain, and the simulation time is measured in terms of MCS. In order to apply the simulations to quantitatively predict microstructural evolution in real systems, it is necessary to obtain a one-to-one correlation between $\mathrm{MC}$ and real parameters of grain size and time. The following section describes a methodology which was developed as part of this CRADA by which this correlation can be obtained for curvature-driven grain growth, and the application of the methodology to predict the grain growth kinetics in the $\mathrm{HAZ}$ of a $0.5 \mathrm{Cr}-\mathrm{Mo}-\mathrm{V}$ steel in real space-time coordinates.

\subsubsection{Methodology}

The inputs for this technique are the experimental measures of grain size versus time for a given material, at different temperatures. Also required is a simulated grain growth curve, using the new algorithm, described earlier. Let us assume that the real grain size is related to the $\mathrm{MC}$ grain size as

$$
D_{R}=K_{1} D_{M}
$$

where $D_{R}$ is the real grain size, $D_{M}$ is the simulated grain size, and the constant, $K_{1}$, is a scaling factor which relates the simulated grain size to real grain size. The relationship between real time, $t$ and $M C S$ is defined as

$$
M C S=K_{2} t
$$

where $\mathrm{K}_{2}$ is a temperature-dependent constant given by 


$$
K_{2}=K_{2}^{0} \exp \frac{-Q_{M}}{R T}
$$

where $K_{2}{ }^{0}$ an empirical "frequency factor" for a microcrystal and $Q_{M}$ is the activation energy for grain boundary migration. At any temperature

$$
\frac{d D_{R}}{d t}=K_{1} \frac{d D_{M}}{d t}
$$

Equation 10 can be written as

$$
\frac{d D_{R}}{d t}=K_{1}\left(\frac{d D_{M}}{d M C S}\right)\left[\frac{d M C S}{d t}\right)
$$

From equation 8

$$
\frac{d D_{R}}{d t}=K_{1} K_{2}\left[\frac{d D_{M}}{d M C S}\right]
$$

Since $K_{1}$ is known from our assumption (see Eq. 7), $K_{2}$ can be calculated. Equations 7 through 9 can be used together to convert a real thermal cycle into an effective MCS, which, in turn, can be used for simulating the evolution of the grain structure cycle as a result of the thermal cycle. Since there is a one-to-one correlation between the simulated and real variables of grain size and time, the simulation output can be directly used to predict the real microstructural evolution during thermal processing.

\subsubsection{Application of the Methodology to $\mathrm{Cr}-\mathrm{Mo}-\mathrm{V}$ Steel}

2-D MC simulations were carried out using a $300 \times 300$ lattice in which the lattice points were arranged in a square geometry. The total number of initial orientations was 90,000. A neighborhood of eight lattice points consisting of the first- and second-nearest neighbors was used for local interaction energy calculations. The details of the MC algorithm used for the simulations are described elsewhere. ${ }^{22}$ The MC algorithm predicts a grain growth exponent of 0.5 for an ideal material in which anisotropy in grain boundary energy, preferred orientation and solute-drag are absent. However, the Cr-Mo-V steel under consideration showed an experimental grain growth exponent of $0.368 .{ }^{24}$ The lower grain growth exponent was attributed to solute drag, the presence of a texture, and a non-equiaxed grain structure in the initial microstructure. ${ }^{24}$ It has been shown ${ }^{11}$ that a lower grain growth exponent can be obtained in MC simulations through the introduction of an anisotropy parameter. In the present simulations, the anisotropy parameter was treated as an adjustable parameter. It was found that an anisotropy parameter of $0.45 \pi$ resulted in a grain growth exponent of 0.368 , which was the same as the experimental value. The effect of solute drag is to enhance the orientation dependence of grain boundary energy and mobility, and thereby influence the magnitude of the grain growth exponent. Hence, although solute-drag has not been modeled from a fundamental sense, the overall effect of solute drag is built into the grain growth exponent through the anisotropy term. 


\section{Isothermal Simulations}

Initially, the simulation was carried out for an MCS of 500, in order to generate a grain growth curve which was later used in calculating the constants $\mathrm{K}_{1}$ and $\mathrm{K}_{2}$. Using the isothermal grain growth data from Alberry et al..$^{24}$, and the simulated curve, $\mathrm{K}_{2}$ was determined as a function of temperature for an assumed value of $\mathrm{K}_{1}$, by using the methodology described earlier. Using $\mathrm{K}_{1}$ and $\mathrm{K}_{2}$, the MCS value corresponding to each of the isothermal treatments was obtained.

The isothermal grain growth data of Alberry et al. ${ }^{24}$ were for a holding period of $100 \mathrm{~s}$, at temperatures ranging from $1391 \mathrm{~K}$ to $1576 \mathrm{~K}$. Assuming a $\mathrm{K}_{1}$ value of 25 microns, the MCS for a 100 second hold at $1391 \mathrm{~K}$ was 102 . However, for the same value of $K_{1}$, the MCS corresponding to a 100 second hold at $1576 \mathrm{~K}$ was 148000 . Since a much larger computer time is required to carry out the simulation for an MCS of 148000 , a higher $K_{1}$ value was assumed for the $1576 \mathrm{~K}$ heat treatment. For $\mathrm{K}_{1}$ equal to 141 microns, the MCS for a 100 second hold at $1576 \mathrm{~K}$ was 100 . As described earlier, the advantage of the above methodology for relating $\mathrm{MC}$ and real times is that the constant $\mathrm{K}_{1}$ can be chosen such that it matches the scale of the microstructural evolution. Consequently, $\mathrm{K}_{2}$, and hence MCS, can be kept reasonably small, and the computational time can be kept reasonably constant for a large grain growth range.

The simulations were then repeated for the above MCS values in order to obtain grain growth data in real space and time at the corresponding temperatures and check the validity of the methodology.

\section{Simulation of Weld HAZ}

In order to generate the thermal cycle for each HAZ location, the welding parameters and material properties used by Alberry et al. ${ }^{24}$ for the $\mathrm{Cr}-\mathrm{Mo}-\mathrm{V}$ steel shown in Table 2, were chosen. Thermal cycles were calculated using the form of the Rosenthal equation used by Alberry et al. ${ }^{24}$ MCS values corresponding to each thermal cycle were calculated by breaking down the thermal cycle at a given location into a number of isothermal steps using a time step of $0.01 \mathrm{~s}$. For all weld simulations, $\mathrm{K}_{1}$ was assumed to be 25 microns, and the appropriate value of $\mathrm{K}_{2}$ as a function of temperature was calculated as described previously. The initial grain size in the simulations was assumed to be $25 \mu \mathrm{m}$, which is approximately the same as that in the steel samples used by Alberry et al. ${ }^{24}$ Hence, the initial microstructure consisted of one lattice point per grain.

Since the thermal cycle in a weld HAZ is a function of the distance from the fusion line, there is a corresponding gradient in the MCS. The gradient in MCS was incorporated into the simulations by carrying out the simulations for the maximum value of $M C S, \mathrm{MCS}_{\max }$, which occurs near the fusion line, and visiting each $\mathrm{MC}$ site with a probability $\mathrm{p}(\mathrm{x})$ given by

$$
p(x)=\frac{M C S(x)}{M C S_{\max }}
$$

where $\operatorname{MCS}(x)$ is the MCS at a distance $x$ from the fusion line. The mean grain size at various distances from the fusion line was measured using linear intercept counts on test lines placed parallel to the fusion line. In MC simulations, periodic boundary conditions are normally used so that the grains at the top of the domain wrap around those at the bottom, and those at the left end wrap around those at the right end of the domain. Although such a scheme can be applied to isothermal grain growth, in the case of grain 
growth under a temperature gradient, the peak temperature must be located at the center of the domain, so that the grains that wrap around are at the same temperature. Hence, in the simulations, the center of the domain corresponds to the region adjacent to the fusion line, and the ends correspond to the locations which are roughly $3.75 \mathrm{~mm}$ from the fusion line.

Alberry et al. ${ }^{24}$ described the thermal pinning by computing the grain size in a bulk sample subjected to a thermal cycle corresponding to a HAZ location $\sim 120 \mu \mathrm{m}$ from the fusion line and comparing it with the grain size obtained in an actual weld $\mathrm{HAZ}$ at an identical location. Hence, in order to calculate thermal pinning, the simulations were repeated by applying to the entire domain the MCS corresponding to the thermal cycle at a distance of $120 \mu \mathrm{m}$ from the fusion line. All simulations were repeated using five different starting seed values for the random number generator, and the results shown in each case are an average of 5 runs.

\section{Results and Discussion}

The simulated isothermal grain growth curve using an anisotropy parameter of $0.45 \pi$ is shown in Fig. 13 . The derivative of the best-fit function to the data of Fig. 13, dD $\mathrm{MCS}_{\mathrm{dMCS}}$, is plotted as a function of $\mathrm{D}_{\mathrm{MCS}}$ in Fig. 14. Figure 15 shows the derivative of the best-fit function to a typical set of isothermal grain growth data of Alberry et al. ${ }^{24}, \mathrm{dD}_{\mathrm{R}} / \mathrm{dt}$, plotted as a function of $\mathrm{D}_{\mathrm{R}}$. Arrhenius plot of $\ln \left(\mathrm{k}_{2}\right)$ versus $1 / T$, shown in Fig. 16, yields an activation energy of $470 \mathrm{KJ} / \mathrm{mole}$, which is the same as that obtained using the data of Alberry et al. ${ }^{24}$, shown in Fig. 16. Figure 17 shows the raw grain growth data of Alberry et al. ${ }^{24}$, on which the grain growth kinetics obtained by simulation are superimposed. The agreement between simulated and experimental curves is excellent.

Figure 18 shows the thermal cycles in the weld HAZ calculated using the Rosenthal equation and the parameters shown in Table 2. The effective MCS as a function of distance from the fusion line is shown in Fig. 19. Figure 20 shows the kinetics of grain growth at the $120 \mu \mathrm{m} \mathrm{HAZ} \mathrm{location}$ and the kinetics of grain growth for bulk heating using an identical thermal cycle. It can be clearly seen that the kinetics of grain growth in the HAZ location is lower than that for bulk heating for an identical thermal cycle, thus indicating grain boundary pinning in the $\mathrm{HAZ}$ due to the temperature gradient.

A comparison of the experimental and simulated isothermal grain growth data shown in Fig. 17 indicates that the $\mathrm{MC}$ technique, in conjunction with the methodology used for obtaining the correlation between MC and real parameters, can be satisfactorily used to simulate isothermal grain growth data for the $\mathrm{Cr}-\mathrm{Mo}-\mathrm{V}$ steel. The methodology also appears to successfully simulate the grain growth under bulk heating conditions, using a thermal cycle characteristic of a $\mathrm{HAZ}$ location. The present simulations predict an average grain size of $393 \mu \mathrm{m}$ for a thermal cycle corresponding to a distance of $120 \mu \mathrm{m}$ from the fusion line, which compares favorably with the grain size of $320 \mu \mathrm{m}$ computed by Alberry et al. ${ }^{24}$ using an identical thermal cycle. The welding parameters, material properties, and the initial austenite grain size used in the current simulations are all identical to the ones used by Alberry et al. ${ }^{24}$ Since the MC technique appears to essentially capture the thermal pinning phenomenon, the simulated grain size at a given distance from the fusion line should also compare favorably with the experimentally measured values reported by Alberry et al. ${ }^{24}$ However, there seems to be an appreciable discrepancy between the two. While Alberry et al. ${ }^{24}$ obtained a grain size $\sim 100 \mu \mathrm{m}$ at a weld HAZ location $120 \mu \mathrm{m}$ from the fusion line, the current simulations predict a grain size of $288 \mu \mathrm{m}$ at the same location. Thus, although the MC simulation clearly demonstrates the presence of thermal pinning, the extent of calculated pinning for the $\mathrm{Cr}-\mathrm{Mo}-\mathrm{V}$ steel using the simulations appears to be different from that reported by Alberry et al. ${ }^{24}$ Since present simulations successfully predict the grain size in both isothermal and bulk heating 
conditions, the lack of agreement between experimental and simulated grain sizes in the weld HAZ could be due to the fact that there may be an additional pinning which is not related to the temperature gradient effects described earlier.

Alberry et al. ${ }^{24}$ assumed that the pinning in the weld $\mathrm{HAZ}$ of the $0.5 \mathrm{Cr}-\mathrm{Mo}-\mathrm{V}$ steel was entirely due to the steep temperature gradients that existed in the weld HAZ of the steel. The liquidus temperature for the steel is $1813 \mathrm{~K}$. Alberry et al. ${ }^{24}$ assumed that the presence of liquid in HAZ locations below $1813 \mathrm{~K}$ did not have any effect on grain growth. However, one of the ways by which additional pinning can occur, especially in the regions close to the fusion line, is through the formation of grain boundary liquid. ${ }^{25}$ The presence of grain boundary liquid can result in a complete arrest of grain growth in the time scales encountered in welding. This is because in the presence of grain boundary liquid the kinetics of curvature-driven grain growth is orders of magnitude slower than in the absence of grain boundary liquid. ${ }^{26}$ Experimental evidence for liquid pinning is found in the $18 \mathrm{Ni}$ maraging steel, where the formation of subsolidus grain boundary liquid by the constitutional liquation of Ti-rich inclusions present in the steel arrests grain growth..$^{25}$ Since no grain growth occurs in the presence of grain boundary liquid, the portion of the thermal cycle in which grain boundary liquid exists need not be considered for the calculation of MCS. The equilibrium solidus for the $\mathrm{Cr}-\mathrm{Mo}-\mathrm{V}$ steel was calculated to be $1743 \mathrm{~K}$. The solidus temperature on cooling is a function of the extent of backdiffusion of solute into the solid. Since the cooling rates are extremely high (of the order of $800^{\circ} \mathrm{K} / \mathrm{sec}$ ), it is reasonable to assume that the solidification on cooling will not be complete at the equilibrium solidus temperature. The extent of undercooling is difficult to estimate in a muticomponent system, since the diffusion coefficients for the solute elements are not accurately known. However, a rough estimate of the temperature range in which grain boundary liquid can exist can be determined from available differential thermal analysis (DTA) data for low-alloy steels with a similar carbon content as the $\mathrm{Cr}-\mathrm{Mo}-\mathrm{V}$ steel. DTA studies of a $0.10 \mathrm{C}-0.82 \mathrm{Si}-1.6 \mathrm{Mn}$ steel at a cooling rate of $10^{\circ} \mathrm{K} / \mathrm{min}^{27}$ indicate an undercooling of $85 \mathrm{~K}$. In the case of the weld $\mathrm{HAZ}$, the undercooling would be still higher because the cooling rates are an order of magnitude higher and, consequently, the extent of solute backdiffusion lower.

Yet another mechanism by which grain boundary liquid can form is through the spreading of the liquid from the fusion zone along the grain boundaries, especially if the liquid wets the grain boundaries. In such cases, the liquid can spread along the boundaries up to a location in the weld HAZ where the peak temperature is a local solidus which is lower than the equilibrium solidus of the alloy. The local solidus will depend upon the relative rates of spreading and backdiffusion. Hence, in the presence of a weld pool, the maximum temperature in the HAZ above which intergranular liquid can form is lower than the equilibrium solidus temperature.

Based on the above arguments, the $\mathrm{HAZ}$ simulations for the $0.5 \mathrm{Cr}-\mathrm{Mo}-\mathrm{V}$ steel were carried out for various assumed on-heating liquation temperatures for the HAZ. The solidification temperature on cooling was assumed to be equal to the liquation temperature in each case. The portion of the thermal cycle above the assumed liquation temperature on heating, and the solidification temperature on cooling were not considered for the calculation of MCS. The cumulative MCS values for the thermal cycles shown in Fig. 18 , for various assumed on-heating liquation temperatures, are shown in Fig. 21. Note that the MCS values at HAZ locations where the peak temperatures are above the liquation temperature are lower than the corresponding values in the absence of liquation. Hence, in the presence of subsolidus or near-solidus liquation, the grains are pinned by grain boundary liquid close to the fusion line and by temperature gradient away from the fusion line. Figure 21 also shows that the MCS initially increases with distance from the fusion line before it starts to decrease. This is because of the fact that the heating and cooling rates decrease as a function of the distance from the fusion line. Figure 22 shows the HAZ grain structures 
obtained for various liquation temperatures. Note the initial increase in the grain size as a function of distance from the fusion line, before it starts to decrease, which can be clearly seen for a liquation temperature of $1643 \mathrm{~K}$. Figure 23 shows the ultimate grain size obtained at a distance of $120 \mu \mathrm{m}$ from the fusion line as a function of the liquation temperature. The horizontal, dotted line in Fig. 11 represents the grain size that would be obtained under bulk heating conditions using the thermal cycle corresponding to the location $120 \mu \mathrm{m}$ from the fusion line.

In the case of bulk heating, it must be realized that the on-heating liquation occurs at the equilibrium solidus, since subsolidus liquation due to the intergranular spreading of liquid from the weld pool described previously is absent. In the present simulations, the peak temperature at a distance of $120 \mu \mathrm{m}$ from the fusion line was $1708 \mathrm{~K}$. Since it was less than the equilibrium solidus, it was assumed that there was no liquation during bulk heating. However, if the on-heating temperature is high enough to cause liquation in the bulk heating case, the on-cooling solidification temperature would again be determined by the kinetics of solute backdiffusion as in the weld HAZ. The grain size obtained under bulk heating conditions may be overestimated, if a possible liquation at the grain boundaries below the equilibrium solidus is overlooked. Such a subsolidus liquation is not expected to occur for the $0.5 \mathrm{Cr}-\mathrm{Mo}-\mathrm{V}$ steel under bulk heating conditions because the enrichment of the matrix at the precipitate-matrix interface with respect to $\mathrm{Cr}, \mathrm{Mo}$, or $\mathrm{V}$, as a result of incomplete dissolution of precipitates containing these alloying elements, does not result in an appreciable reduction in the local solidus. However, subsolidus liquation by the above mechanism occurs in the HAZ of many commercial alloys, ${ }^{28-32}$ and, hence, should be carefully considered in estimating the on-heating liquation temperature under bulk heating conditions in these alloys.

From Fig. 23, it can be seen that in order to match the pinning results of Alberry et al., a liquation temperature approximately $100 \mathrm{~K}$ less than the equilibrium solidus must be assumed for the weld $\mathrm{HAZ}$ of the $\mathrm{Cr}-\mathrm{Mo}-\mathrm{V}$ steel. As described earlier, the spreading of the liquid from the weld pool along $\mathrm{HAZ}$ grain boundaries, and the undercooling of this liquid due to lack of backdiffusion into the matrix, may account for such a subsolidus liquation in the weld HAZ. DTA studies of undercooling in low-alloy.steels with approximately the same level of carbon as in the $\mathrm{Cr}-\mathrm{Mo}-\mathrm{V}$ steel ${ }^{27}$ indicate that the assumption of undercooling of the order of $100 \mathrm{~K}$ is not unreasonable under welding conditions. The contribution of liquid pinning increases with decreasing liquation temperature and appears to become greater than that of thermal pinning for a liquation temperatures below $1643 \mathrm{~K}$.

Figure 24 shows the kinetics of grain growth at the HAZ location $120 \mu \mathrm{m}$ from the fusion line for various liquation temperatures. The data for Fig. 24 were obtained by calculating the MCS at different HAZ locations for each real-time step of $0.01 \mathrm{~s}$ based on the current temperature of that location, and executing the MC algorithm at the end of each time step using the criterion shown in equation 10. The arrest of grain growth by grain boundary liquid can be clearly seen for liquation temperatures of $1643 \mathrm{~K}$ and 1693 $\mathrm{K}$. The peak temperature at the $120-\mu \mathrm{m}$ location is $1708 \mathrm{~K}$, and hence grain boundary liquid formed at this location for the above liquation temperatures. For a liquation temperature of $1743 \mathrm{~K}$, no grain boundary liquid formed at the $120-\mu \mathrm{m}$ location. However, the formation of grain boundary liquid in the vicinity of this location resulted in a significant reduction in the grain growth rate compared to the case where no liquation occurs in the HAZ (Tliq $=1813 \mathrm{~K}$ ) as shown in Fig. 24.

It must be mentioned that the ultimate grain sizes shown in Fig. 24 are slightly lower than those shown in Fig. 23 for the same liquation temperature. This is because of the fact that, in the simulations used for generating the data for Fig. 24, the MCS was calculated and MC algorithm executed at every real-time step. Since MCS is an integer by definition (1 MCS corresponds to one reorientation attempt per lattice 
site for all the sites in the lattice), the calculation of MCS as an integer at every time step resulted in a truncation error, and the total MCS for the entire thermal cycle was slightly less than in the calculations used for the data in Fig. 23. However, the reason for illustrating the grain growth as a function of real time is not to calculate the ultimate grain size, but to show the effect of grain boundary liquation in the HAZ on the kinetics of grain growth. The ultimate grain sizes shown in Fig. 23 should be considered more accurate, since there was no truncation error at the end of each real-time step in these calculations.

\section{Conclusions}

The grain structure in the weld $\mathrm{HAZ}$ can be simulated with reasonable accuracy using the $\mathrm{MC}$ technique and a methodology for converting the $\mathrm{MC}$ parameters of grain size and time to real parameters. The MC technique also effectively captures the thermal pinning phenomenon that has been reported in the weld $\mathrm{HAZ}$. However, the extent of thermal pinning reported in the literature for a $\mathrm{Cr}-\mathrm{Mo}-\mathrm{V}$ steel is significantly higher than the thermal pinning that can be obtained based on the temperature gradient alone. It is suggested that the formation of grain boundary liquid at HAZ locations where the peak temperatures on heating are above the liquation temperature, and the retention of the grain boundary liquid to lower temperatures on cooling because of incomplete backdiffusion of solute, can account for additional pinning at $\mathrm{HAZ}$ locations close to the fusion line. Incorporating the additional pinning due to grain boundary liquid has resulted in a closer match between simulated and experimentally measured grain sizes in the weld HAZ of a Cr-Mo-V steel.

\subsection{PARALLELIZATION OF MONTE CARLO GRAIN GROWTH CODE}

The MC algorithm for 2-D and 3-D grain growth has been ported to the ORNL KSR1 computer. As in the parallelization of the welding code, the calculation domain was split into contiguous subregions or blocks, and each block was assigned to a different processor. Because the calculations for each point in the lattice involve only its nearest neighbors, only the outermost points of a block need any contact with neighboring processors. In this implementation, the outermost points of every subregion are stored in a shared-memory area that can be accessed by all of the processors. At the start of a time step, each processor retrieves its boundary values it needs from the shared memory region, then updates all of the points in its domain. At the end of each time step, each processor copies its outermost nodes into the shared-memory area where they can be used by the other processors at the next time step. This process is illustrated in Fig. 25. Barriers are used to implement the synchronization points at which all of the processors must wait for everyone to catch up.

Results from massively parallel 2-D and 3-D grain growth simulations are shown in Figs. 26 and 27. Figure 28 shows the effect of parallelization on the computational time. Speedup is defined as the execution time for the single-processor case divided by the execution time for the multi-processor case. In Fig. 28, the line identified as linear behavior shows the situation in which using $n$ processors makes the problem run $n$ times faster. Note that for the analyses performed, the performance is close to, and sometimes above, the linear line. Superlinear behavior is usually achieved when the whole problem will not fit into one processor's data cache, but the reduced size of the subregion will. For small problems in which the communications overhead becomes large, the speedup falls below linear as the number of processors is increased. For larger problems, no falloff was noted for the 64 processors available on the KSR1. 


\subsection{SIMULATION OF WELD FUSION ZONE MICROSTRUCTURE USING CELLULAR AUTOMATON (CA)}

\subsubsection{Introduction}

Melt-pool shape is a strong factor in the development of microstructures developing in the fusion zone of a weld. These structures play a major role in such defect formations as microporosity or hot-cracking and can affect solid-state transformations that may subsequently occur during cooling. In this sense, they are an important step in any welding process prediction. This section treats some of the fundamental aspects associated with weld-pool solidification. Included are such effects as heterogeneous nucleation of grains in the bulk of the liquid, growth kinetics, preferential growth directions of dendrites (as simulated by grain crystallographic axes), and competition between growth morphologies.

The dominant methods for simulating joining processes are based on finite-element and finite-difference analysis. While these techniques give excellent results on a macroscopic level, their application on a mesoor microscale level, where grain structure effects are important, is not entirely satisfactory. The advent of CA techniques in recent years may provide another method of efficiently simulating material behavior under various solidification and joining processes. This section summarizes the approach, results, and discussion of results of our R\&D effort in this topic.

\subsubsection{CAs as Efficient Modelers}

Although CA techniques have been used for many years as discrete microscale simulators, we have begun to explore their use in modeling mesoscale thermal and metallurgical problems with complicated boundary conditions. The classical CA is an autonomous device having no coupling to the external world $^{33}$ Once its internal states are set and its rules chosen, it evolves as an independent system with either absorbing boundaries or within a toroidal (wrap-around) geometry. In an earlier paper, Dress ${ }^{34}$ showed how to modify conceptually the CA, allowing realistic boundaries for simulating the physics of matter and energy exchange at these boundaries with an external system comprised of fields and heat baths. In this sense, the method is reminiscent of standard finite-element analysis but allows a simple means of specifying complex boundary conditions, both temporal and spatial.

The recent set of papers by Rappaz and Gandin ${ }^{35}$ and Gandin, Rappaz, and Tintillier ${ }^{36}$ have shown the value of the $\mathrm{CA}$ for realistic simulations for microstructure formation in solidification processes. Dress explored the use of CAs in heat-transfer problems. ${ }^{34}$ The present work incorporates both the thermal and grain-growth CAs into a single simulation with the goal of extending the application of CA simulators to the dynamic welding process.

\subsubsection{Initial Simulation of Grain Microstructure}

The present study attempts to model the fusion zone structure in a linear, autogenous GTA weld. The orientation and configuration of the grains that grow at the trailing edge of the melt pool are of primary interest. The goal of this work is to deyelop a model that qualitatively and quantitatively reproduces what is seen in actual situations. Rappaz and Gandin ${ }^{35}$ simulated solidification in a casting by a CA. These authors showed that the grain growth dynamics are both qualitatively and approximately quantitatively correct for the case of solidification of an ingot. 
A CA is specified by a set of states for each cell, a set of rules determining cell behavior, and a neighborhood function specifying which cells influence each other. The rules determine the transitions between states and are functions of the prior state and the neighborhood. In the microstructure simulation, the states were chosen to be a crystallographic orientation, a grain membership function, and a time of grain seeding. A reasonable model of crystal growth is to consider a wave of solidification spreading out from a seed or the boundary of a solidified grain, subject to the appropriate thermodynamic constraints. As pointed out in ref. 35, this Huygen's Principle method can only reproduce the shapes having symmetry of the underlying CA lattice, i.e., squares for a rectangular lattice of cells and hexagonal for a hexagonal lattice of cells. To achieve grain-shape independence from the CA lattice, we depart from the technique developed in ref. 35 , and define a velocity density, or probability of cell attachment to a given grain, that is based on a growth velocity as a function of the angle between the direction of the candidate CA cell in question and the crystallographic axis of the grain about to "attach" that cell. Although this is a departure from the method of ref. 35, it leads to results statistically indistinguishable from those therein, while maintaining the spirit of the $\mathrm{CA}$ computation of communication of information only between near neighbors.

The velocity of the front spreading out from a grain boundary is proportional to the probability that a grain adds a cell located on the boundary at an angle, $\alpha$, with respect to the principal axes of the grain. If we assume that the tip grows at the maximum velocity, and that the velocity $45^{\circ}$ from the tip grows at a rate proportional to $\cos \left(45^{\circ}\right)$, we obtain the velocity a distribution proportional to $1 /(\cos \alpha+\sin \alpha)$. By taking a modulo $90^{\circ}$, a four fold grain symmetry is maintained. This form obviously neglects the microprocesses of dendritic growth and concentrates on the grain as the entity of physical importance. While not strictly correct, this simplifying assumption allows reasonable qualitative results to be obtained in mesoscale simulations. The velocity distribution around a cubic grain is shown in Fig. 29. The [100] axis is assumed to lie along the zero-degree direction.

\subsubsection{Equiaxed Grain Growth}

This velocity distribution described above was used to compute an initial grain structure for the melting and solidification simulation. The method follows that of ref. 35 in that a certain undercooling is assumed, resulting in a tip velocity of about $0.25 \mathrm{~m} / \mathrm{s}$. The initial grain structure was obtained by seeding growth sites with randomly chosen locations and orientations throughout the plate and running the CA forward in time until all the cells were attached to a grain. Where a CA cell was adjacent to two or more grains, a competition based on the time for the growth front to reach that cell determined to which grain it belonged. The growth of a typical single (isolated) grain is shown in Fig. 30.

Subsequent simulation of a cooling ingot with physical size, cell size, and undercooling specified as in ref. 35 resulted in a close reproduction of the results shown therein. This method successfully simulates both equiaxed and columnar grain growth. The success of the $\mathrm{CA}$ in thermal calculations, ${ }^{34}$ and simulation of a cooling ingot with both columnar and equiaxed grain growth provides an impetus for attempting a simulation of solidification microstructure in an arc welding problem. The CA appears to be a useful tool for a certain class of metallurgical problems. In the next section, we briefly review the results of thermal calculations as carried out by a coarse-cell CA and then turn to the method and results of simulating grain growth in the weld fusion zone as calculated by a fine-cell CA.

\subsubsection{Weld Simulation}

A CA array in two or three dimensions can simulate the entire welding process of an arc traveling along a plate, melting the material to a certain depth as it moves. Each cell in the array must be assigned an 
appropriate set of states that represents the physical properties of the material comprising the plate. The CA rules are particular, discrete versions of the appropriate physical laws of heat transfer and enthalpy. Those cells having a face on the plate boundary must be able to exchange energy with the plate's environment.

\subsubsection{Thermal Simulation}

Consider a GTA welding of thin sheet as described by Zacharia et al. (2). The CA model used in this simulation is an array of $30 \times 60$ cells having dimensions $1 \times 1 \mathrm{~mm}$ in the plane of the plate. The plate, $5 \mathrm{~mm}$ thick, is represented by one cell as we are considering only a 2-D model at this time. The simulated heat source specification, taken from ref. 5, was Gaussian in shape, with a circular cross section delivering $95 \%$ of its power within a $3 \mathrm{~mm}$ radius. The simulated arc delivered $150 \mathrm{~A}$ at $15.1 \mathrm{~V}$ with $60 \%$ efficiency and traveled at a rate of $0.423 \mathrm{~mm} / \mathrm{s}$. The results of this simulation are shown in Fig. 31 as a contour plot of isotherms within the plate, $33 \mathrm{~s}$ after the arc crossed the left edge.

Although not necessary, the thermal calculation was decoupled from grain growth calculation to provide greater flexibility in exploring the effect of various rules and neighborhoods on grain growth patterns. This was accomplished by deriving an approximate form for the solid-liquid interface. The results of the thermal simulation were used as an external driving field that was coupled to the grain growth CA, and any consistent set of thermal calculations may be used as input to the grain growth $\mathrm{CA}$.

A solidus isotherm was fit to a fourth-order polynomial to approximate the shape of that curve. The results of this fit are shown in Fig. 32. The description of the isotherm as a polynomial allowed both arbitrary scaling and arbitrary sampling, as well as providing a time-dependent critical solidus line that could be swept along any plate of arbitrary length modeled by a CA grid of arbitrary cell size. In this way, the results of thermal CA served as input to the grain growth $\mathrm{CA}$, decoupling the two calculations.

Once the isotherm function has been determined for a particular plate geometry, it is a simple matter to sample the function for different cell sizes to compute the thermal gradient at each cell site. Thus, both the cells leaving the melt pool and the local interface velocity can be computed as a function of time. If $y_{7}(x, 0)$ is the polynomial expression for the position of the isotherm as a function of distance across the plate where $x$ is the coordinate in Fig. 32, then the position of the isotherm at time $t$ is simply

$$
y_{T}(x, t)=y_{T}(x, 0)+v_{\text {arc }} t
$$

Once the moving interface has been defined, it is used to determine those cells changing from solid to liquid during any given time step. The method requires a choice of time step that is small enough so that only a few cells have crossed the interface at any particular instant. The criterion for cell selection is to choose only those cells whose center position as measured by $x$ has just fallen beyond the $y_{T}(x, t)$ curve. Under the physical parameters mentioned above and with a $20 \mu \mathrm{m}$ cell size, a time step of $10^{-3} \mathrm{~s}$ results in approximately $15 \%$ of those cells lying on the solid-liquid interface being solidified at each step. These few cells then become candidates for attachment to existing grains.

\subsubsection{Local Growth Directions and Angles}

To attach the candidate cells to adjacent grains, we make use of the two dominant features of the welding process: heat-flow direction and direction of arc travel. The direction of heat flow is assumed normal to the solid-liquid interface and is proportional to the gradient discussed above. New candidate cells can only 
be attached to existing grains on which they border. If a candidate cell touches only one grain, it will be attached to that grain during the current time step. Only in the case of a candidate cell bordering on two or more grains can a choice be made. The competition as to which grain attaches the candidate cell determines the crystalline growth pattern of the solidification. This competition is based on the probability of attachment calculated from the crystallographic direction, the heat flow direction, and a direction of attachment.

Consider the portion of the CA array illustrated in Fig. 33. The candidate grains are indicated by the shaded squares and the solid-liquid interface by the heavy line. The arc is traveling to the right. In Fig. 33 , we are examining a section of the CA lying along the upper portion of the plate, somewhere behind the arc position.

To keep the interface at a constant shape, as determined by the moving curve given by equation 14 , each of the candidate cells must solidify during the time step that they are produced by attaching to one of the neighboring grains. For each of the possible solid cells to which a candidate can attach, we define a local growth direction (direction of attachment) as a vector from the center of the solid cell in the neighborhood of the candidate grain through the center of the candidate grain itself. The local growth direction from neighbor 2 (lying in grain 2) is shown in Fig. 33. Both of the geometrical directions-the gradient or normal to the interface and the direction of the [100] crystallographic axis-are referred to this local growth direction, giving the angles labeled $\gamma_{1}$ and $\gamma_{2}$ in Fig. 33. The only ambiguity is the choice for the crystallographic direction of the grain in question (labeled [hkl] in the Fig. 33) as there are four possibilities due to the cubic symmetry in the plane. We choose that axis lying closest to the local growth direction; note that this direction is necessarily forward, in the direction of arc travel.

The probability that a candidate cell attaches to a parent grain is proportional to $\cos \gamma_{1} \cdot \cos \gamma_{2}$, where $\gamma_{1}$ is the angle between the local growth direction and the direction of maximum growth denoted by [hkl], and $\gamma_{2}$ is the angle between the normal to the solidification front and the local growth direction. This probability is calculated for each of the solid cells in the neighborhood, and the attachment of the candidate cell to a parent grain is made according to these probabilities in the usual manner.

\subsubsection{Results}

The grain structure resulting from a simulation of welding both single and polycrystalline alloys shows patterns consistent with experimental data, suggesting that the model is qualitatively correct within the approximations made. Figure 34 shows the results of one such simulation. The melting started about $2 \mathrm{~mm}$ from the left edge of the plate, and the arc traveled to the right at a velocity of $0.423 \mathrm{~mm} / \mathrm{s}$. While the thermal simulation was carried out for the plate shown in Fig. 32, only a central 12- $\times 17-\mathrm{mm}$ region of the plate was used in the grain growth simulations to reduce the number of inactive cells in the CA. The initial grain configuration was computed by allowing 1500 randomly placed seeds to grow according to the method described, until each cell belonged to a grain. Each seed had a principal axis direction randomly chosen to lie between -44 and $+45^{\circ}$ with respect to the horizontal direction. The integer angles were chosen with steps of $1^{\circ}$. The size of each CA cell was $20 \mu \mathrm{m}$, resulting in CA dimensions of 600 $\times 850$.

\subsubsection{Discussion}

The random nature of the competition alluded to above is evident in the curvature of the grains as solidifying cells are attached at the solidus interface. A "winner-take-all" competition would result in predominantly vertically and horizontally oriented grain boundaries, with any change of direction in 
growth taking place at a 90 degree angle as the previously winning grain abruptly looses the competition due to the changing gradient direction as the melt pool travels to the left. Since the winner is chosen in a probabilistic fashion, certain grains also taper off in width as they gradually loose to a competitor. In places, this tapering off leads to the appearance of intermingling of two grains for short distances.

\subsubsection{Summary}

We have demonstrated that CAs are efficient and accurate simulators of the welding process for a thin plate. They reproduce the thermal behavior of material samples and show good results when simulating equiaxed and columnar grain growth based on a growth front distribution.

\subsection{TRANSFORMATION PLASTICITY MODEL}

Temperature distribution, microstructure and stress-strain relationships are known to change in a complicated manner during welding. Such thermo-mechanical-metallurgical couplings can be listed as follows: (1) coupling between temperature and phase transformation histories through T-T-T diagrams and C-C-T diagrams, and influence of phase transformations on temperature through latent heat effects, and phase dependent thermal properties, (2) coupling between temperature and stress-strain histories through thermal dilatations and temperature-dependent mechanical properties, and influence of mechanical behavior on temperature through internal energy dissipation, and (c) coupling between phase transformation and stress-strain histories through transformation associated volume changes, transformation plasticity, and stress assisted phase transformations. Such couplings make it very difficult to model the residual stresses during cooling of the weld and the $\mathrm{HAZ}$, and it requires a thorough knowledge of the thermal, mechanical and metallurgical transformation phenomena and their interactions. A finite element model based on the LAGAMINE code was developed to calculate the residual stresses during cooling of a steel cylinder. Figure 35 shows the contours of temperature, residual stress, percentage of austenite, proeutectoid ferrite, pearlite and bainite after $1400 \mathrm{~s}$ of natural cooling of a cylinder of $42 \mathrm{CD} 4$ steel, $0.2 \mathrm{~m}$ in radius.

\subsection{INTEGRATION OF THE WELD SIMULATION SOFTWARE WITH CTC'S RP'D TECHNOLOGY}

\subsubsection{Introduction}

The weld simulation codes that have been developed have to be integrated into a design framework, if they are to be used successfully by design engineers. The weld quality, productivity and profits will be enhanced if the welding engineers themselves are able to analyze the effect of various process parameters on the weldment. Thus there is a great need to convert these research tools into a design tool. This section describes some of the initial steps that were taken in an effort to provide the welding engineer with a tool that is easy to use but is based on scientifically proven first principles. Based on CTC's experience in casting process analysis, it was believed that the ultimate usefulness of simulation efforts will be realized when the simulation techniques are based on the Rational Product and Processing methodology. This new approach to manufacturing parts right-the first-time is based on the principles of concurrent engineering.

\subsubsection{Rational Product and Process Design}

Based on the principles of concurrent engineering, CTC has developed the Rational Product and Process Design methodology. This methodology is shown schematically in Fig. 36, indicating the inter-relationships among different factors during a product and process design phase. 
$R P^{2} \mathrm{D}$ is a problem-solving service which enforces continuous quality improvement throughout the design, production, performance (or consumption), and recycle phases of the component life cycle. This methodology has been successfully used in the computer modeling of phenomena associated with the casting processes, ${ }^{37}, 38$ resulting in the elimination of the trail and error method of prototyping and a drastic reduction in the lead time for part production. Physical phenomena occurring during the casting process were represented by appropriate mathematical equations and computer coded in a modular fashion. This resulted in a design tool called RAPID/CAST for use by foundry engineers. Process design times, quality, and yield have been substantially improved through the use of this tool. ${ }^{39}$

\subsubsection{Rational Product and Process Design for Welding Processes}

Based on the successful application of RP2 D to the casting process, in the current investigation, a 3-D, transient, mathematical model for welding has been integrated with the same philosophy to create a true design tool aimed towards use by welding engineers. This highly interactive and graphic tool simulates the welding process from the start to finish and provides the user with capabilities to view the progression of welding and the associated heating and cooling of the substrate. The following sections briefly describe the requirements and the development of this tool.

As shown in Fig. 36, a welding process under simulation can be logically divided into four major steps: (1) solid modeling, (2) welding simulation setup, (3) welding simulation, and (4) welding analysis. Each of these steps can be referred to as a module, which may be made up of one or more submodules. Integration of these modules through a graphic user interface leads to a highly interactive welding design tool for use by welding engineers. The following sections describe these modules.

\subsubsection{Solid Modeling}

Most of the current welding research models simulate the welding of two plates in various configurations. Real-world welding may not be as simple and may require fairly complex 3-D parts. Thus, the geometry under consideration needs to be accurate and realistic. This can be achieved in two ways. In the first method, one can rely on importing geometries created in various commercially available solid modeling packages. However, it has been seen that there is considerable difficulty in fully exchanging geometry files between packages. The second approach overcomes this by providing a built-in geometry creator. This means that an easy, but efficient and robust, module for creating 3-D geometric models is necessary. CTC's experience during the development of the casting design tool is that there should be a standard file format through which file exchange can be achieved through various packages. This has been chosen to be STEP (STandard for Exchange of Product model data) which has been recognized by the IGES/PDES (Initial Graphics Exchange Specification/Product Data Exchange Standard) Organization as the standard format. Therefore, in the current design tool, a capability is provided to modify geometry through the use of a solid modeling kernel.

\subsubsection{Welding Setup and Welding Simulation}

While the welding simulation setup module links itself tightly to the simulation needs, the welding simulation module is the core of the: design tool. The accuracy of the welding simulation will decide whether the predictions will lead to a satisfactory weld or not. Towards this, the welding code is used as the simulation module. Because of the modular nature of the tool, any piece of it can be replaced by a more recent and accurate model if necessary. 


\subsubsection{Welding Simulation Analysis}

The output from welding simulation codes consists of various entities in the computational domain. These include fields for velocity, temperature, density, pressure, composition, etc. Thus the larger the number of finite volumes, the larger the amount of data generated. To create a true design tool aimed towards use by welding engineers, various analysis modules have been developed for visualization and post-process analyses. Analysis modules analyze the temperature profiles to predict residual stresses and evolving microstructures. They also analyze velocity information to predict distortion of the geometry (e.g., weld-pool shape) and macrosegregation due to the fluid flow pattern.

\subsubsection{Welding Engineering Knowledge}

As can be seen from Fig. 36, welding simulations need welding engineering knowledge. The success of the simulation heavily depends on the knowledge or the understanding of the welding process. The framework allows that expert systems can be added into different stages of the welding simulations. These expert systems can be either rule based or algorithmic. The rules themselves can be either generic or specific for every welding shop. The use of these types of systems has been shown in the casting ${ }^{40}$ as well as in the welding ${ }^{4}$ literature.

\subsubsection{User Interface for the Welding Simulation}

An important aspect of the design tool is the user interface which, in general, includes both user controls as inputs and visualization as outputs. Various graphic tools have been created for the user to fully understand the simulation results. For example, 2-D thermal history plots, 3-D temperature maps, and 3-D velocity vector maps, etc., have been developed. All these modules are color coded for easy comprehension. Various transformations like zooming, rotating, and translating can be applied to any data field. Thus, if the viewer is viewing the temperature profile, the person can zoom in on a particular area of interest or rotate the weld to any desired angle to view an otherwise hidden surface. Internal features can be viewed to examine the conditions inside the weld pool. This can be done by cutting through the weld by any desired plane or by isolating hot spots by drawing portions of the weld transparent. An important feature of all these visualization techniques is that the whole process is interactive. This simulates how a welding engineer would actually examine the weld once it is made. The overall framework is shown in Fig. 37. Figure 38 a shows a closeup of the internal temperature map of the weld pool by cutting/masking the solid. By proper rotation, the information about the weld pool from both depth and breadth can be viewed in a single plot. The temperature data can be used to predict the evolving microstructure and macrostructure and to predict residual stresses. Figure $38 b$ shows a typical weld fusion microstructure. These predictions were made using the $C A$ approach described earlier. 

T. Zacharia, A. H. Eraslan, and D. K. Aidun, Weld. J, 66, 18s (1988).

2.

T. Zacharia, A. H. Eraslan, D. K. Aidun, and S. A. David, Metall. Trans. 20B, 645 (1989).

3.

K. E. Gates and W. P. Peterson, Technical Report, Swiss Federal Institute of Technology, 1993.

4. Message Passing Interface Forum. MPI: Technical Report, University of Tennessee, 1994. 5.V Kumar, A. Grama, and G. Karypis, Introduction to Parallel Computing: Design and Analysis of Algorithms, Benjamin/Cummings Pub. Co., 1994

6. D. J. Srolovitz, M. P. Anderson, G. S. Grest and P. S. Sahni, Scr. Metall. 17, 241 (1983).

7. P. S. Sahni, D. J. Srolovitz, G. S. Grest, M. P. Anderson, and S. A. Safran, Phys. Rev. B 28, 2705 (1983).

8. M. P. Anderson, D. J. Srolovitz, G. S. Grest, and P. S. Sahni, Acta Metall. 32, 783 (1984).

9. D. J. Srolovitz, M. P. Anderson, P. S. Sahni, and G. S. Grest, Acta Metall. 32, 793 (1984).

10. D. J. Srolovitz, M. P. Anderson, G. S. Grest, and P. S. Sahni, Acta Metall. 32, 1429 (1984).

11. G. S. Grest, D. J. Srolovitz, and M. P. Anderson, Acta Metall. 33, 509 (1985).

D. J. Srolovitz, G. S. Grest, and M. P. Anderson, Acta Metall. 33, 2233 (1985). Microstructural Evolution, ed. D. J. Srolovitz, TMS, Warrendale, Pa., 1986. M. P. Anderson, G. S. Grest, and D. J. Srolovitz, Scr. Metall. 19, 225 (1985). F. Righetti, T. M. Liebling, and A. Mocellin, Acta Stereol. 8, 459 (1989). M. P. Anderson, G. S. Grest, R. D. Doherty, K. Li, and D.J.Srolovitz, Scr. Metall. 23, 753 (1989).

17. G. S. Grest, M. P. Anderson, and D. J. Srolovitz, Phy. Rev. B 38, 4752 (1988).

18. Conference on Trends in Welding Research, eds. S.A. David and J. Vitek, ASM, Metals Park, Ohio, 1992,

21. N. P. Louat, Acta Metall. 22, 721 (1974).

22. B. Radhakrishnan and T. Zacharia, Metall. Trans. 26A, 167 (1995).

23. B. Radhakrishnan and T. Zacharia, pp. 298-305 in International Conference on Modeling and Control of Joining Processes, ed. T. Zacharia, AWS, Miami, Fl., 1993.

24. P. J. Alberry, B. Chew, and W. K. C. Jones, Met. Technol. 4, 317 (1977).

25. J. J. Pepe and W. F. Savage, Weld. J, 49, 545s (1970)

26. R. M. German: Liquid Phase Sintering, Plenum Press, New York, 1985, pp. 133-43.

27. S. S. Babu, S. A. David, and J.M. Vitek, private communication.

28. J. J. Pepe and W. F. Savage, Weld. J. 46, 411 s (1967).

29. W. A. Owczarski, D. S. Duvall, and C. P. Sullivan, Weld. J. 46, 423s (1967).

30. J. A. Brooks, Weld. J. 53, 517s (1974).

31. W. A. Baeslack, III, S. J. Savage, and F. Froes, J. Mater. Sci. Lett. 935-939 (1986).

32. A. D. Romig, Jr., J. C. Lippold, and M. J. Cieslak, Metall. Trans. 19A, 35 (1988).

33. T. Toffoli and N. Margolus, Cellular Automata Machines, MIT Press, Cambridge, Mass., 1987.

34. W. B. Dress, On doing Science by Computer, part of a technical report to be published by the U.S. Air Force, Wright-Patterson AFB, Ohio, 1993.

35. M. Rappaz and Ch.-A. Gandin, Acta Metall. Mater. 4, 345 (1993). 
36. Ch.-A. Gandin, M. Rappaz, and R. Tintillier, Metall. Trans. 24A, 467 (1993).

37. C. Wang, A. J. Paul, and R. A. Stoehr, pp. 139-46 in Numerical Simulation of Casting Solidification in Automotive Applications, TMS, Warrendale, Pa., 1991.

38. A. J. Paul, C. W. Wang, K. A. Tench, P. B. Smith, and O. J. Huey, pp. 419-30 in EPD Congress 1992, TMS, Warrendale, Pa., 1991.

39. J. D. Ryan and M. L. Tims, pp. 733-40 in Modeling of Casting, Welding and Advanced Solidification Processes VI, TMS, Warrendale, Pa., 1993.

40. G. Upadhya, A. J. Paul, and J. L. Hill, pp. 135-41 in Modeling of Casting, Welding and Advanced Solidification Processes, TMS, Warrendale, Pa., 1993.

41. S. Madden, H. H. Vanderbilt, and J. Jones, J. Ship Production, 8, 77(1992). 
PROCESSOR 1
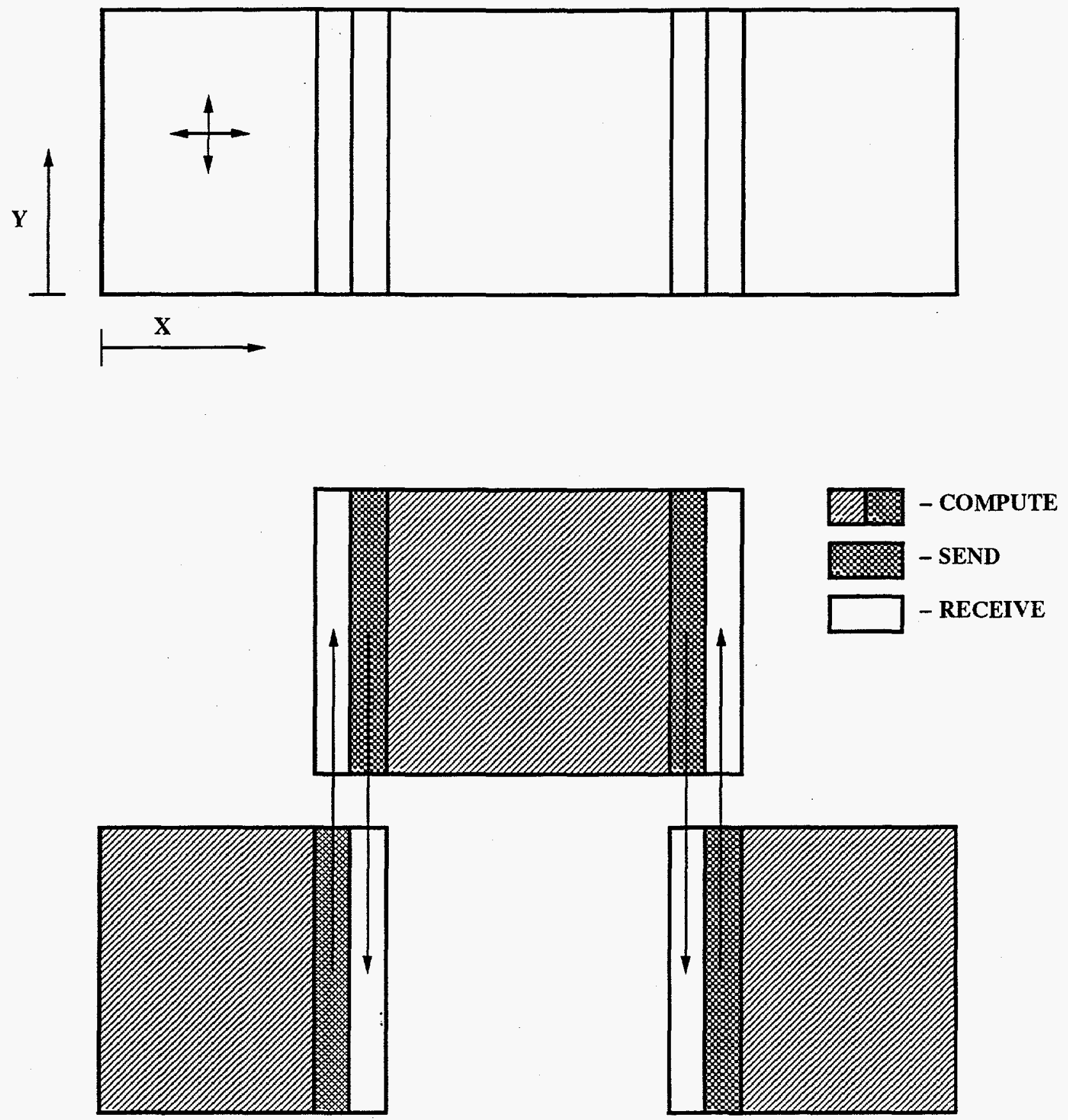

Fig. 1. Domain decomposition and communication. 


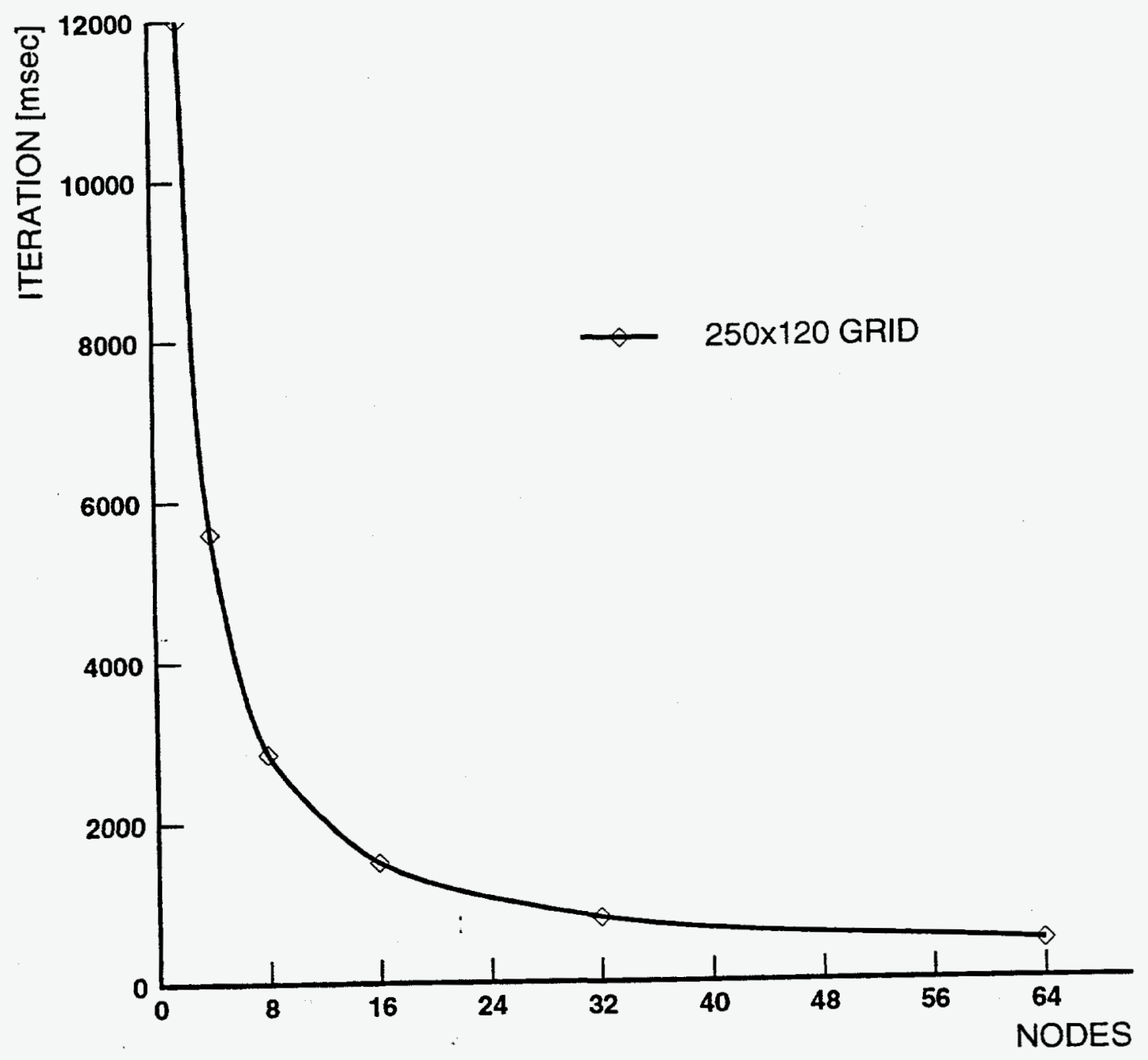

Fig. 2. Timing results. 


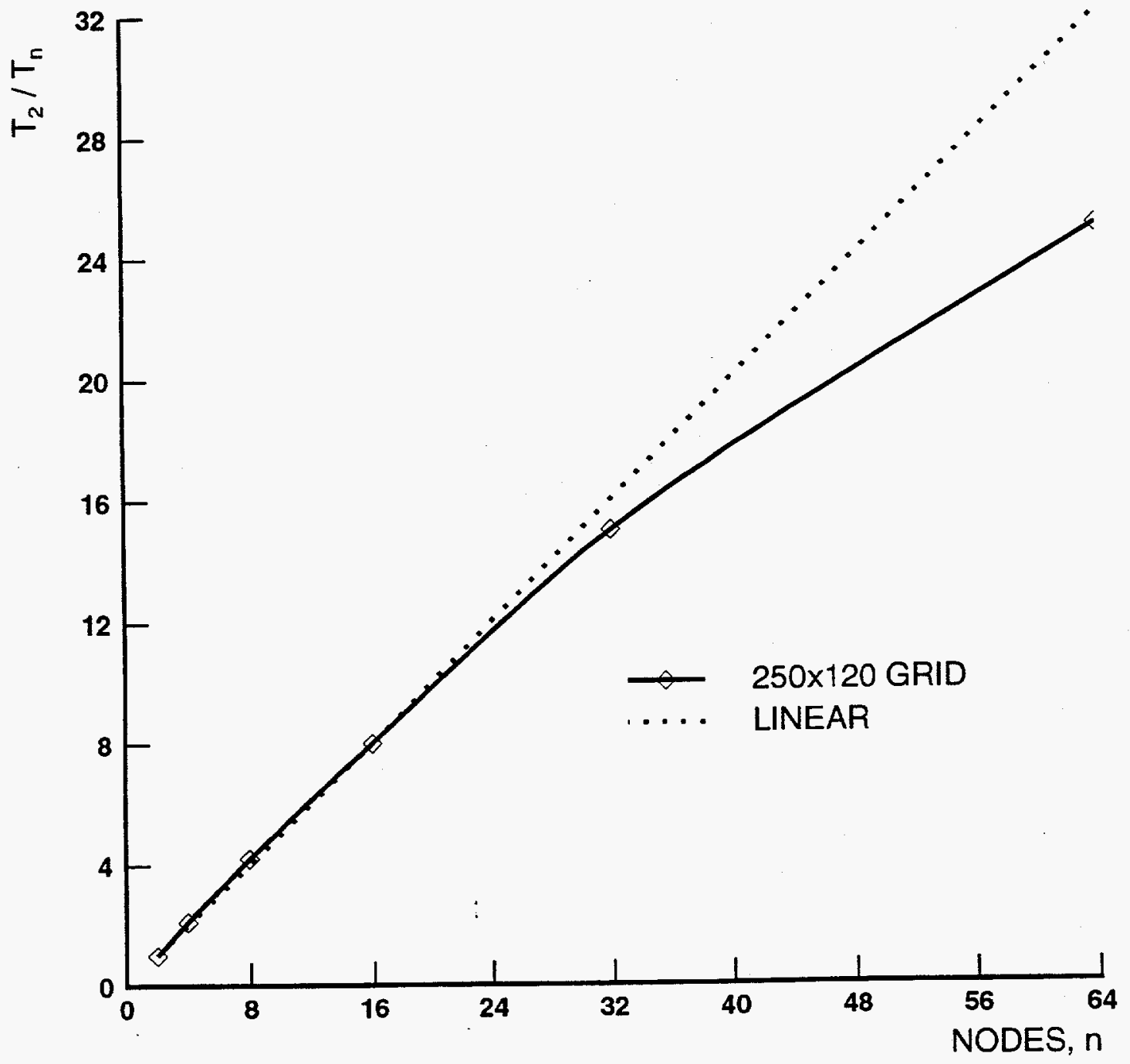

Fig. 3. Timing results. 


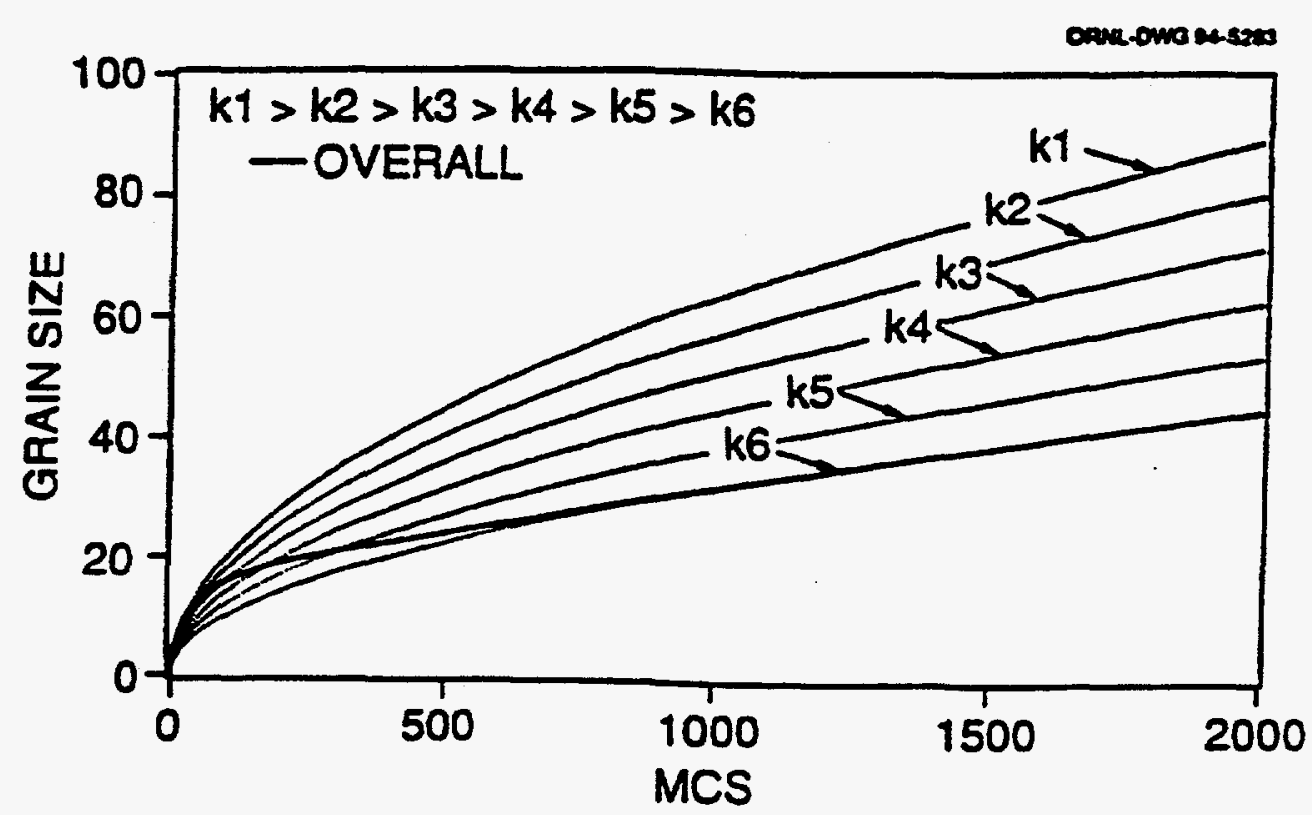

(a)

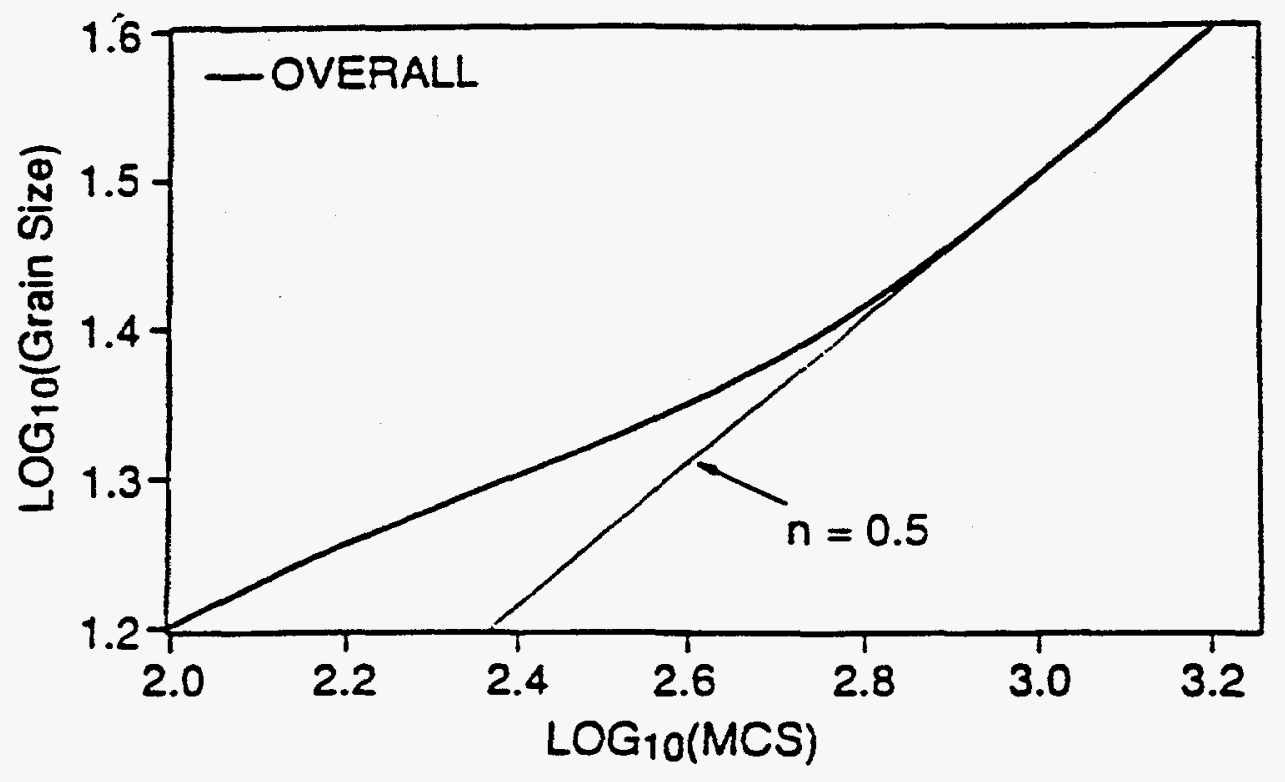

(b)

Fig. 4. Grain growth in the presence of decreasing grain mobility. The solid curve in $(a)$ represents the effective grain growth kinetics, when the mobility decreases from $K_{1}$ to $K_{6}$ during grain growth. The log-log plot of grain size versus MCS of the solid curve in $(a)$ is shown in $(b)$. Note that the grain growth exponent is lower than the theoretical limit of 0.5 , as long as the mobility is decreasing. 


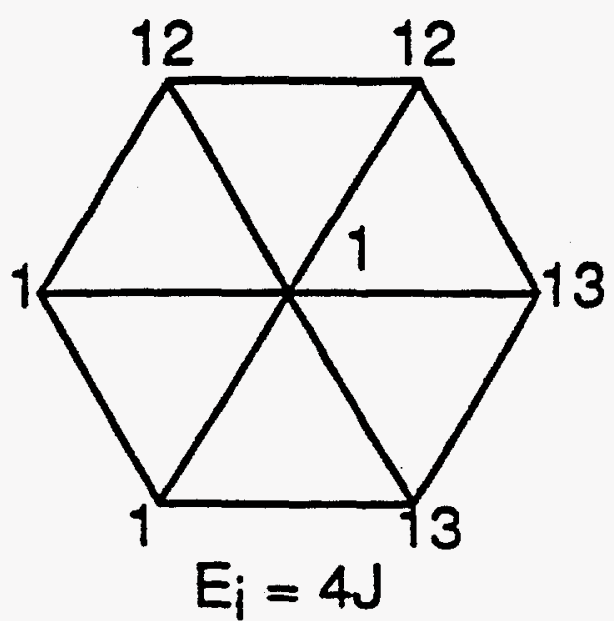

(a)

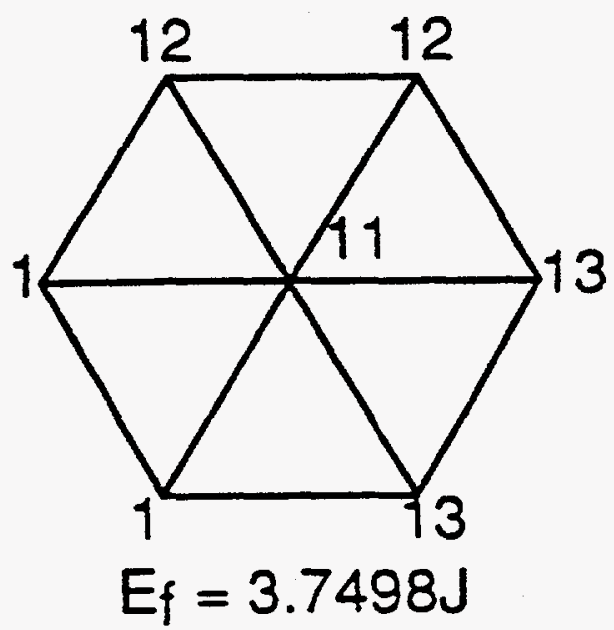

(b)

Fig. 5. The potential for grain nucleation during grain growth in the presence of anisotropy in grain boundary energy, using the old algorithm. Using $Q=64$, and $\theta^{*}=0.3 \pi$, the change in energy $\delta \mathrm{E} \sim=\sim\left(\mathrm{E}_{\mathrm{f}}-\mathrm{E}_{\mathrm{j}}\right)$, when the orientation of the central atom is changed from 1 in $(a)$ to 11 in $(b)$ is negative. Hence, the orientation change is allowed, even though it leads to grain nucleation, which does not occur during grain growth. 


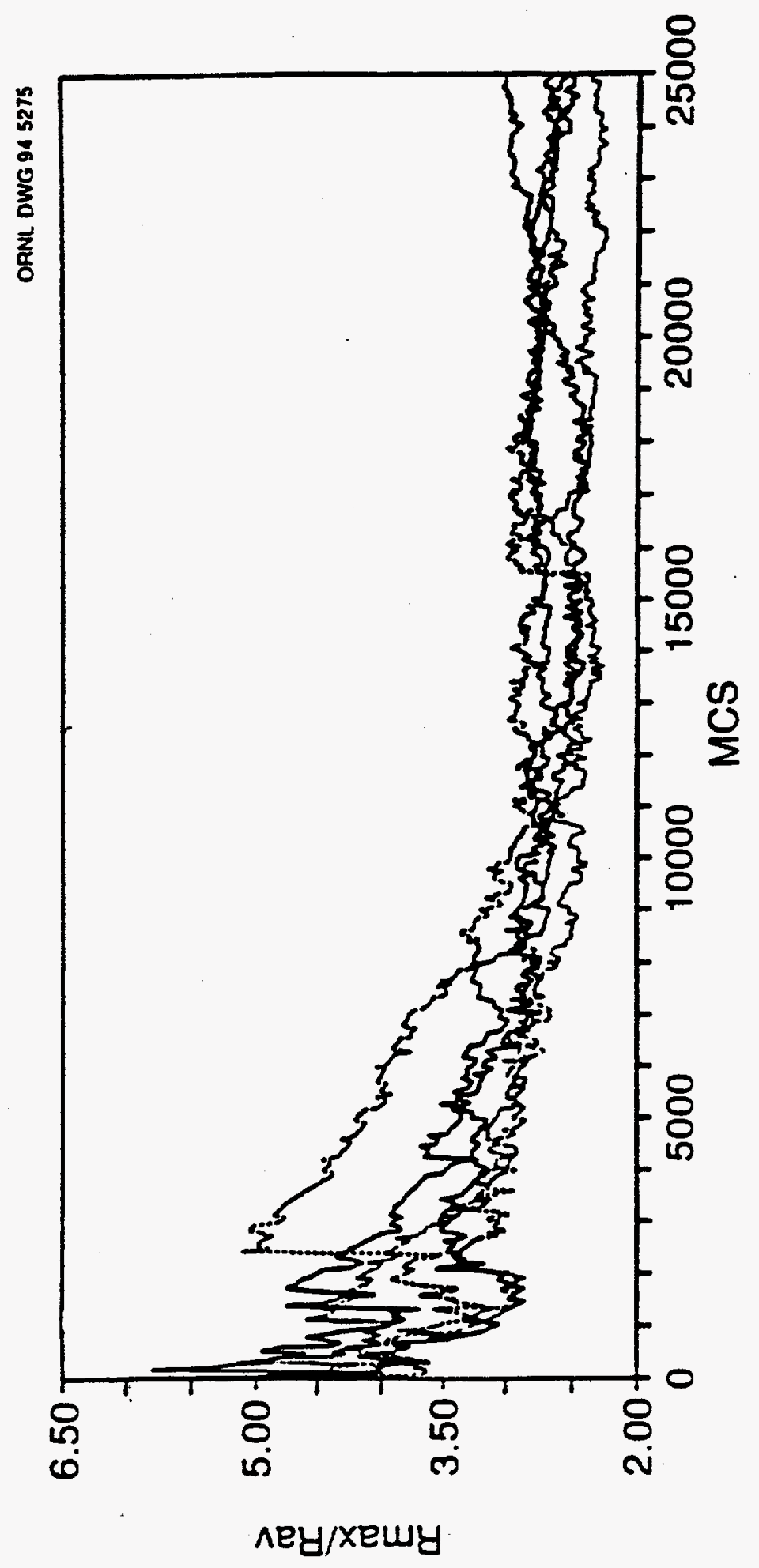

0
0
0
0
0
0

$\stackrel{\mathscr{E}}{\Xi} \stackrel{0}{\mathrm{E}}$

ษ్ํㅗ

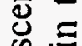

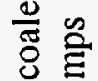

틀

ชั응

ह ग

를

잉

芯

ㄴ.

壱

을

3 .

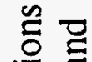

氬

吾

a ?

ஸ่

. 0

N

ज

톰

कo

돈

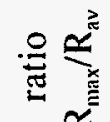

를

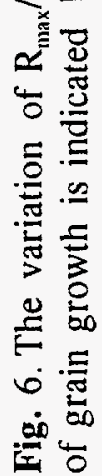




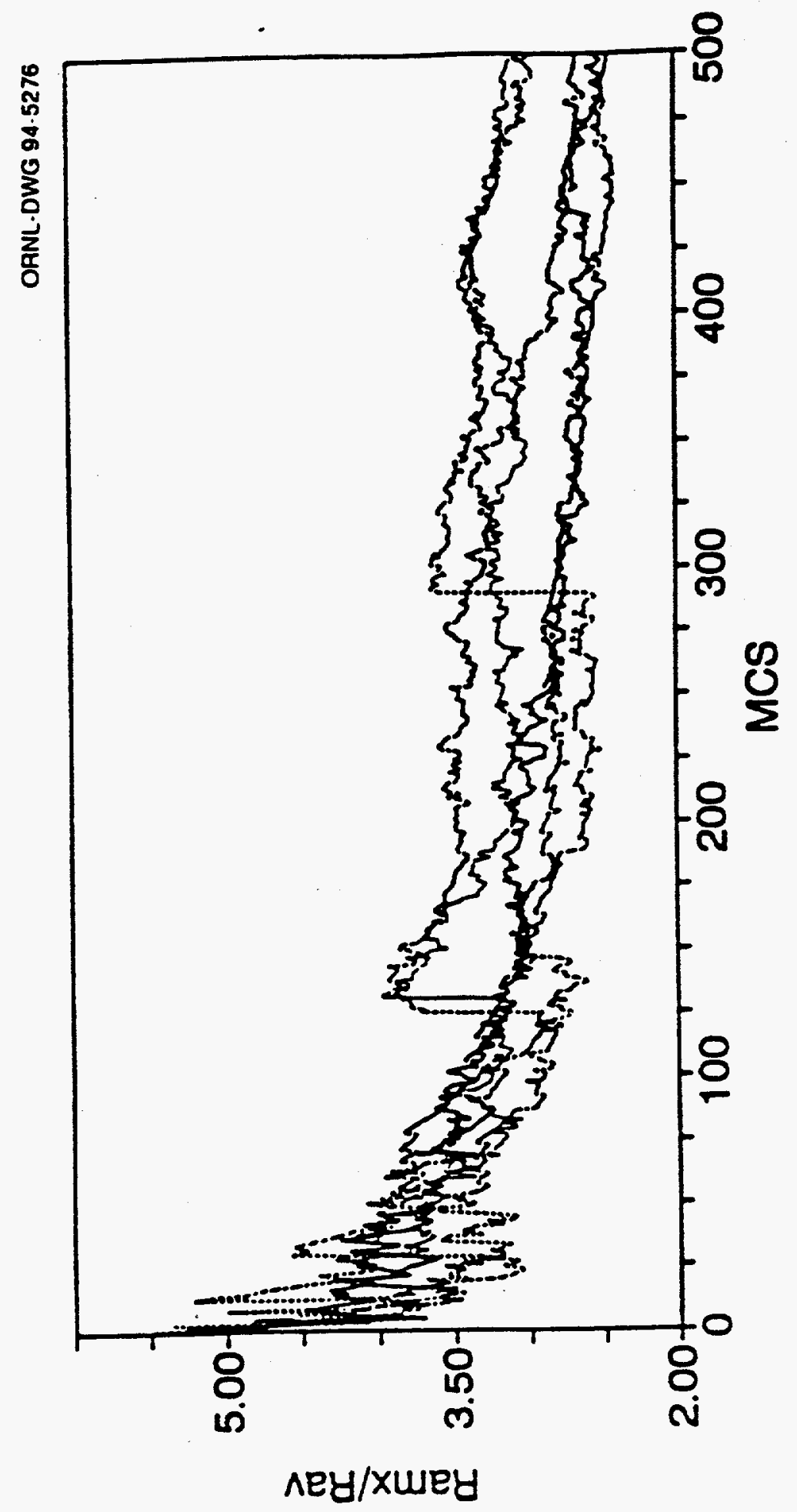

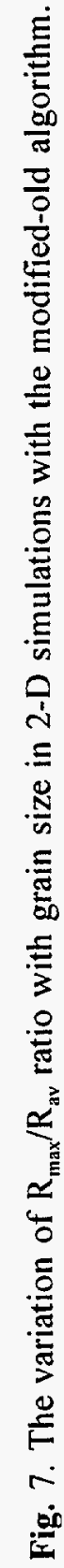









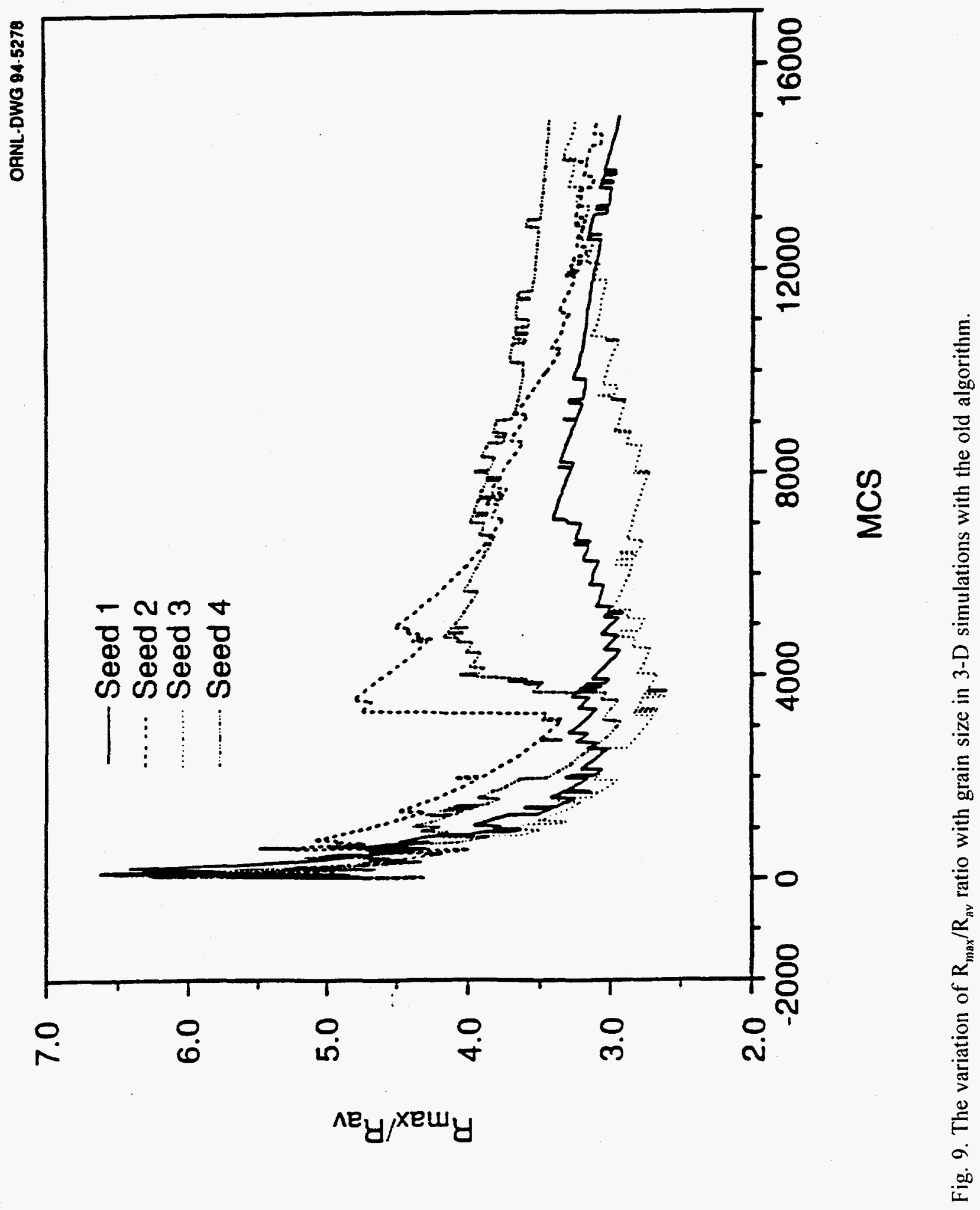




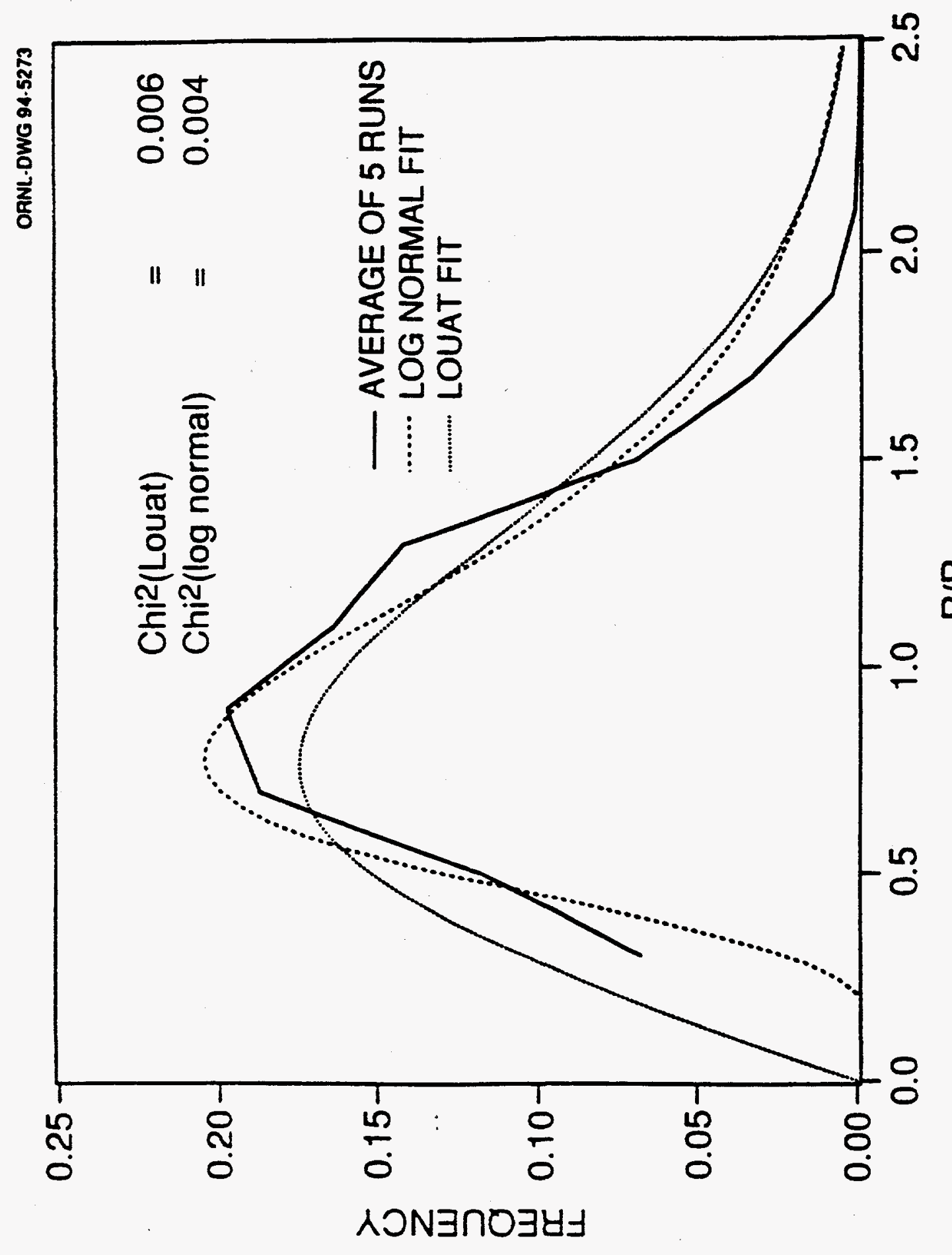




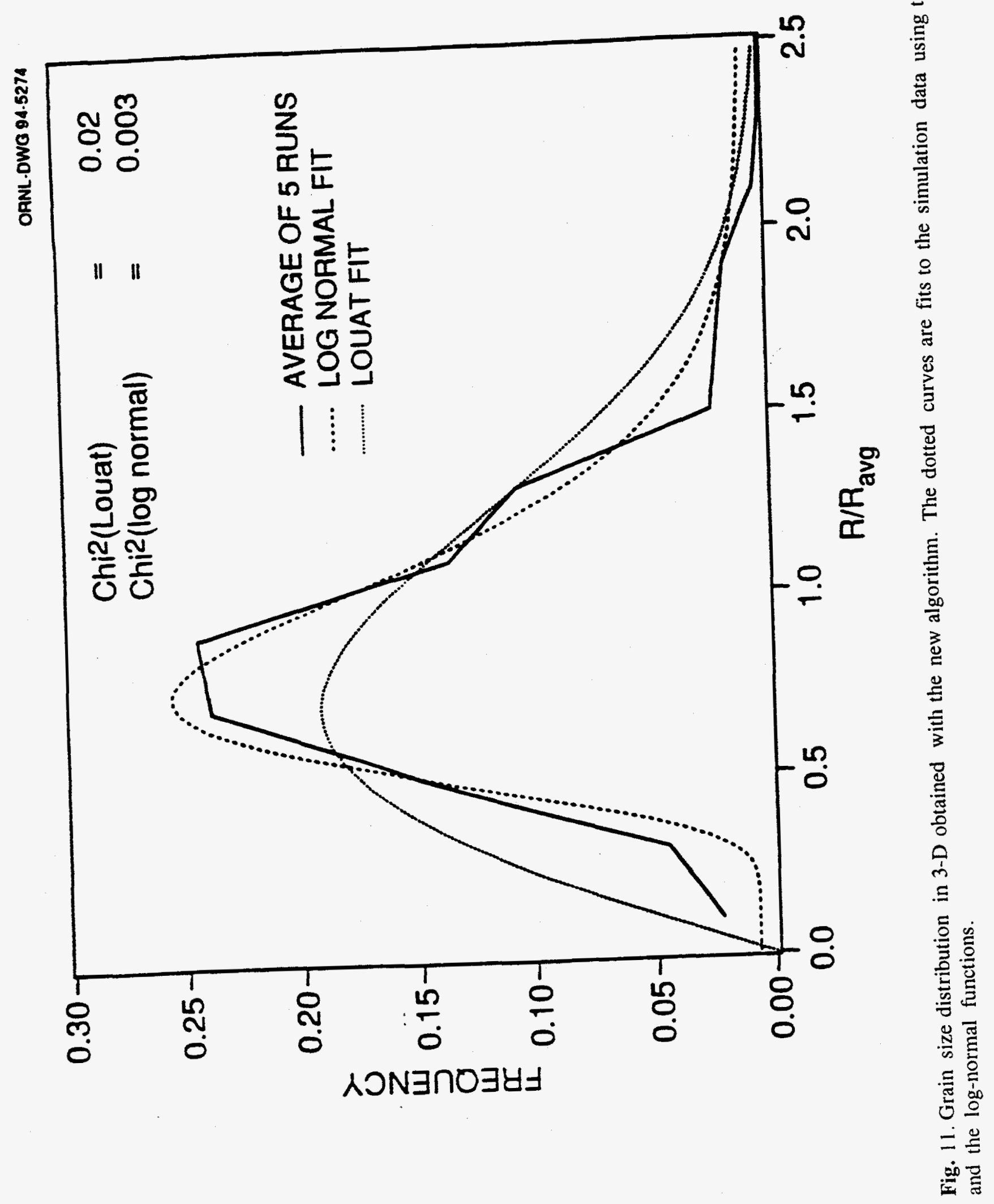




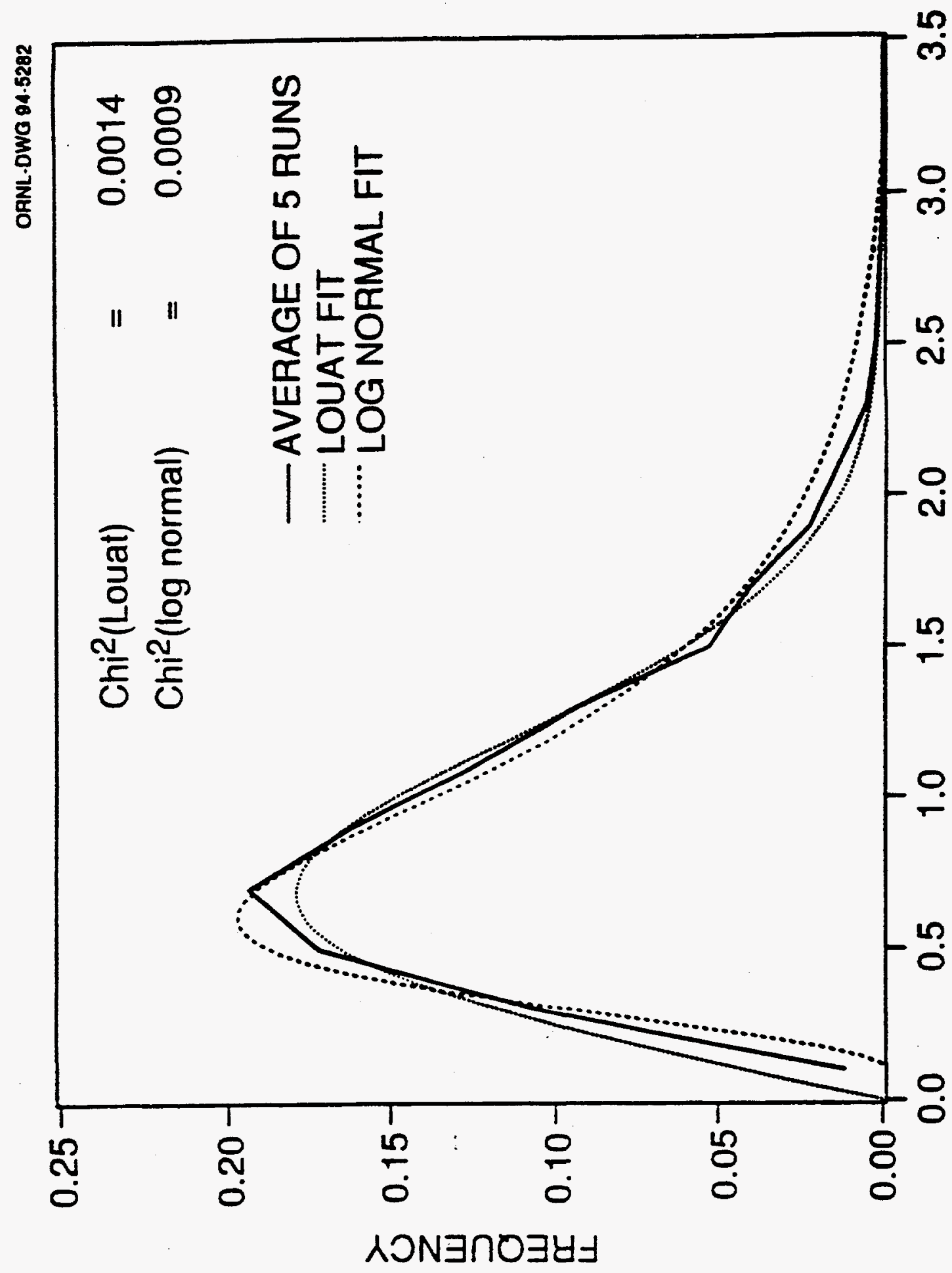

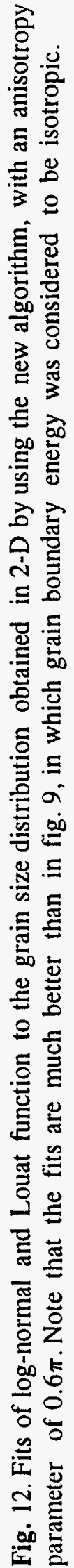




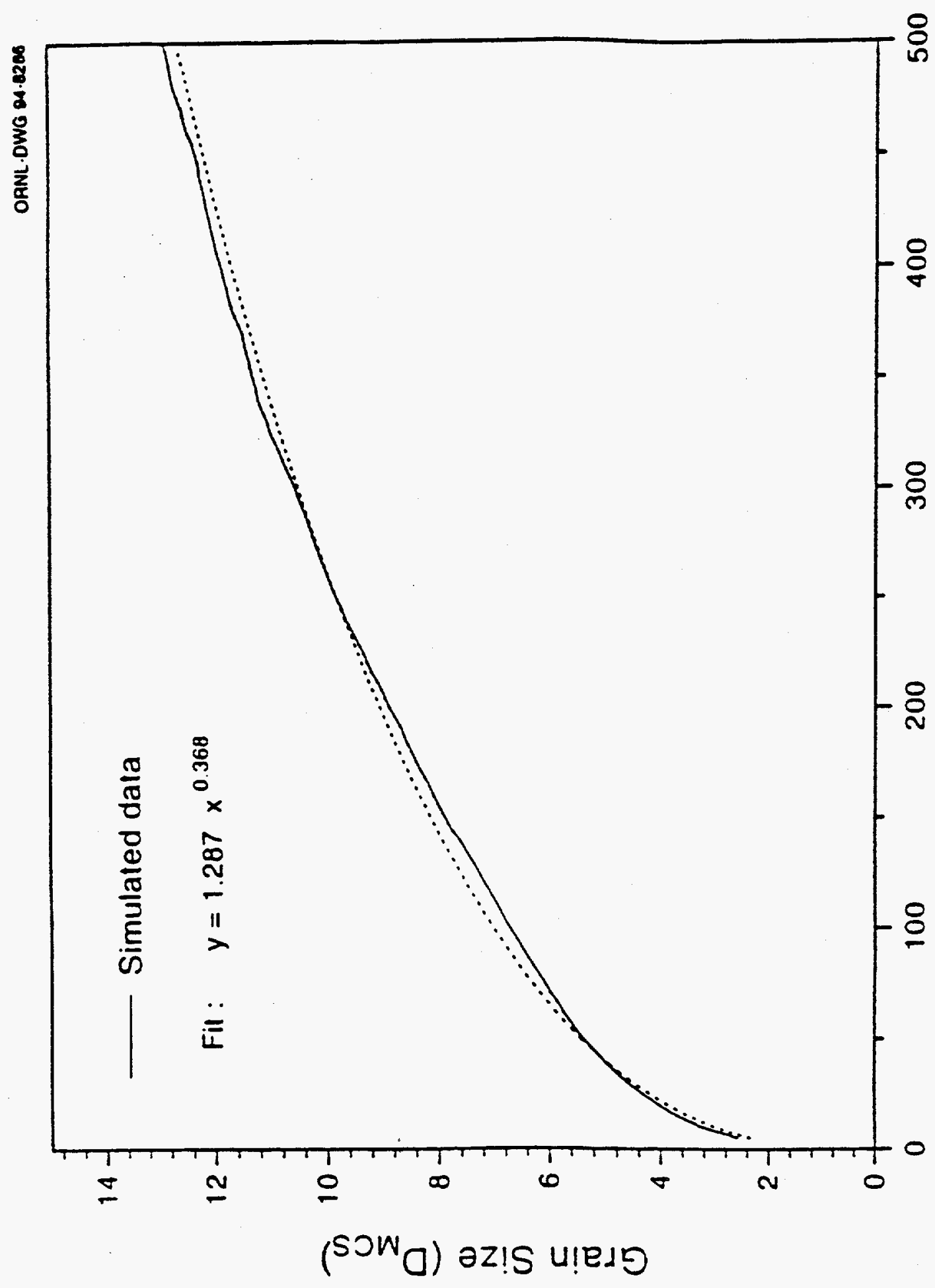




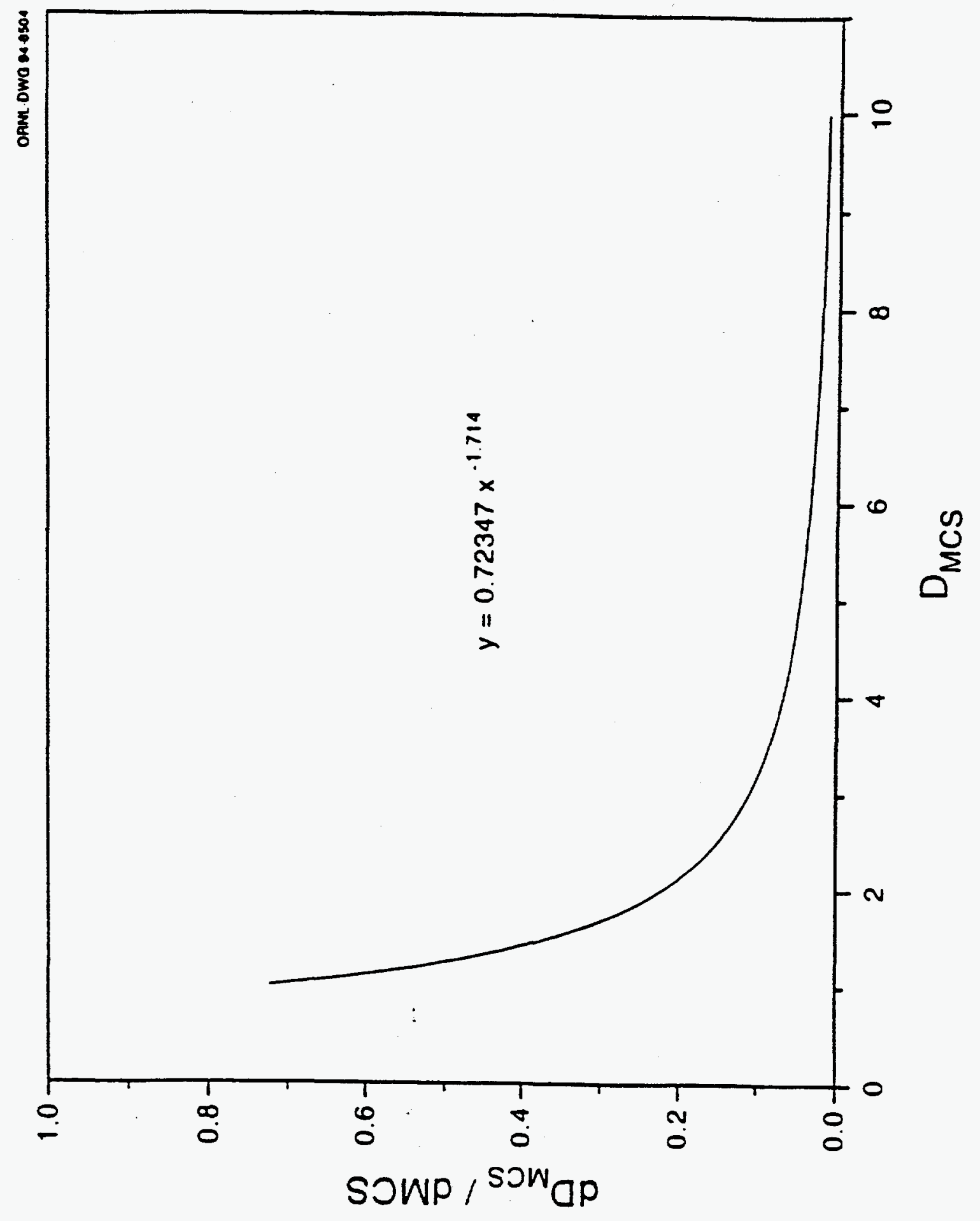

0) 


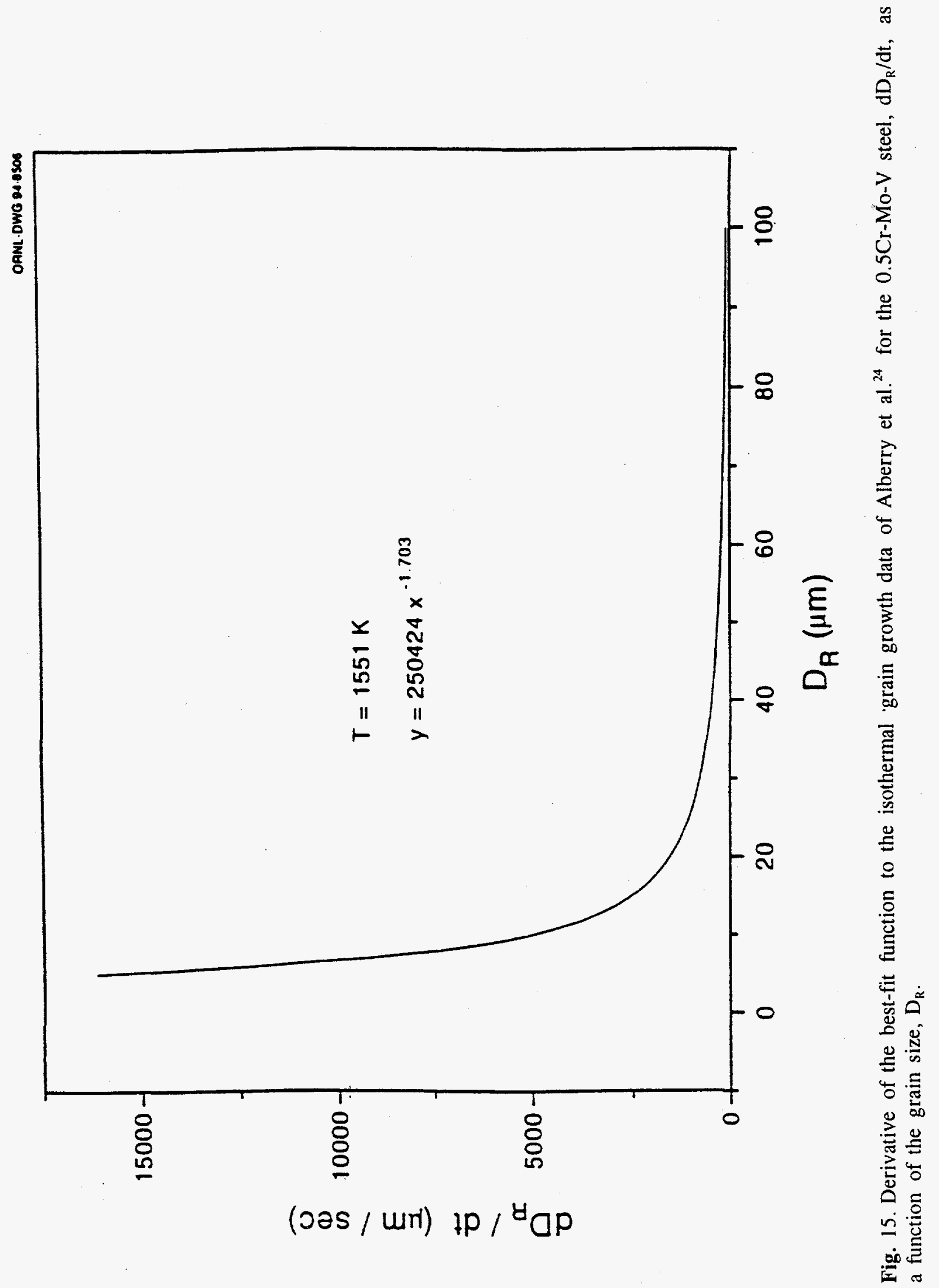




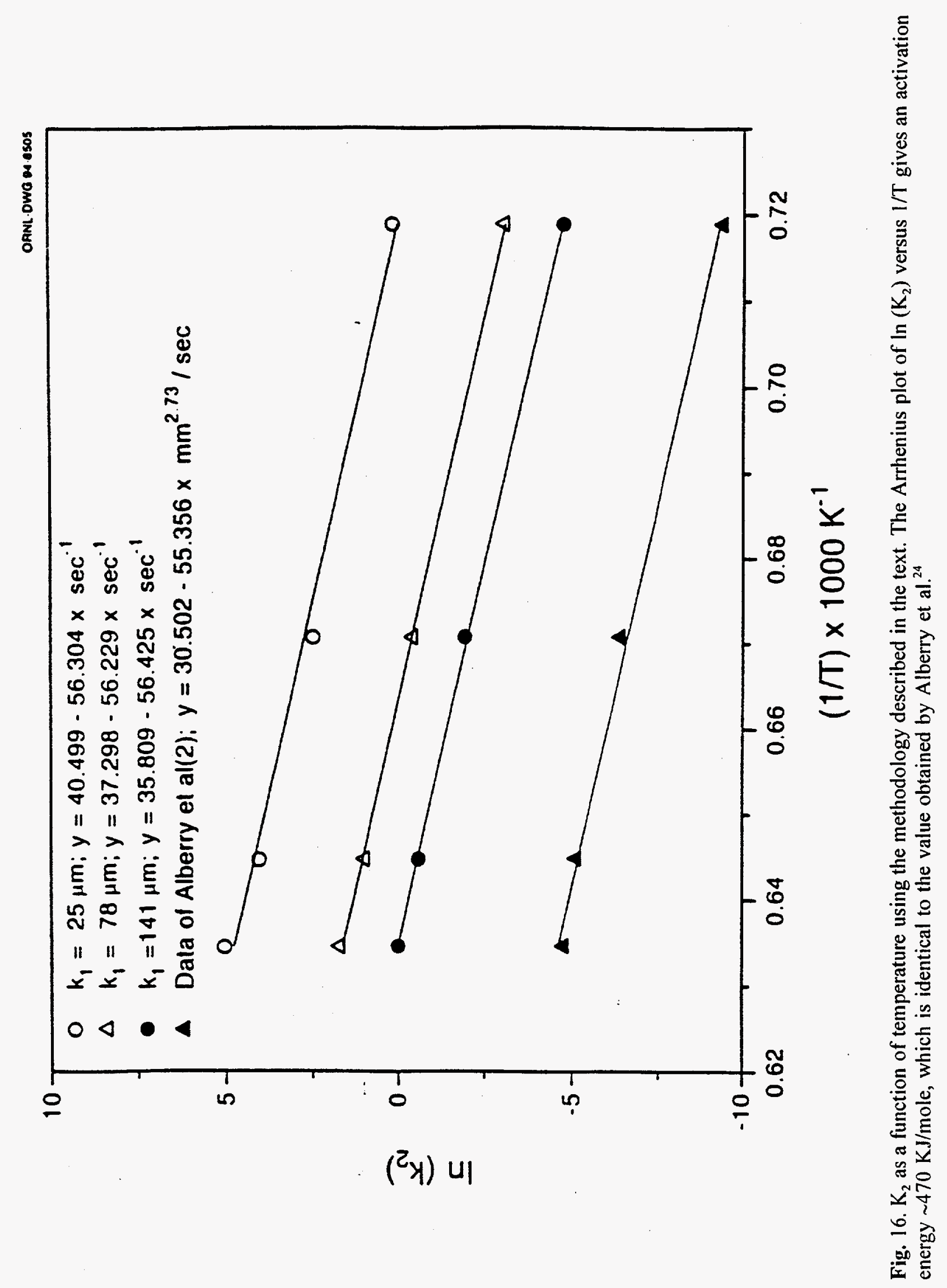




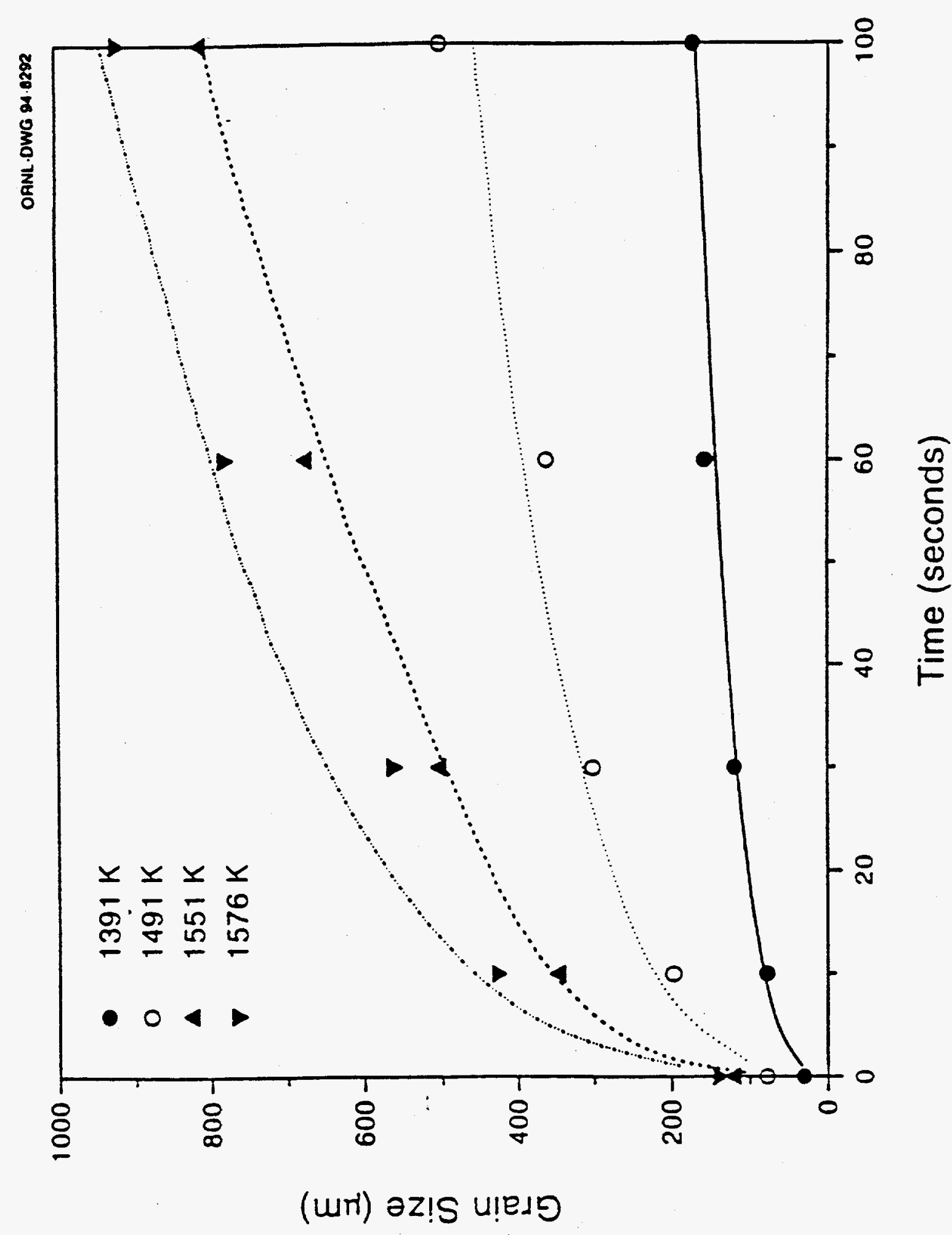

$\stackrel{g}{E}$

㟧

$\stackrel{\Xi}{\Xi}$

氶

코ำ

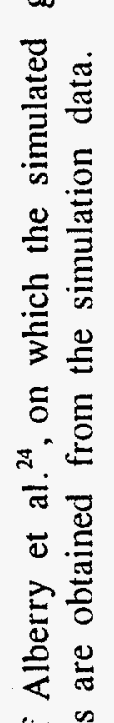

○.

营

릉

कo

$\cong$ 要

क人

氞

름

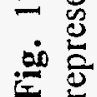




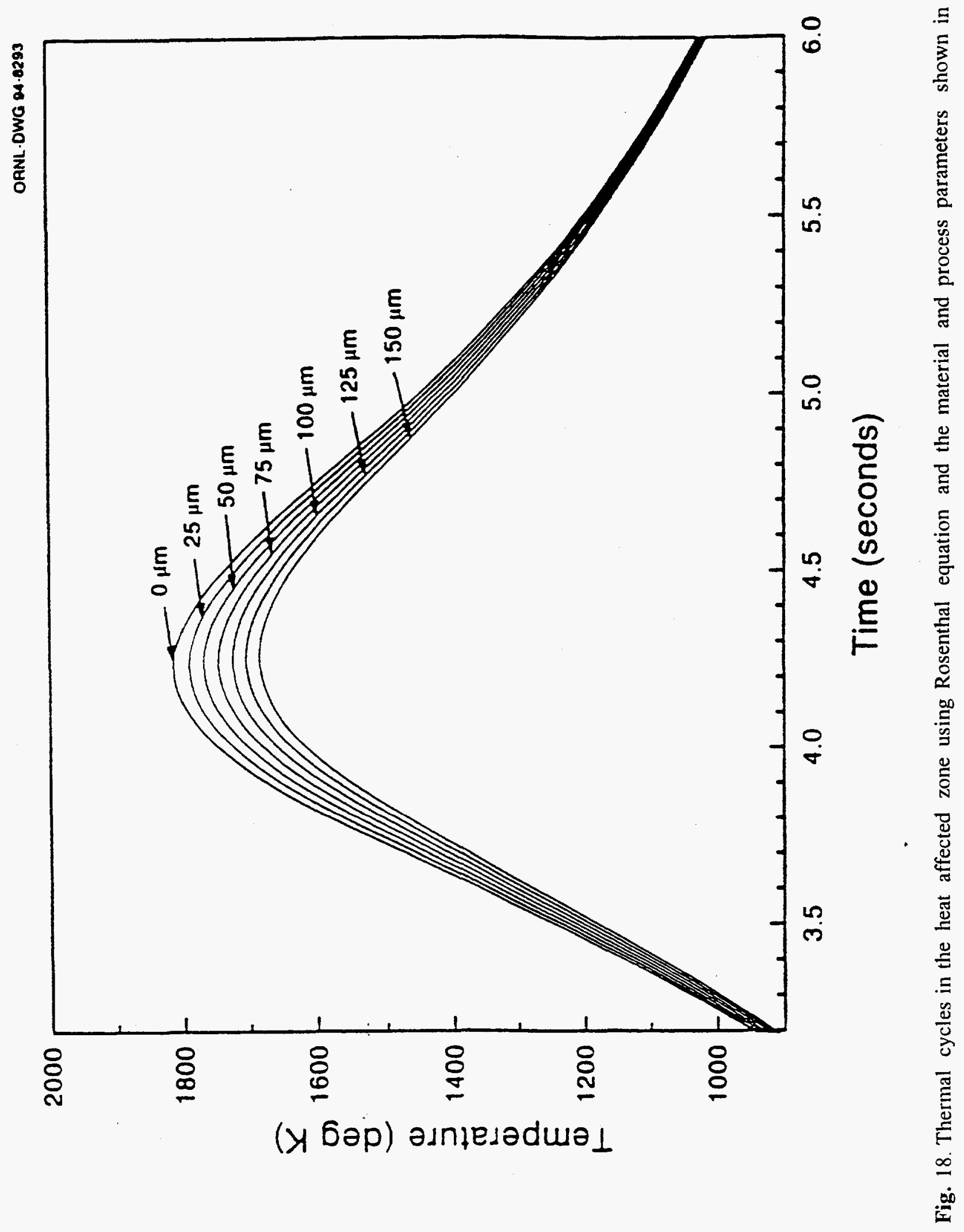




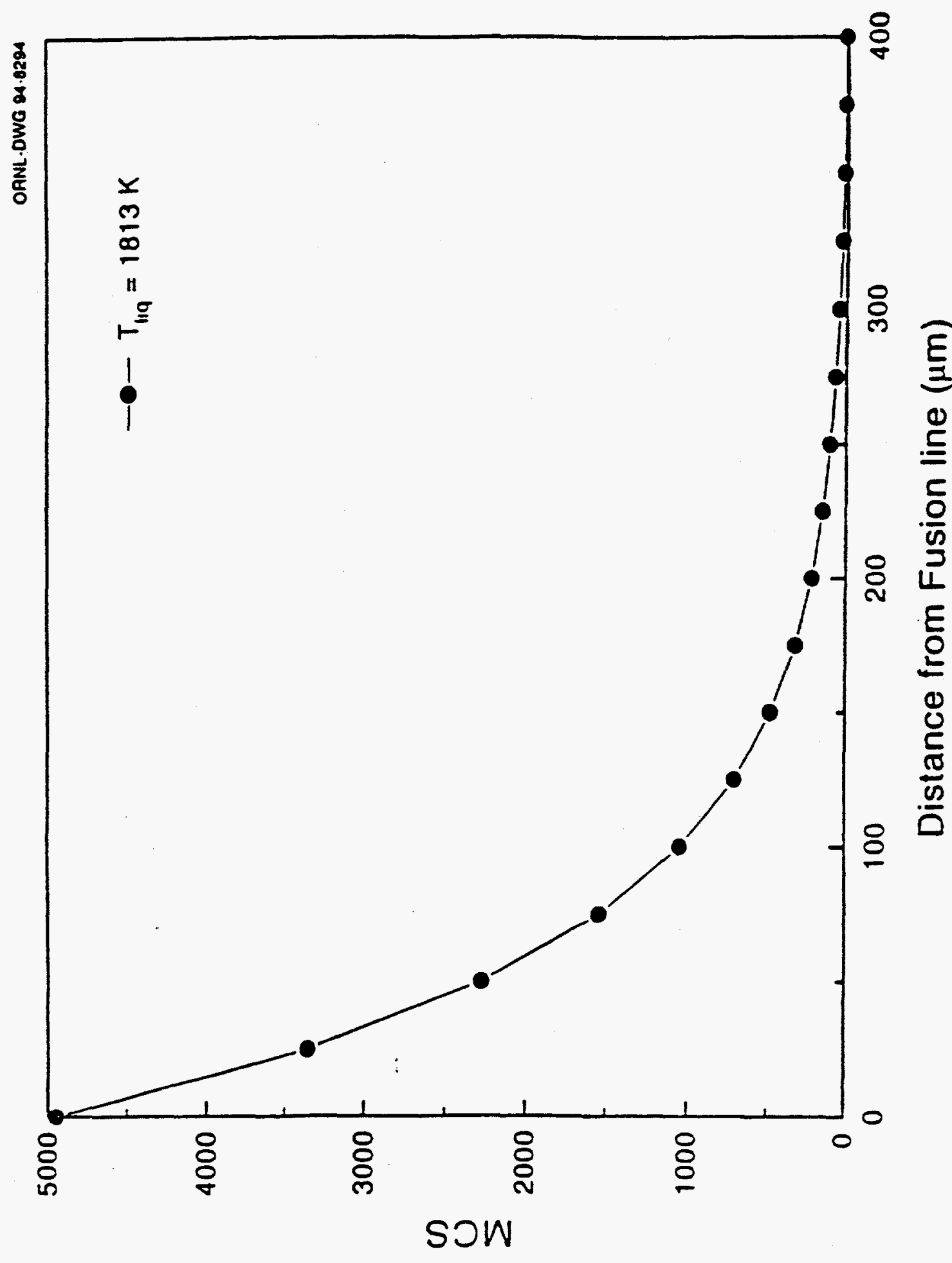

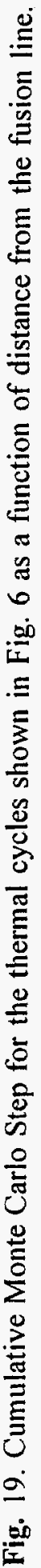




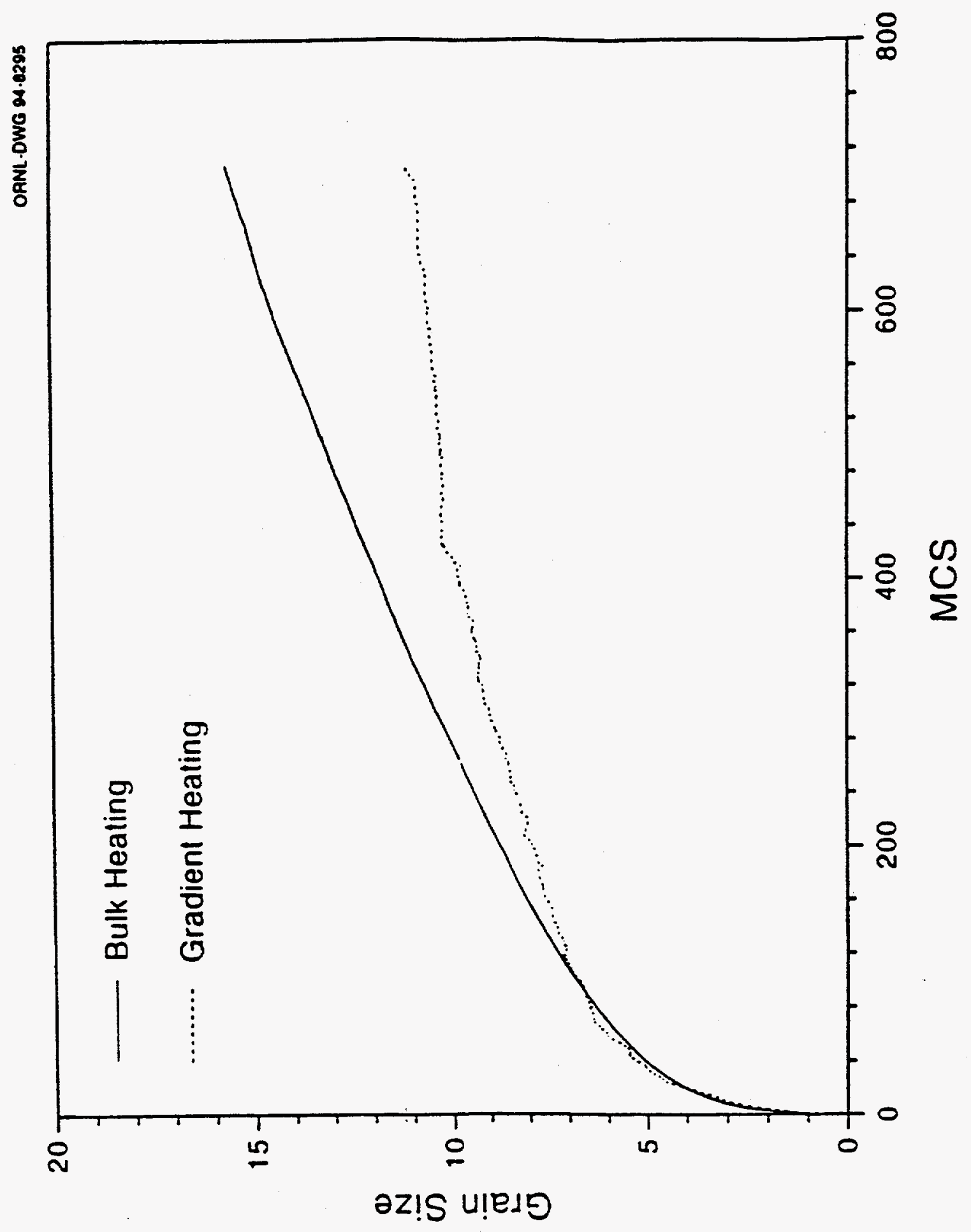

$\stackrel{\varrho}{\Xi}$

E

유로

흔

焉

요

. 을

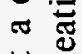

플

这

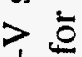

$\sum^{0} \hat{3}$

Uั

눈

งิ

正

0

율

递

¿

可

므도

3

홓

드응

동

ร

ธิ口

. 5

कू

\&

总

工

율

올음 


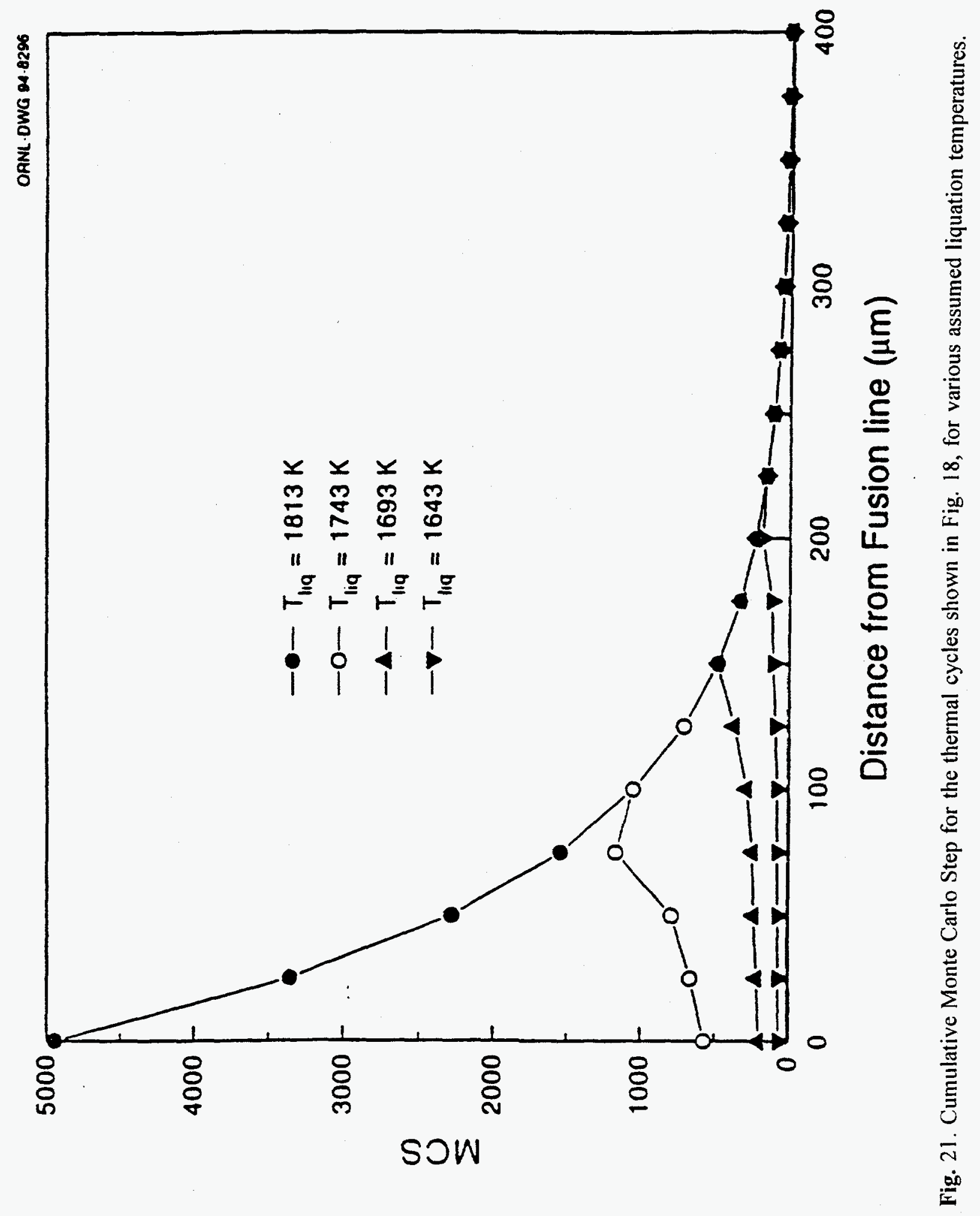



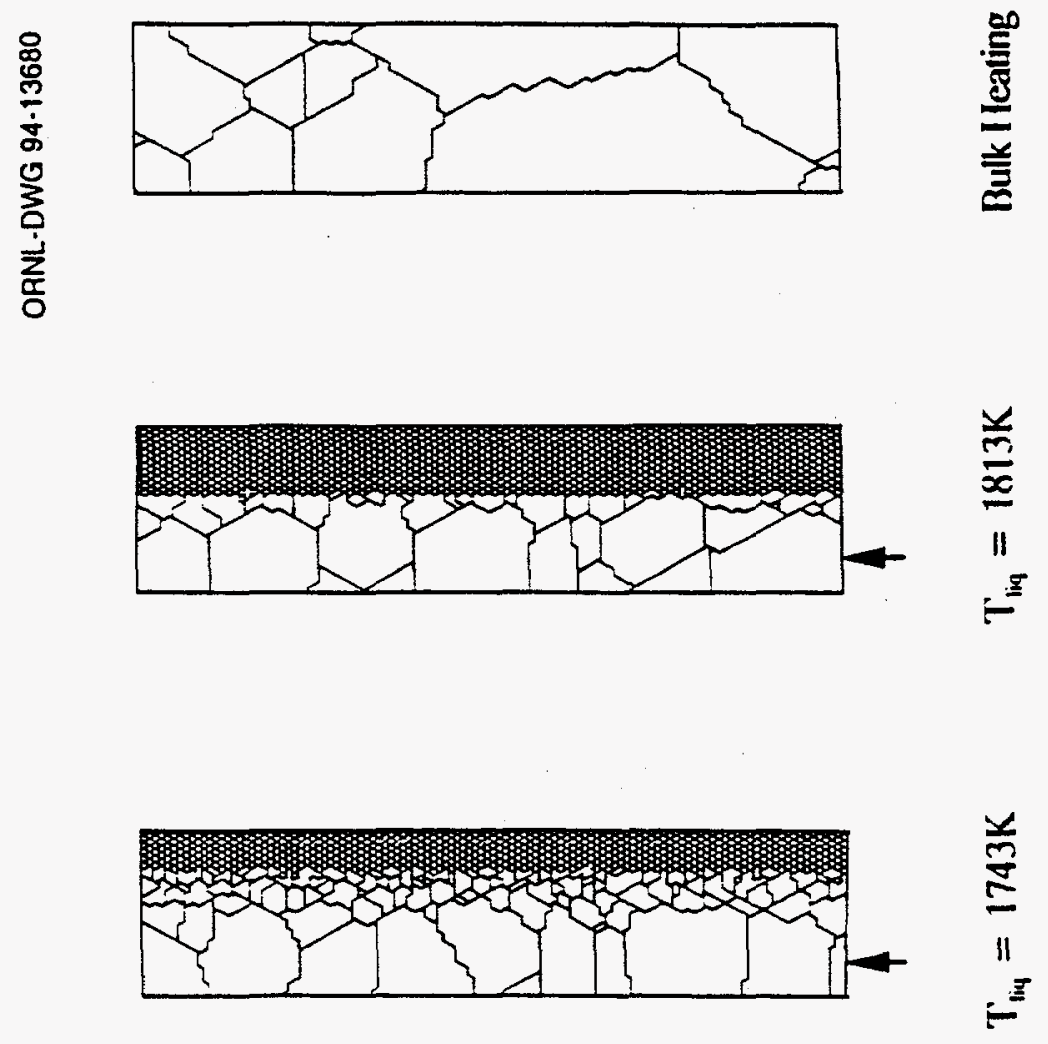

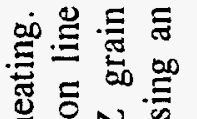
送 兰志里

๖ั 言远配

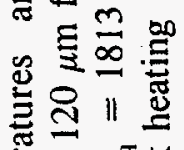
岁㟧 焉这

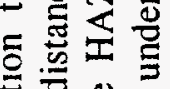
芯宁

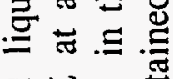
导这。

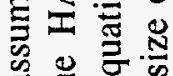
$\because \cong$

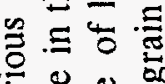

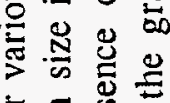

$\overline{5} \equiv$

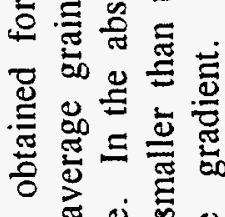
๖ 0 के 氖氖总里 눈

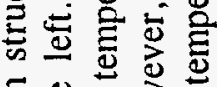

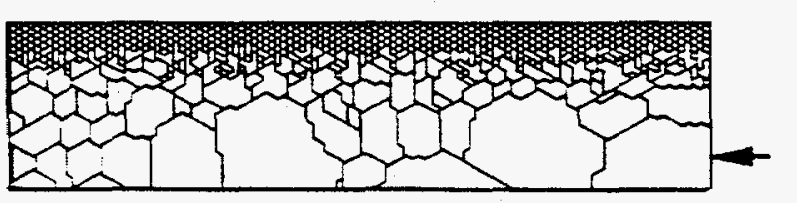

क न งิ

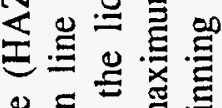
司哭芯 次焉焉 马 叉 退的焉
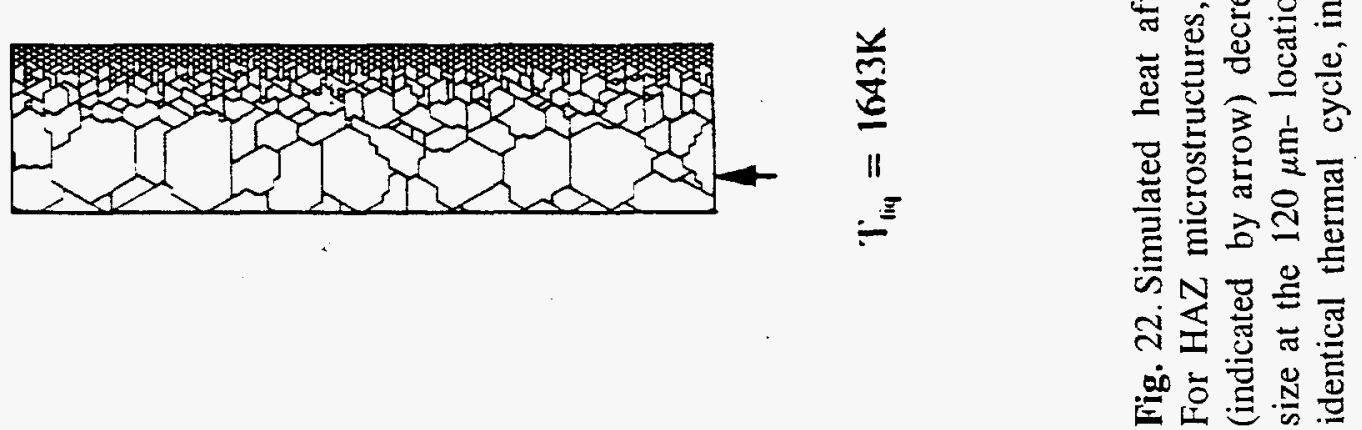


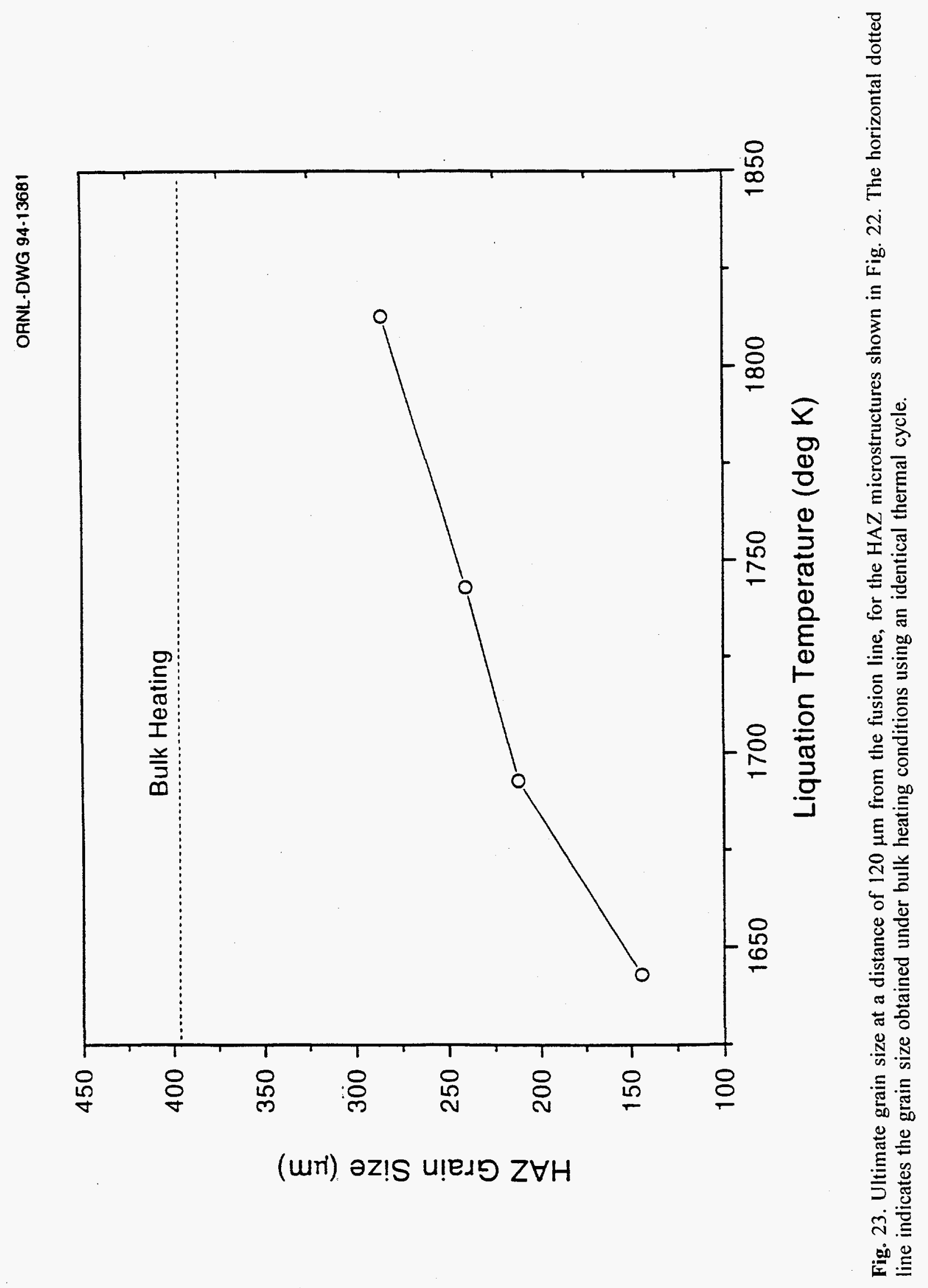









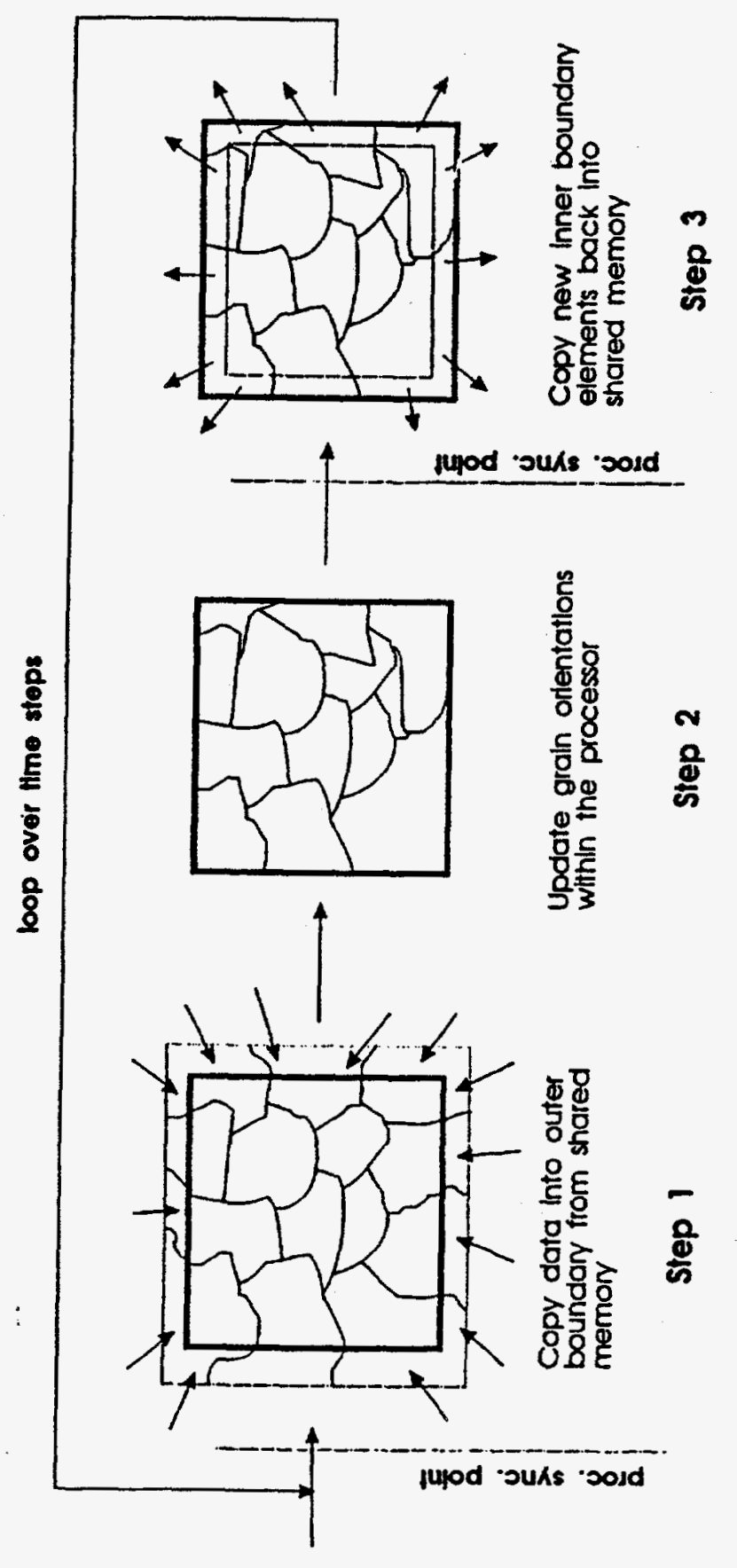

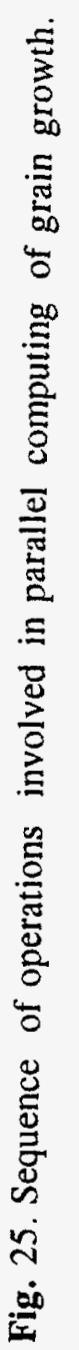




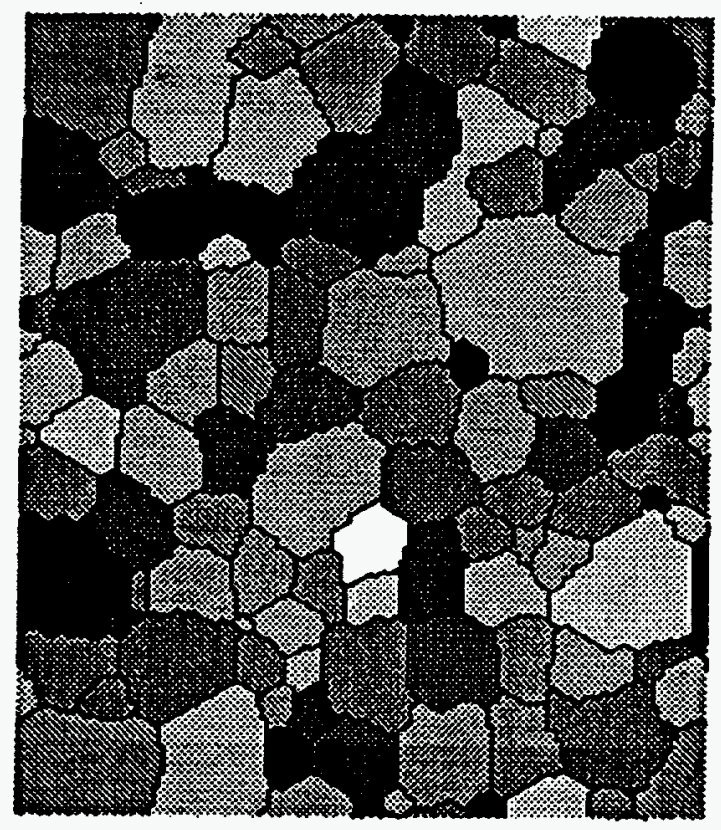

Fig. 26. Results of two-dimensional parallel simulation



Fig. 27. Results of three-dimensional parallel simulation. 


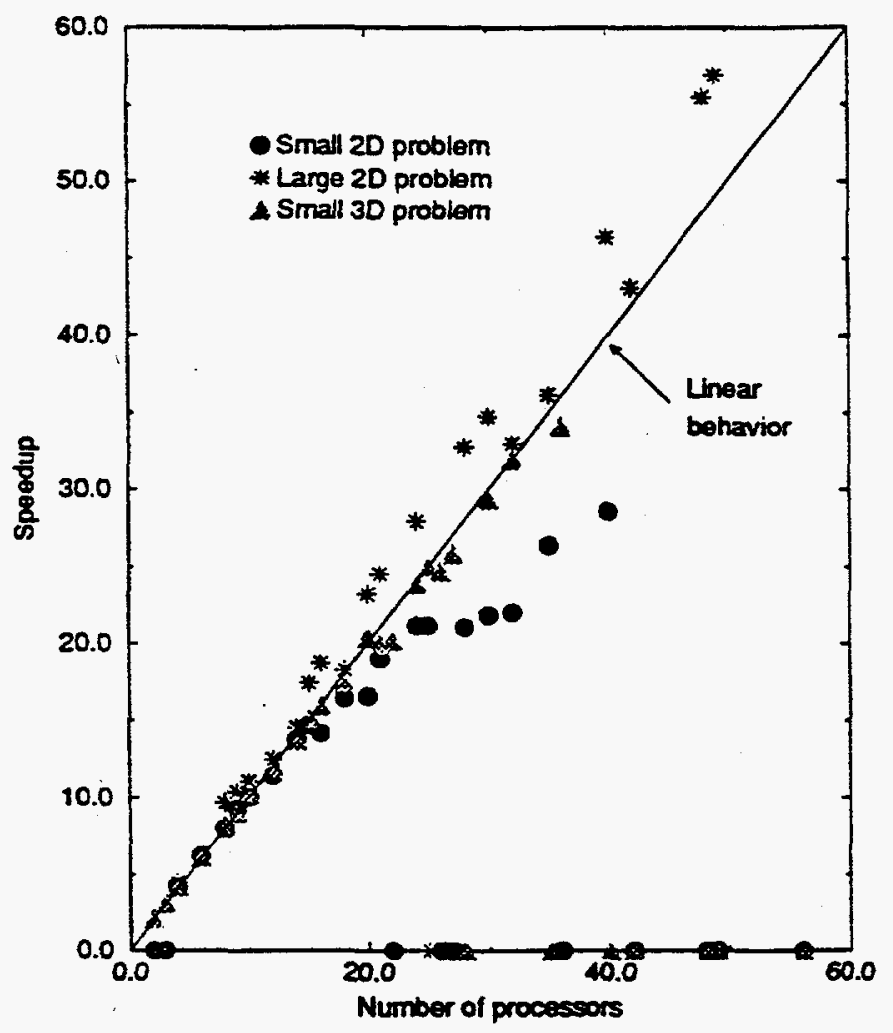

Fig. 28. Speedup of computations in two-dimensional and three-dimensional grain growth using parallel code.

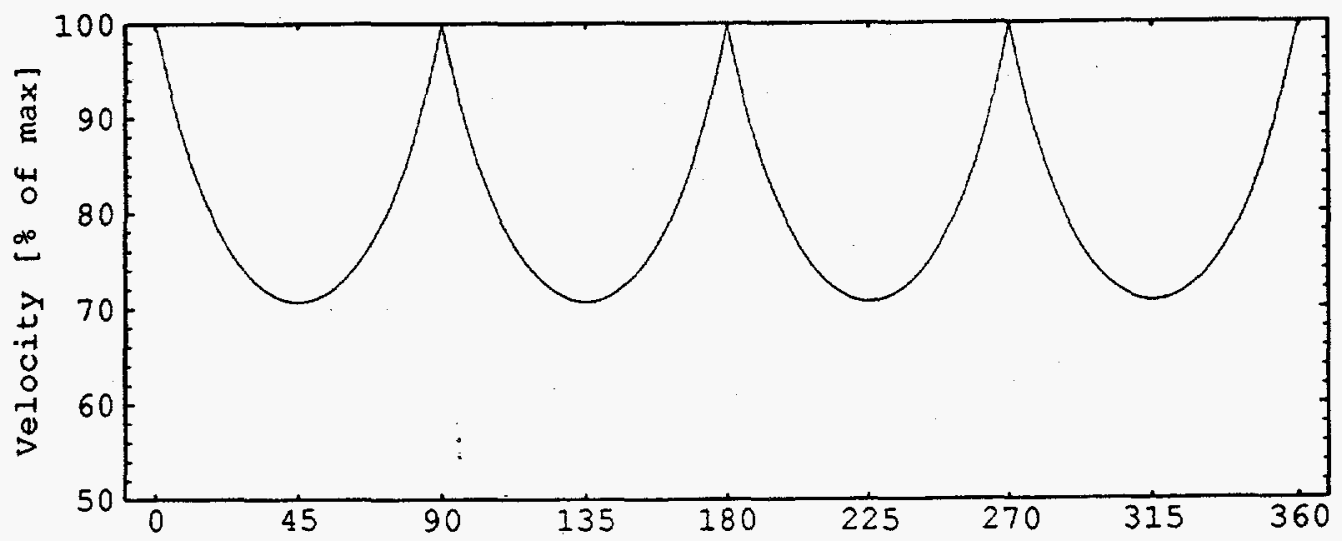

Fig. 29. Velocity distribution around a cubic grain as a function of the angle between the crystallographic axis and an arbitrary point. Note the fourfold symmetry about the $90^{\circ}$ points. The ordinate is in degrees, while the coordinate is in percent of the grain tip velocity. 


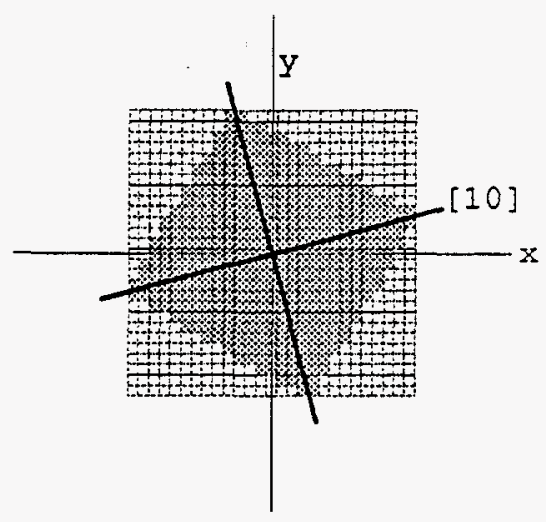

Fig. 30. Growth of a single grain with [100] axis at an angle of $15^{\circ}$ with respect to the $x$ direction. The crystalline axes are shown as heavy lines centered on the grain. The superimposed grid depicts the location of the cellular automaton cells. Assuming a $50 \mu \mathrm{m}$ cell size, this grain has dimensions of $1 \mathrm{~mm}$ on a side.

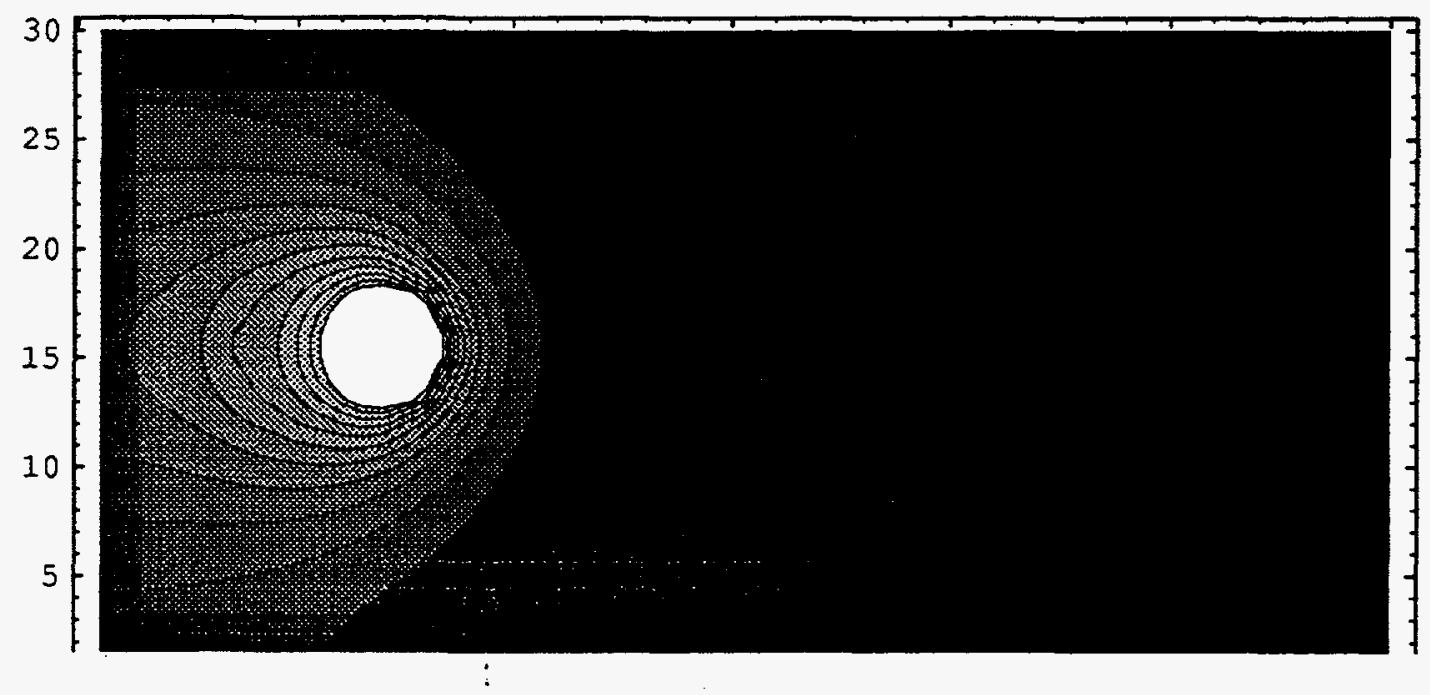

Fig. 31. Contour plot of isotherms $33 \mathrm{~s}$ after starting the arc off the plate to the left. The contours range from $200^{\circ} \mathrm{C}$ to $2200^{\circ} \mathrm{C}$ in steps of $200^{\circ} \mathrm{C}$. The solidus isotherm is the one at $1400^{\circ} \mathrm{C}$ (third in from the outer, fully closed contour). Coordinates are in millimeters, and cellular automata cells are 1 by $1 \mathrm{~mm}$. The boundary of the white central disc indicates the 3 -mm radius of the arc. Units are in millimeters. 


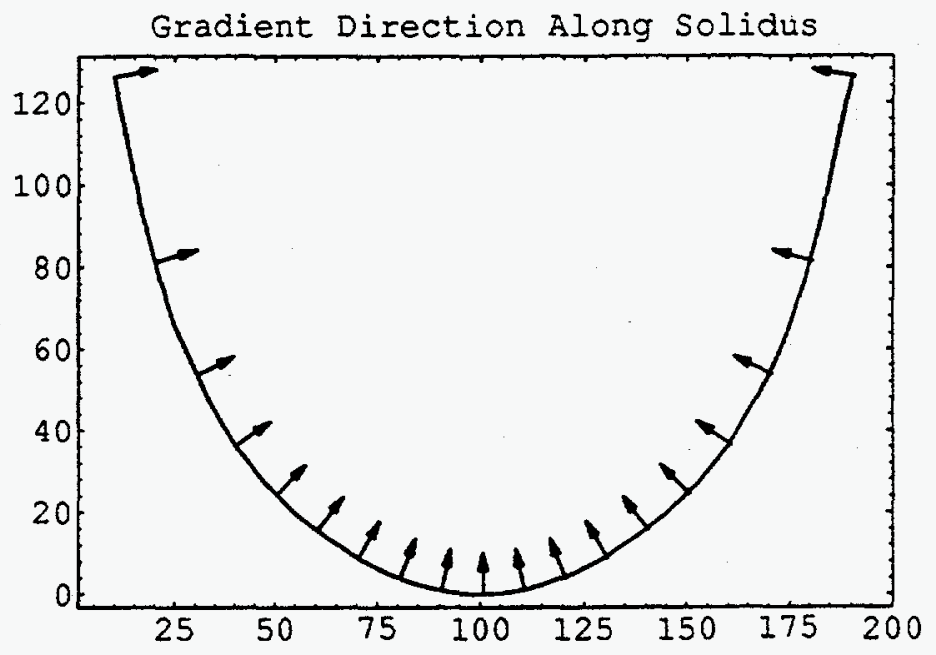

Fig. 32. An isotherm at the solidus interface showing the direction of the temperature gradient at every tenth cell along the width ordinate. The direction of arc travel is upwards in this view; the centered vertical arrow indicates the unit vector in the direction of arc motion. The coordinates refer to cellular automata cells in the array.

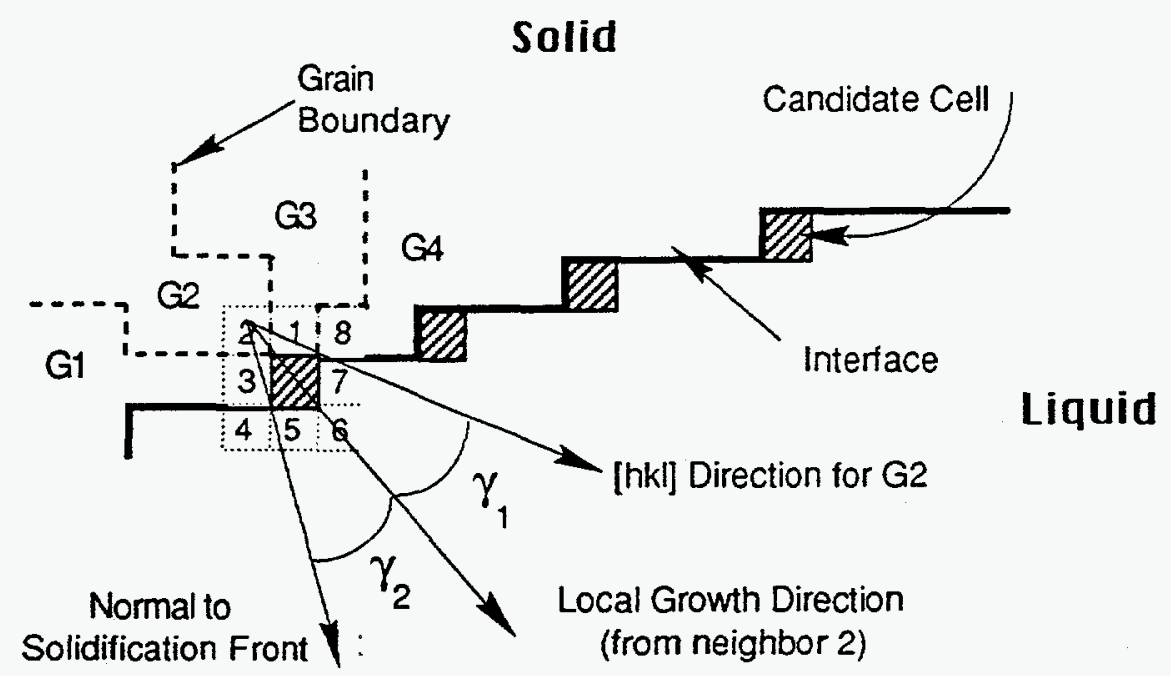

Fig. 33. Illustration of cell attachment. The candidate cells are shown with bar shading, and the heavy line is the solid-liquid interface. The cells are depicted as squares comprising the cellular array, which is not shown for clarity. The candidate cell discussed in the text is the one on the left, shown at the center of a neighborhood of cellular automata cells. This candidate cell borders on four grains indicated as G1 through G4. 


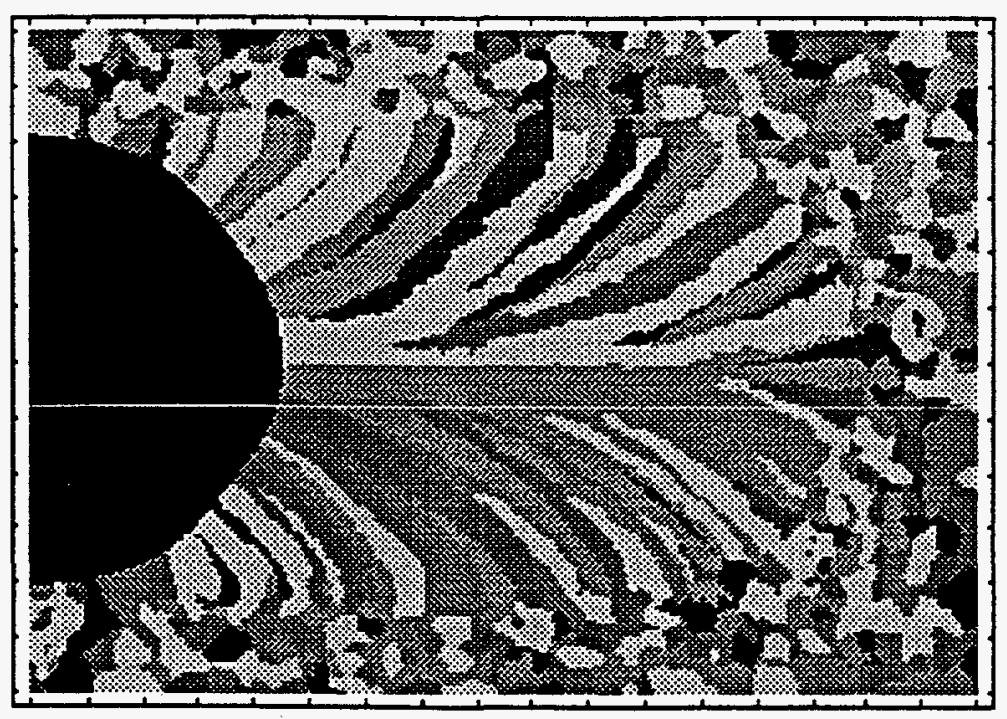

Fig. 34. Partially solidified plate showing grain growth following the arc. Solidified grains follow the thermal gradient and curve toward the arc position, about $3 \mathrm{~mm}$ off the figure to the right. The coordinate tick marks indicate plate dimensions in millimeters. 


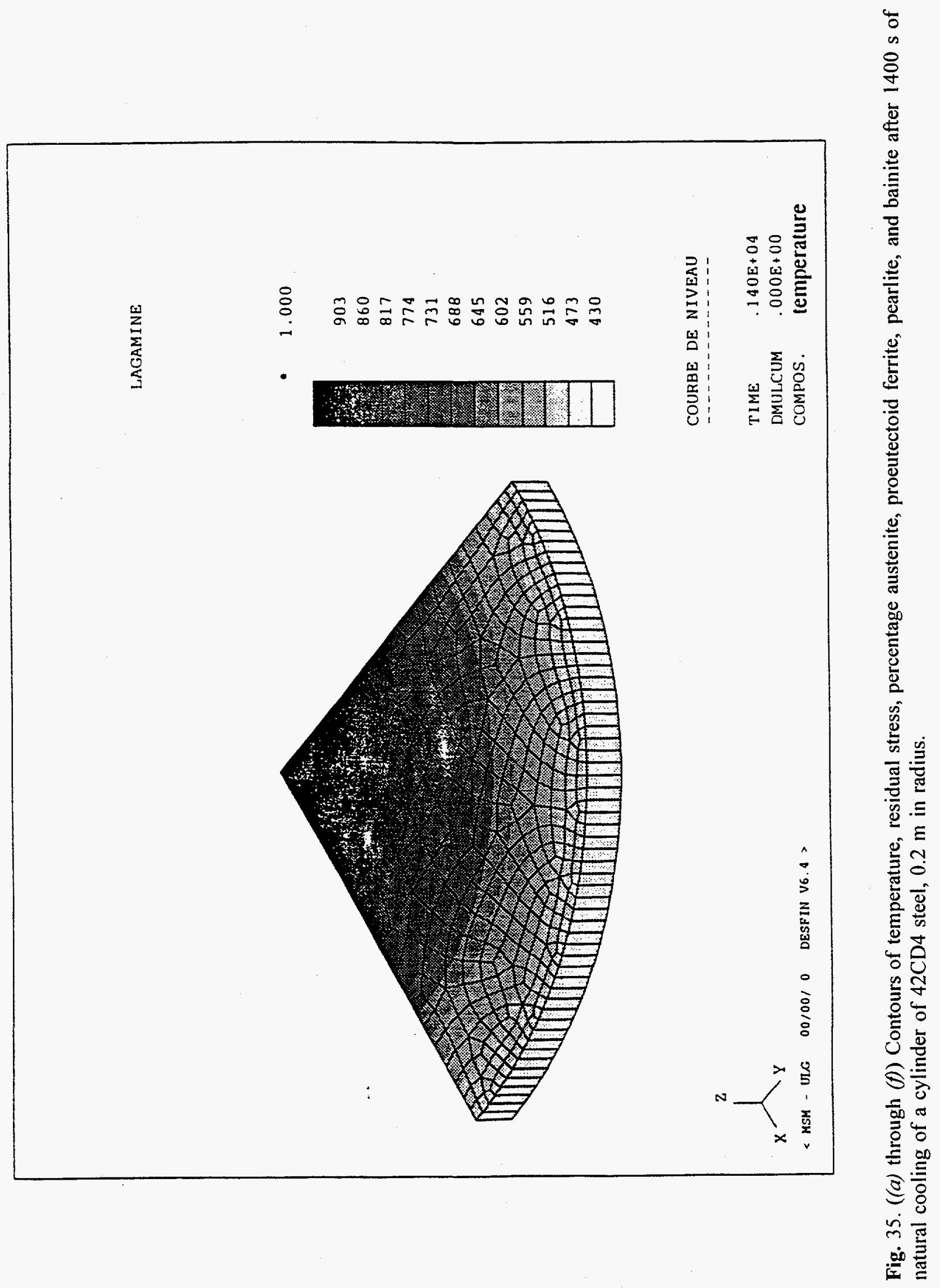




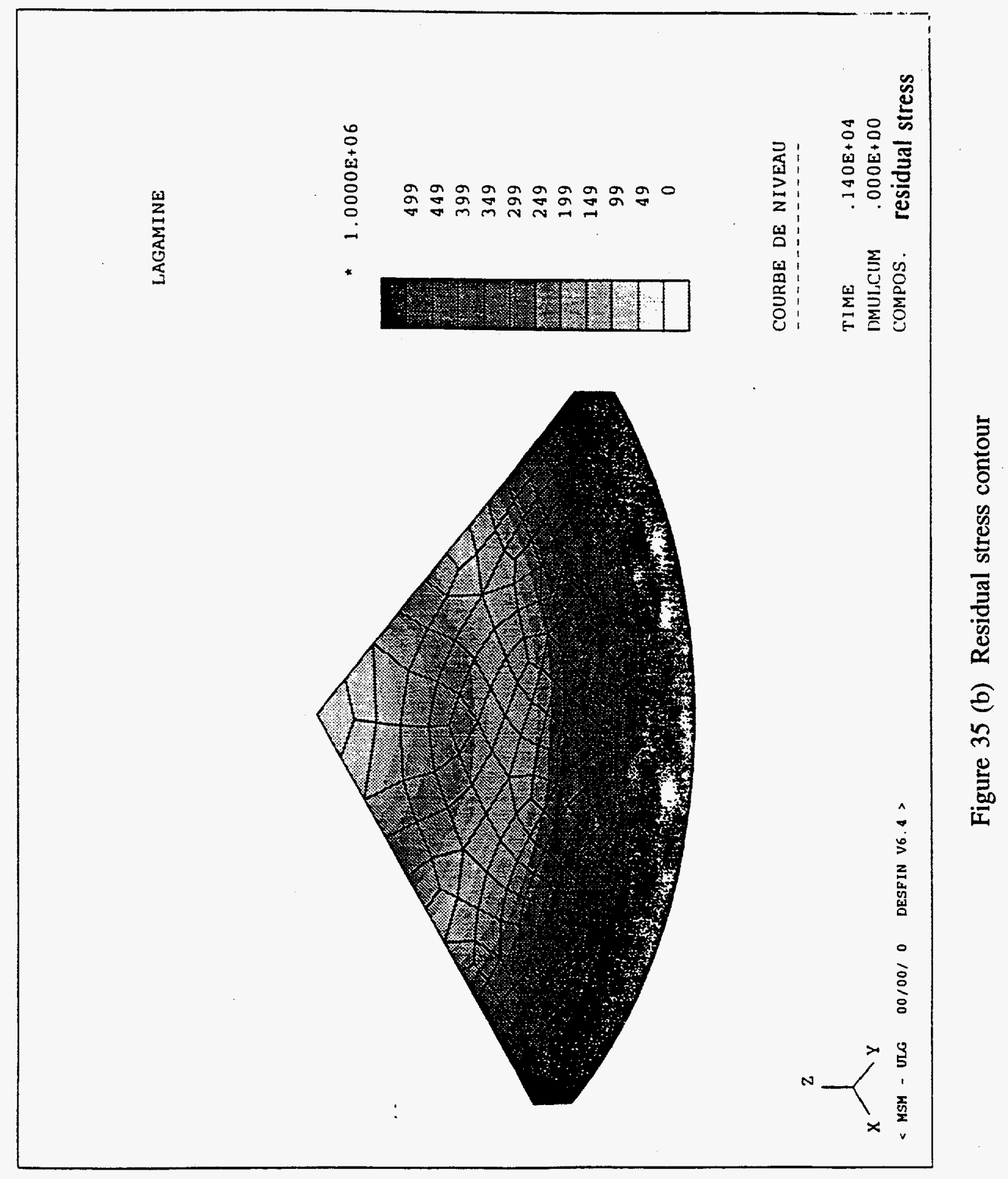




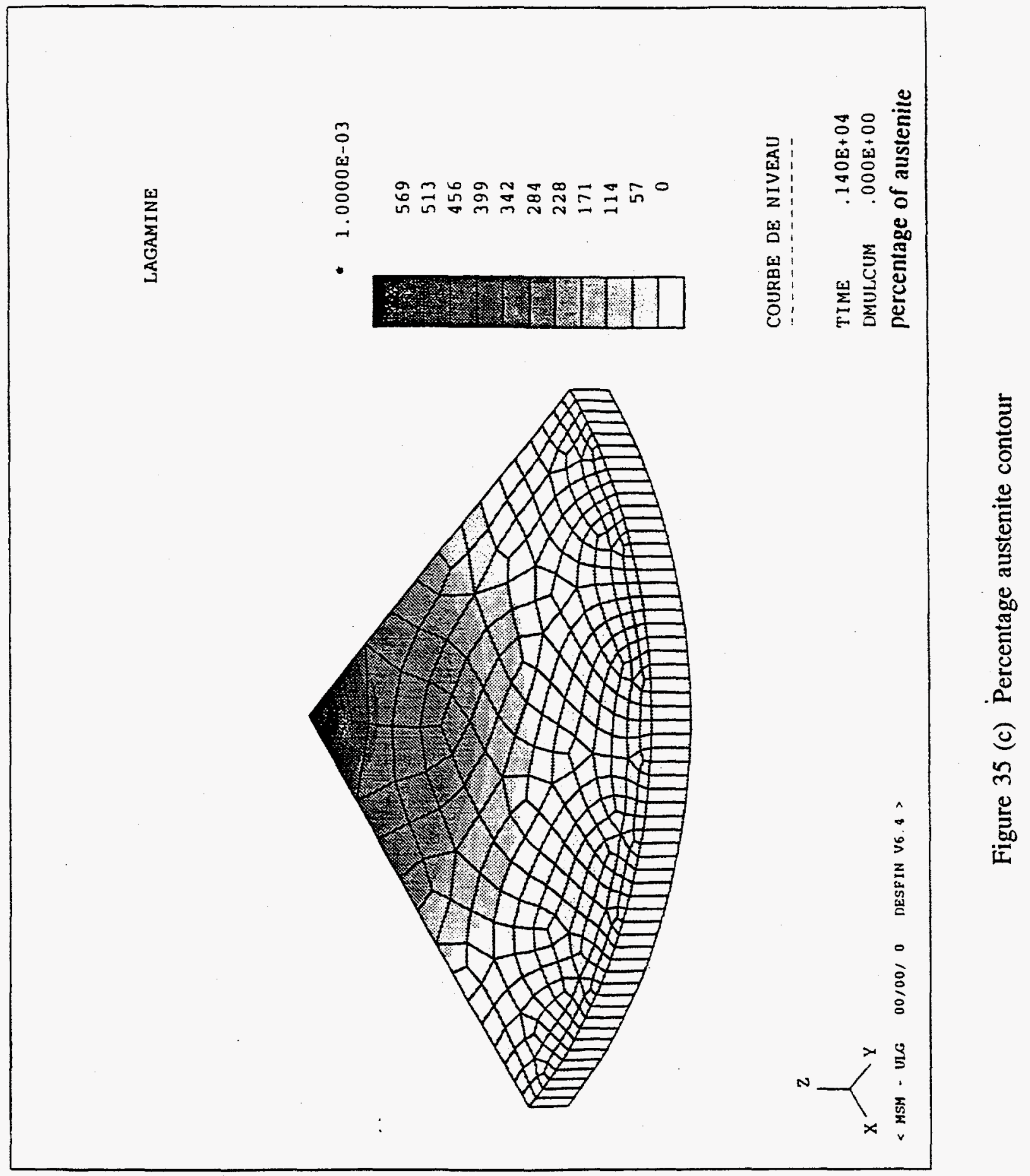




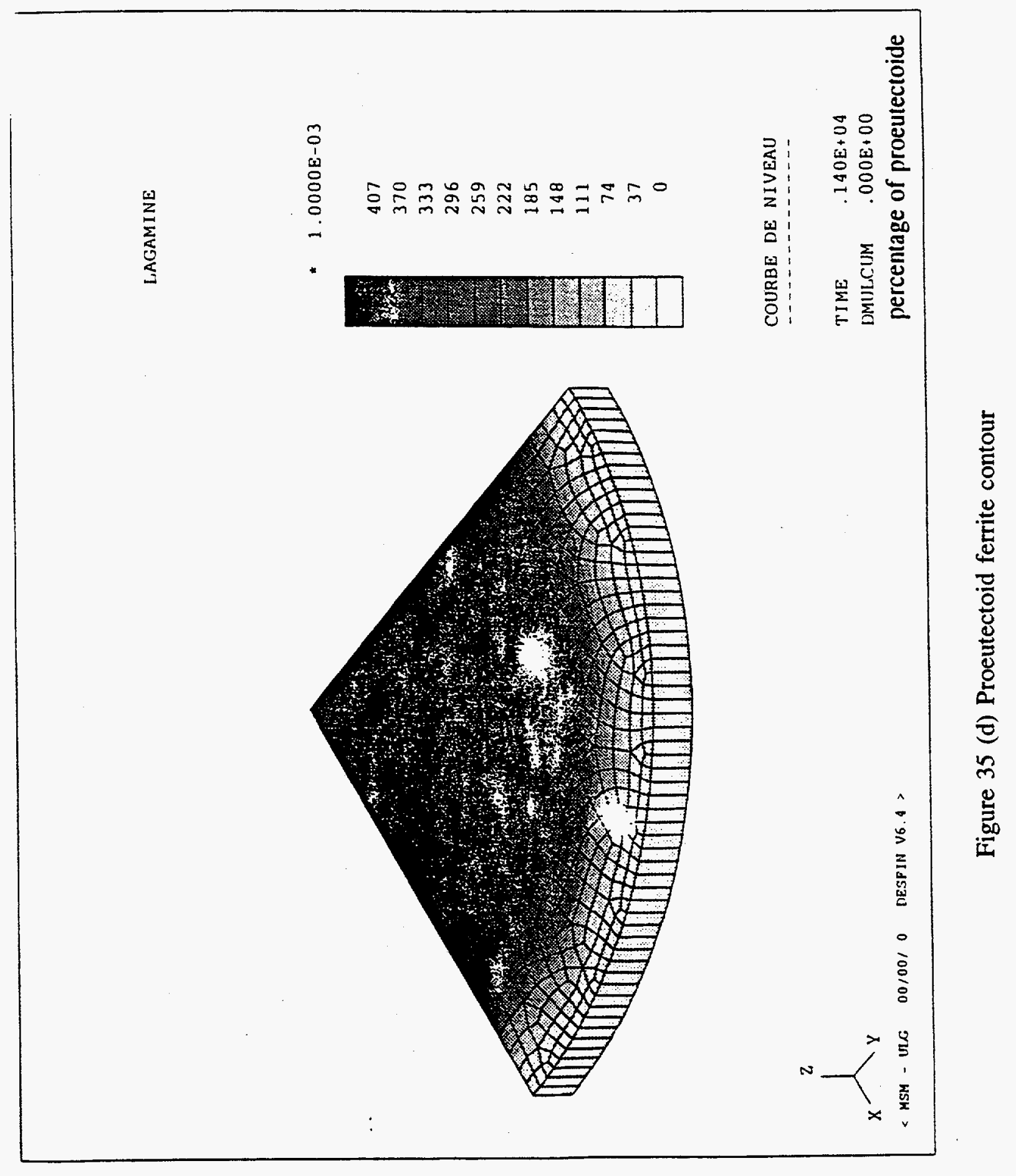




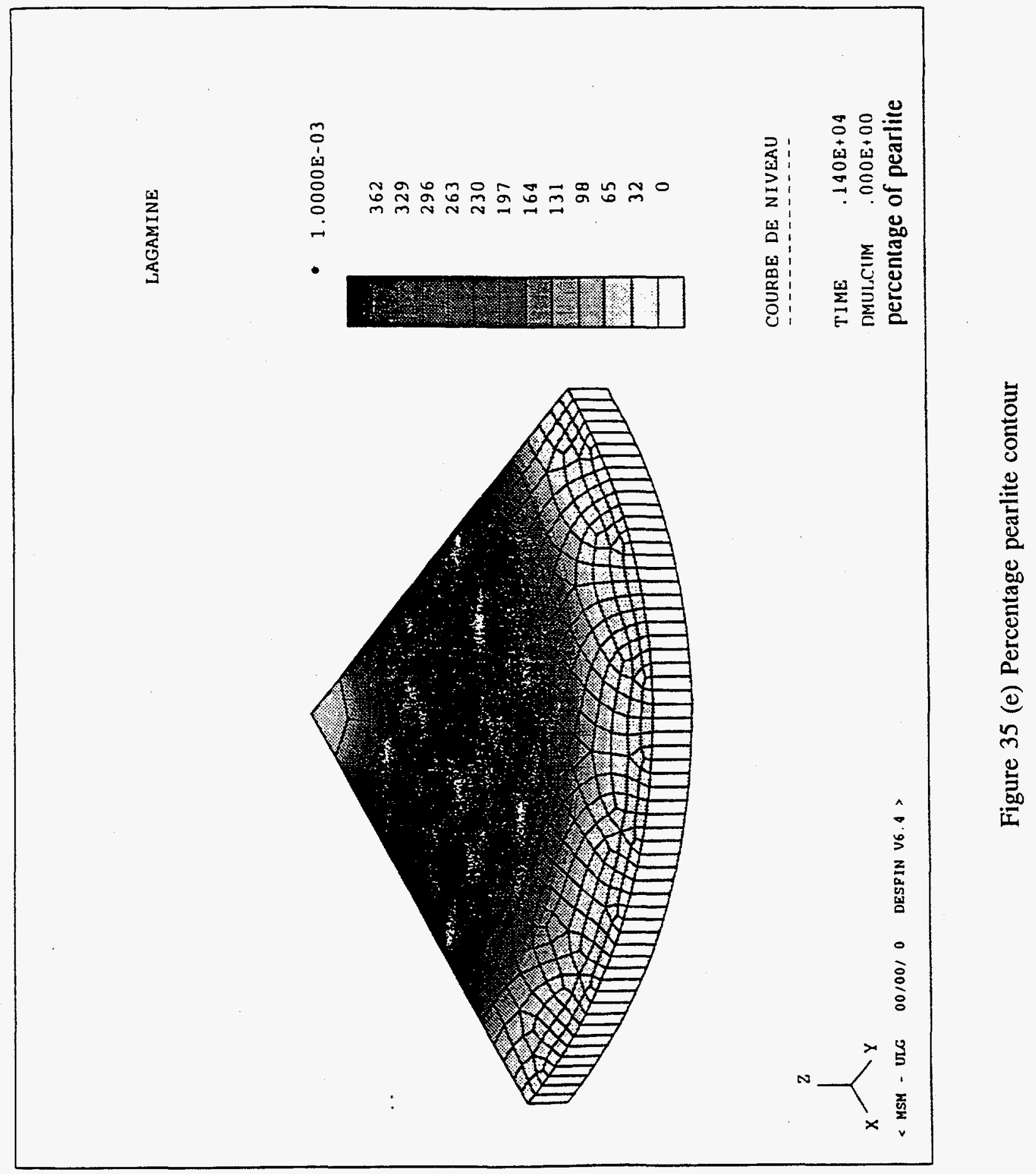




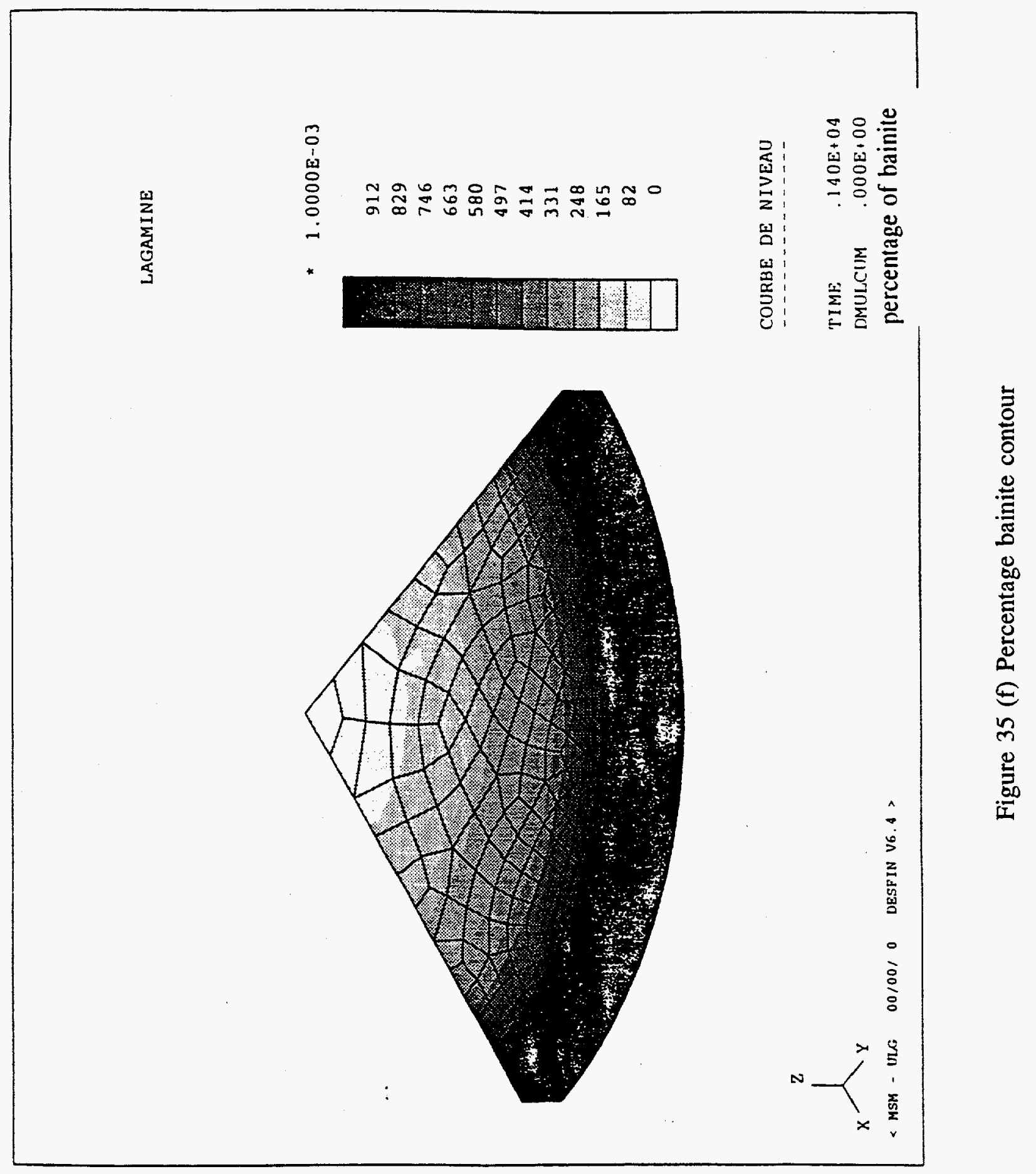




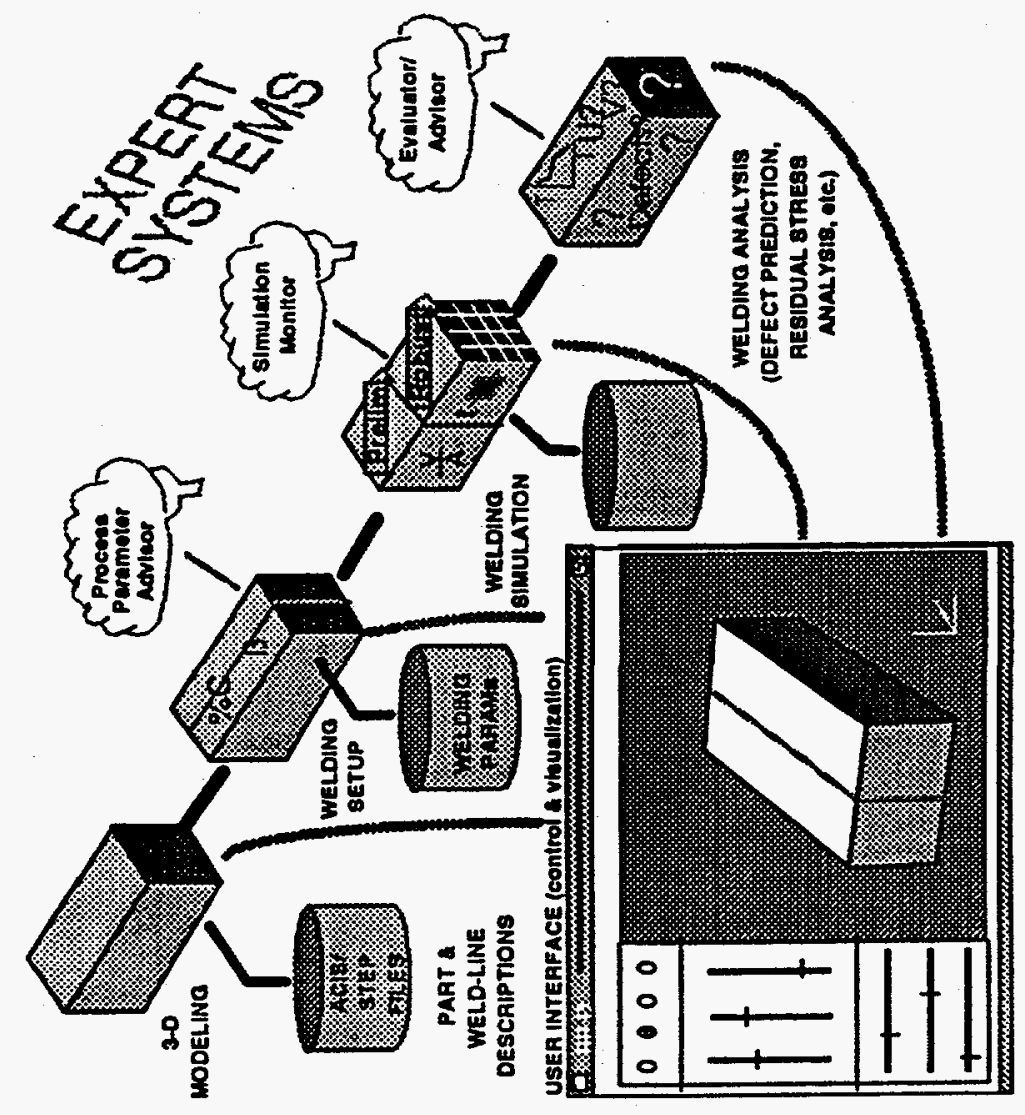

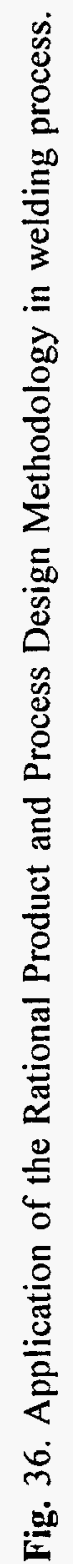



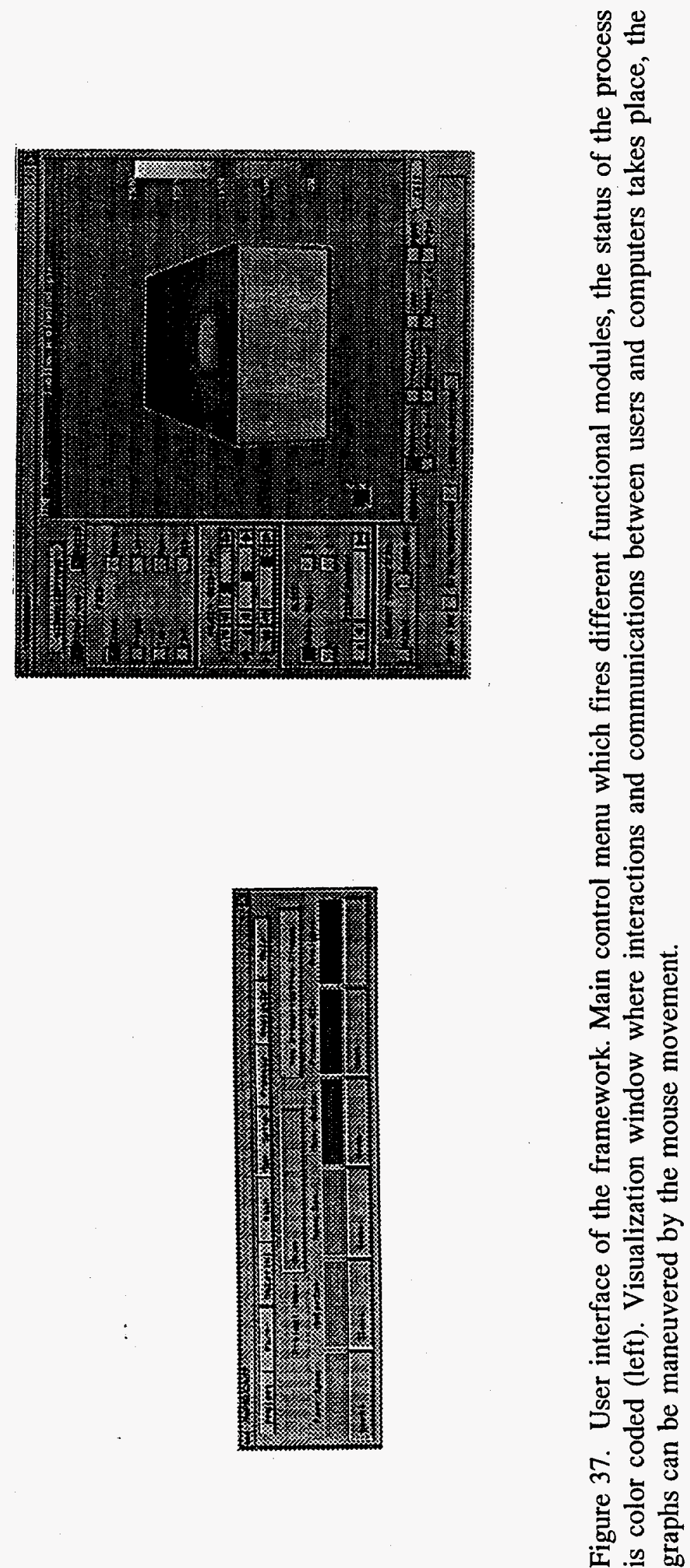


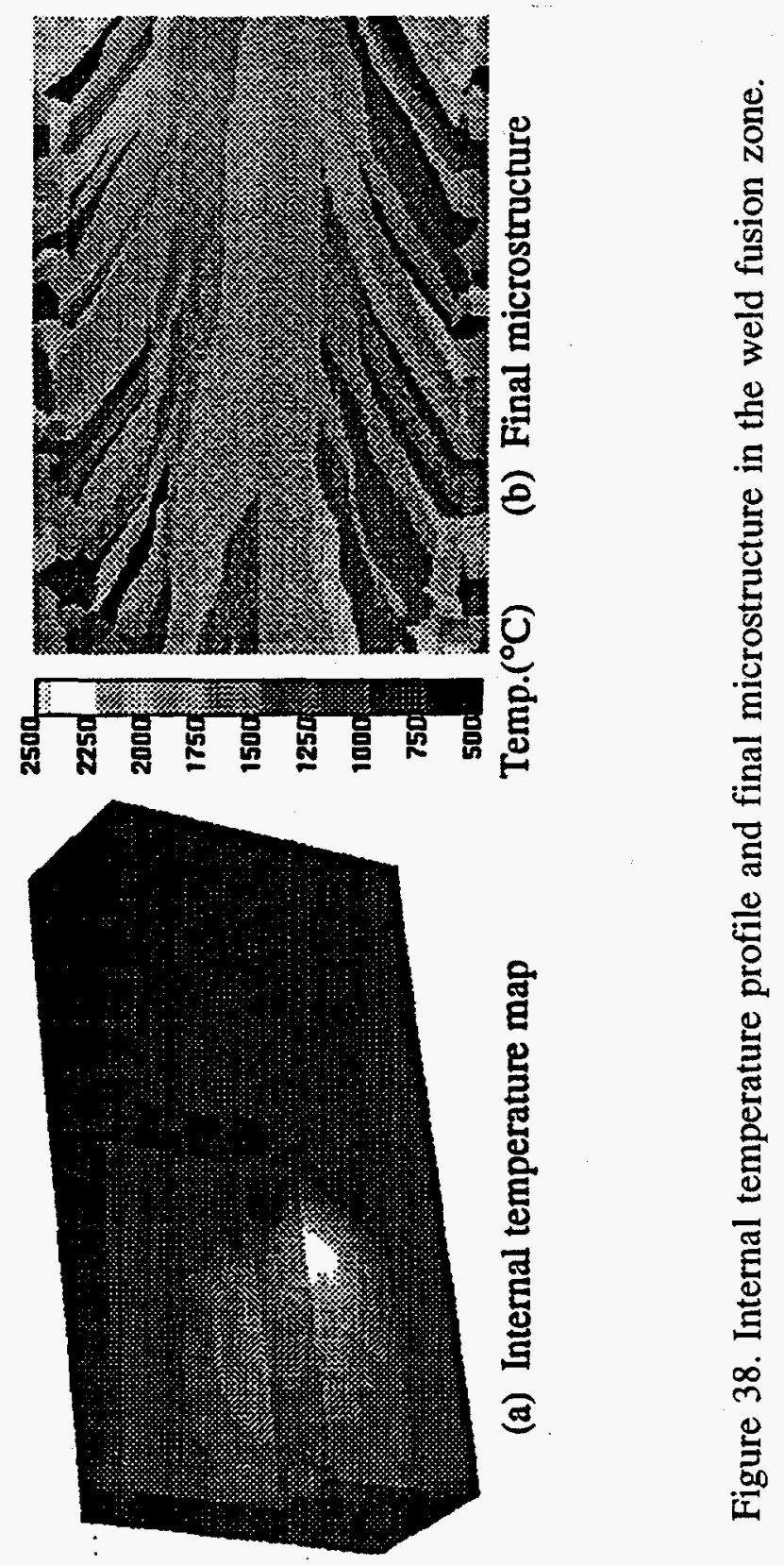


C/ORNL 92-0117

\section{INTERNAL DISTRIBUTION}

1. Central Research Library

2. Document Reference Section

3-4. Laboratory Records Department

5. Laboratory Records, ORNL PC

6. ORNL Patent Section

7. P. Angelini

8. B. B. Bovee

9. R. A. Bradley

10. D. F. Craig

11. R. Ford

12. P. L. Gorman

13. H. W. Hayden

14. B. Painter

15-19. B. Radhakrishnan

20. J. Shepherd

21. P. Sklad

22. C. Valentine

23. T. Zacharia

24-26. Y-12 Central Files

EXTERNAL DISTRIBUTION

27. DOE, OAK RIDGE OPERATIONS, P.O. Box 2001, Oak Ridge, TN 37831-6269

28-32. CONCURRENT TECHNOLOGIES CORPORATION, 2800 Shirlington Road, Suite 1000, Arlington, VA 22206

A. Paul 